\title{
CRUSTAL STRESS ACROSS THE NORTHERN ARABIAN PLATE AND THE RELATIONSHIP WITH THE PLATE BOUNDARY FORCES
}

\author{
A thesis \\ Presented to \\ The Faculty of the Graduate school \\ at University Missouri-Columbia \\ In Partial Fulfillment \\ of the Requirements for the Degree \\ Master of Science
}

BY

Rayan Yassminh

Dr. Eric Sandvol, Thesis Supervisor

December 2013 
The undersigned, appointed by the dean of the Graduate School, have examined the thesis entitled

\title{
CRUSTAL STRESS ACROSS THE NORTHERN ARABIAN PLATE AND THE RELATIONSHIP WITH THE PLATE BOUNDARY FORCES
}

\author{
presented by Rayan Yassminh, a candidate for the degree of master of Science and \\ hereby certify that, in their opinion, it is worthy of acceptance.
}

Dr. Eric Sandvol

Dr. Francisco Gomez

Dr. Brent Rosenlad 


\section{ACKNOWLEDGEMENTS}

I would like to express my gratitude towards my supervisors, Dr. Eric Sandvol and Dr. Francisco Gomez, whose valuable support, advice and comments made this work possible. I am thankful to all friends, staff, and colleagues in the University of Missouri, department of Geological Sciences.

I would like to thank all of North Iraq Seismic Networks (NISN), Syrian

Earthquake Center (SNEC), and Kandilli Observatory and Earthquake Research Institute in Turkey (KOERI) for providing the seismic data used in this study. Especially, I would like to acknowledge Dr. Mohamad Daoud (SNEC) for his support, and Dr. Hafidh Ghaleb (Array Technologies) for access to the NISN data. This research was supported by NSF grant NSF grant EAR-0948487 (PI: F. Gomez).

Finally, I would like to extend special thanks to my family and friends for their love and support: particularly, Karina Burch for her help in proof reading the thesis. 


\section{Table of Contents}

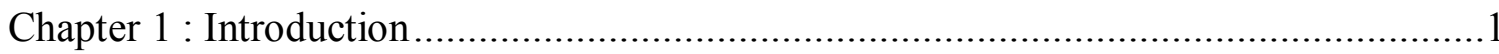

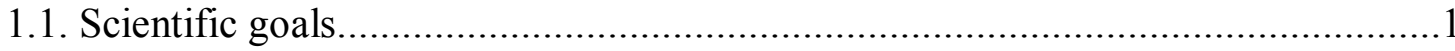

Chapter 2 : Geological Background .....................................................................

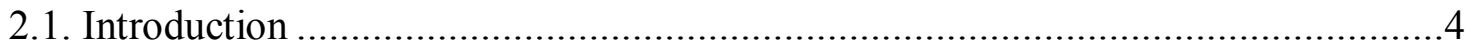

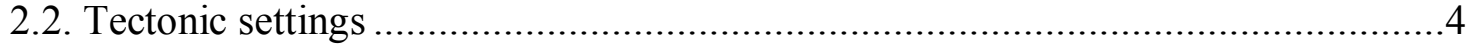

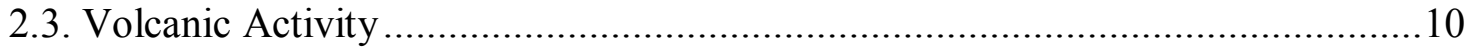

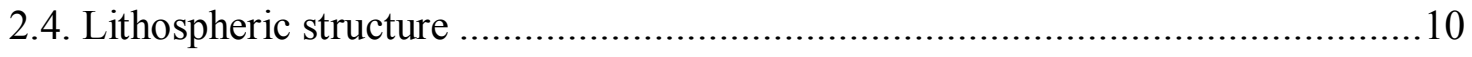

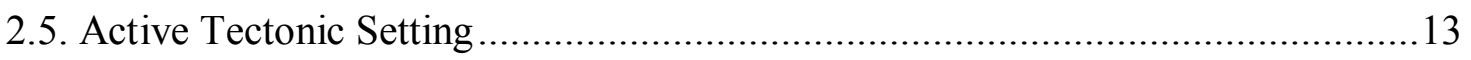

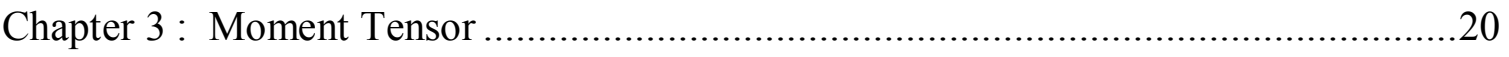

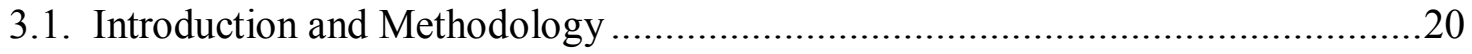

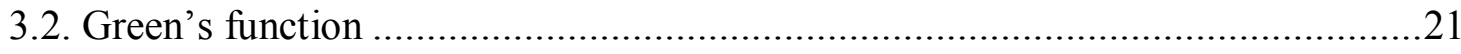

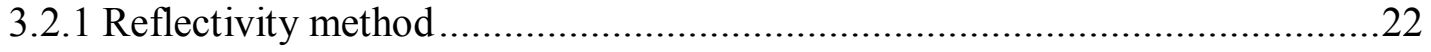

3.3. Global Centroid Moment Technique ………………..................................22

3.4. Regional Moment Tensor (RMT) Method ...........................................................22

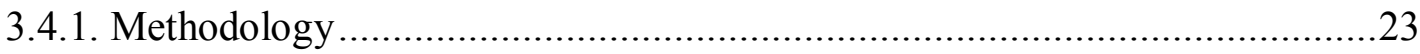

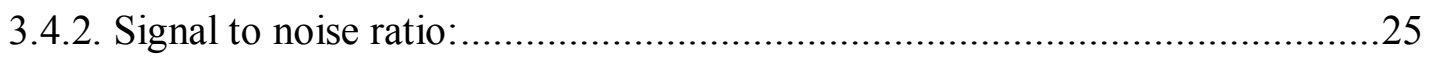

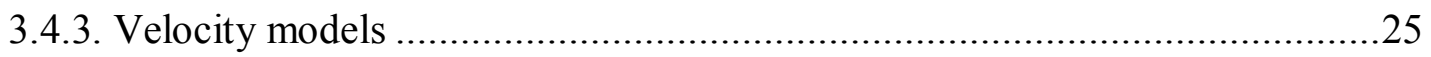

3.5. Using the Grid search and Modeling methods to determine the crustal structure in

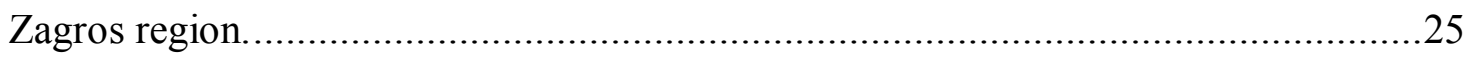

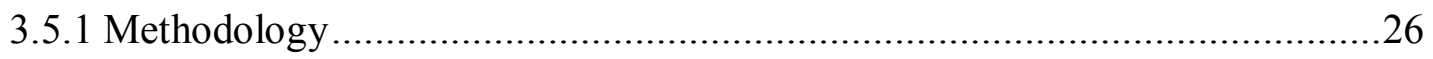

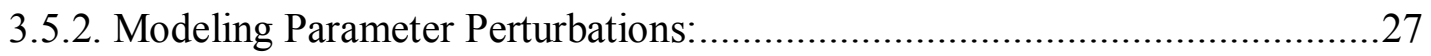

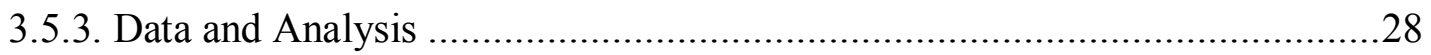




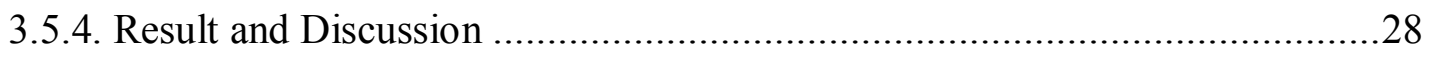

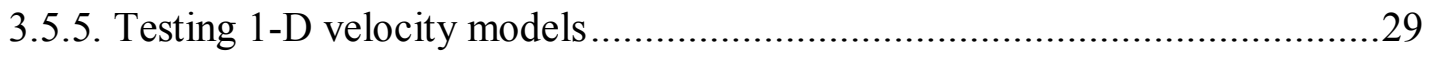

3.6. Anatolian plate velocity models: ..................................................................... 30

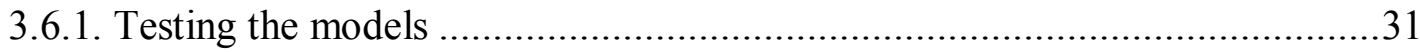

3.6.2. Discussion result of the velocity models of the third region. ...........................32

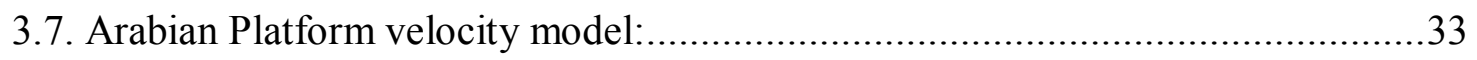

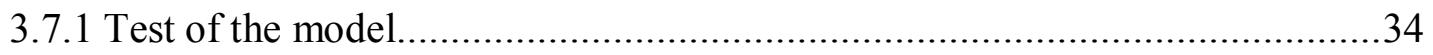

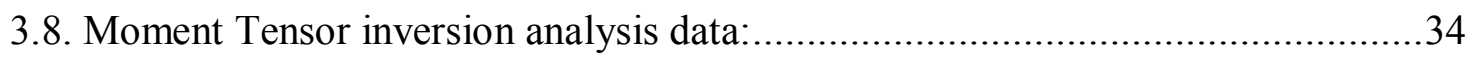

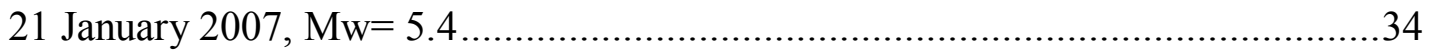

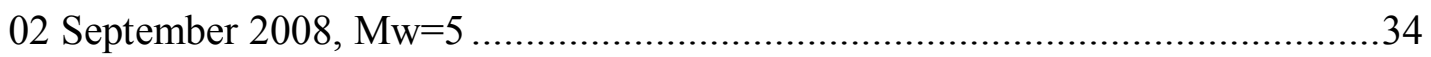

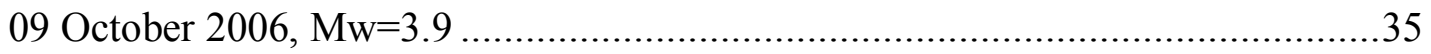

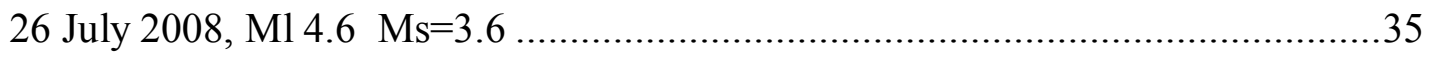

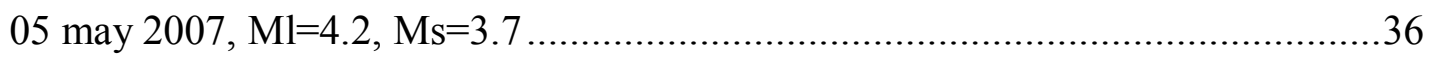

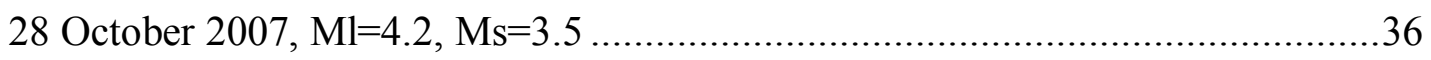

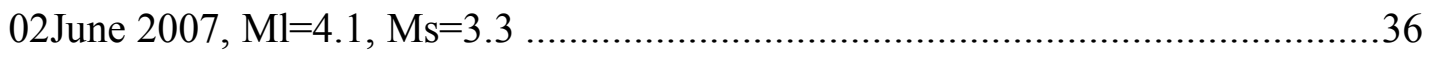

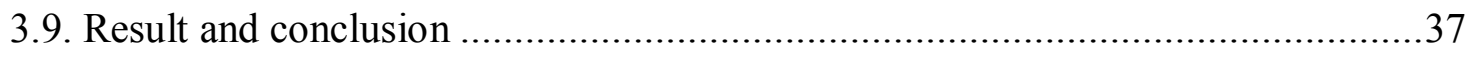

Chapter 4 : First motion focal mechanisms ................................................................69

4.1. Introduction \& Methodology:.........................................................................69

4.1.1. Hypocenter program:.............................................................................

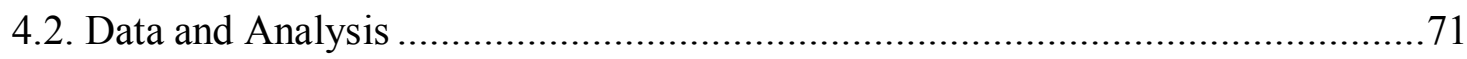

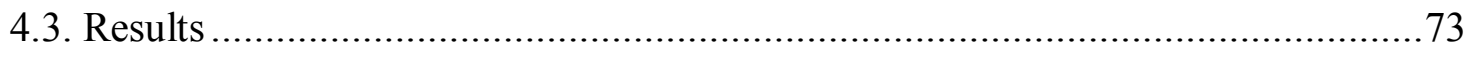

Chapter 5 : Seismotectonic Analysis \& Discussion ...................................................... 84

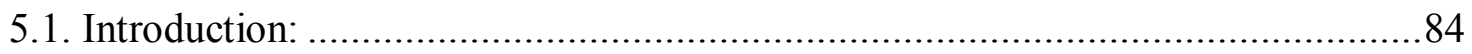

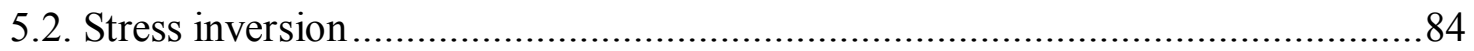

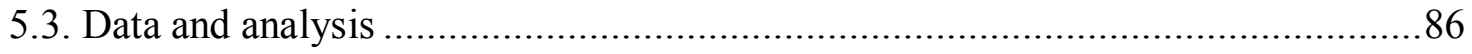




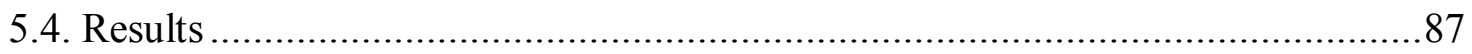

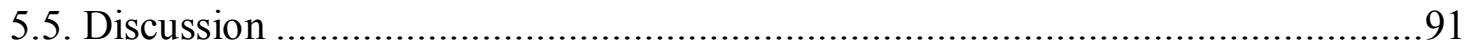

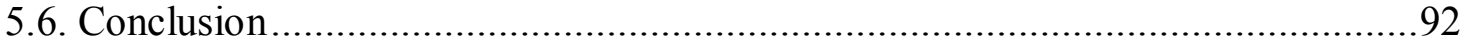




\section{List of Figures:}

Figure 1.1. The studding region with the main tectonic settings, North Anatolian fault, East Anatolian Fault, Caucasus, Zagros Fold Belt, Dead Sea fault, Anatolian Plate, Arabian Plate, and Mesopotamium Foredeep

Figure 2.1. Continental drift of the Arabian plate beginning in late Triassic to present (modified from Glennie)

Figure 2.2. Tectonic map of the study area and the surrounding region with the Topographic feature(SRTM30), Abbreviations are North Anatolian fault (NAF), East Anatolia fault (EAF), Dead Sea fault (DSF), Caucasue, Cyprus arc, Karliova Triple junction (KT), Euphrates Fault System(EFS), Central Anatolian Crystalline Complex (CACC), East Anatolian Accretion Complex (EAAC), Palmyrides Fold Belt PFB.

Figure 2.3. GPS velocities relative to Eurasia and Topography (Reilinger, et al 2006), MK: Makran mountain.

Figure 2.4. Seismicity map for 1980-2012 for studied region and the surrounded area, with color degradation represents the depth variation (ISC-GEM catalogue).

Figure 2.5. Comparative map showing Pn velocity with anisotropy (base map, red-blue colour, see Fig. 7a), volcanic outcrops as green and pink polygons filled with plus signs, Sn attenuation zones as yellow hatched areas enclosed by a solid grey line (after Khaled Al-Damegh, personal communication), and volcanoes as yellow triangles. (AL-lazki, 2004).

Figure 3.1. The GCMT solution for earthquake located in Eastern Turkey.

Figure 3.2. Map showing the subregions of the study area which compatible with geological settings, earthquakes location of the events used in this study(USGS-NIES) and topography, tectonic and geographic features are located. Black stars represent the earthequakes used in this study.

Figure 3.3. Zagros region and NIES seismic network distribution.(blue Triangle), geographic features and topography, white line is Euphrates and Tigris rivers.

Figure 3.4. Body, Surface and all waves probability of nine layers of the best well-fit models resulting of waveform modeling. Left side represents first five layers, and right site shows the last four layers. The value is velocity $\mathrm{Km} / \mathrm{s}$......

Figure 3.5. Velocity models of all the sub-regions in the study area, Zagros, Anatolia, Arabia..

Figure 3.6. Map shows all stations used in testing the velocity models for all the all the sub-regions, as well as the sub-regions.

Figure 3.7. Moment tensor solutions for a group of stations together for first and second Zagros regions. The red line is the observed waveforms, and the dashed line is the synthetic waveforms.

Figure 3.8. Moment tensor solution of the fourth region in the Anatolian plate as group solution. The red line represents the observed waveforms, the dashed line represents the synthetic waveform.....

Figure 3.9. Moment tensor solution for the third region in the Anatolian plate per station. The red line represents the observed waveforms; the dashed line represents the synthetic waveforms.

Figure 3.10. Moment tensor solution of the third region in the Anatolian plate as group solution. The red line represents the observed waveforms, the dashed line represents the synthetic waveform. 49

Figure 3.11. P-waves velocity models for third region in Anatolian plate, CANT,RSDY,CORM and SVSK stations.

Figure 3.12. Comparing resulted velocity model (dashed line) with previous 1-Dvelocity model for the Central Anatolian(Seda, et. al., 2010) (Bold line). 
Figure 3.13. Moment tensor solution for Arabia plate as a group solution. The red line represents the observed waveforms, and the dashed line represents the synthetic waveforms.

Figure 3.14. Focal mechanisms of all the events used in this study with the ranges of acceptant solutions, using first motion method, circle is positive and triangle is negative. And P,T B axis.

Figure 3.15. Map shows the study area. Triangles are stations used in inversion for 20070121 Event. The landmark is the epicenter of the event.

Figure 3.16. Focal mechanisms of 20070121 event, observed and synthetic waveforms are shown by solid and dashed line, respectively. The parameters o the focal mechanism and moment tensor are shown on the right side.

Figure 3.17. Map showing, triangles are stations used in for 20080902Event. The landmark is the epicenter of the event.

Figure 3.18 Focal mechanism of 20080902 event. Observed and synthetic waveforms are shown by solid and dashed line, respectively. The parameters of the focal mechanism and moment tensor are shown on the right side.

Figure 3.19. Map shows the study area. Triangles are stations used in for 200601009 Event. The landmark is the epicenter..

Figure 3.20. Focal mechanism of 200601009 event. The observed and synthetic waveforms are shown by solid and dashed line, respectively. The parameters of the focal mechanism and moment tensor are shown on the right side, bandpass filter $0.03 \_0.06 \mathrm{~Hz}$..

Figure 3.21. Focal mechanism of 200601009 event, observed and synthetic waveforms are shown by solid and dashed line, respectively. The parameters of the focal mechanism and moment tensor are shown on the right side, bandpass filter $0.02 \_0.05 \mathrm{~Hz}$.

Figure 3.22. Map shows the study area, Triangles are stations used in for 20080726 Event. The star is the event epicenter..

Figure 3.23. Focal mechanism of 20080726event. Observed and synthetic waveforms are shown by solid and dashed line, respectively. The parameters of the focal mechanism and moment tensor are shown on the right side.

Figure 3.24. Map shows the study area. Triangles are stations used in for 20070505 Event. The landmark is the epicenter of the event.

Figure 3.25. Focal mechanism of 20070505 event. Observed and synthetic waveforms are shown by solid and dashed line, respectively. The parameters of the focal mechanism and moment tensor are shown on the right side.

Figure 3.26. map showins the study area. Triangles are stations used in for 20071028 Event. The landmark is the epicenter of the event.

Figure 3.27. Focal mechanism of 20071028 event. The observed and synthetic waveforms are shown by solid and dashed line, respectively. The parameters o the focal mechanism and moment tensor are shown on the right side.

Figure 3.28. Map shows the study area. The triangles are stations used in for 20070206 Event. The landmark is the epicenter of the event.....

Figure 3.29. Focal mechanism of 20070602 event. The observed and synthetic waveforms are shown by solid and dashed line, respectively. The parameters of the focal mechanism and moment tensor are shown on the right side.

Figure 4.1. Earthquake source and mechanism, and the stereographic projection of the hemisphere........ 76 
Figure 4.2. Seismicity map of Syria and surrounded area 2000-2010(red circle). Location of seismic stations (white triangle). selected events (blue squares), and the seismicity histogram (2000-2010).....

Figure 4.3. Samples of focal mechanism solutions with different qualities: $A=$ Excellent solution; $B=V e r y$ good solution; $C=$ Usable solution. T: Tension axis; $P$ : Compression axis), and histogram represents all the qualities.

Figure 4.4. First plane solutions for all the regions, dark blue beachball=NDSF, red beachball=CDSF, greed beach ball=SCDSF, dark orange beachball=SPLM, light orange beachball= NESyria. Black beachball $=I S C$ catalog, gray beachball $=($ Salmon , et al 1996$) ..$

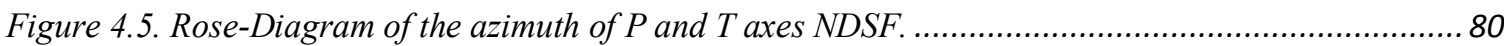

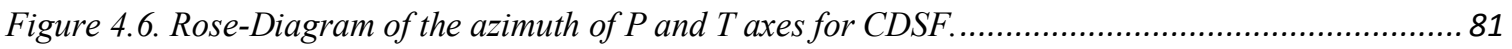

Figure 4.7. Rose-Diagram for the azimuth of the $P$ and $T$ axes for PFB ..............................................82

Figure 4.8. Triangle diagram (Frohlich,C., 1992) of the focal mechanisms in the subregions: NDSF, NCDSF, SCDSF, NPLM, SPLM, SPLM, NE.

Figure 5.1. Focal Focal mechanisms in the study area, black::contractional quadrant; white: dilatation quadrant.

Figure 5.2. Map shows the divided subregions in the study area, the stars are the focal mechanisms used in the stess inversion. 1=Northern Dead Sea Fault, 2=Northern Central Dead Sea Fault, 3=Southern Central Dead Sea Fault, 4=Northern Palmyrides, 5=Southern Palyrides, 6=Abd-Aziz, 7=Euphrates system, $8=$ Eastern Anatolian, $9=$ western Anatolian. nd 10= North west Zagros. Histogram of the events used (both moment tensor inversion and first polarity methods).

Figure 5.3. Triangle diagram (Frohlich, C., 1992) of the focal mechanisms in the subregions of study (see map in Figure 5.2).

Figure 5.4. The result of the inversion. Maximum principal stress $\sigma 1$ (square), intermediate principal stress - $\sigma$ 2(triangle), and least principal axis - $\sigma 3$ (circle). Determination inverting $P$ and $T$ axes of selected focal mechanism. 99

Figure 5.5. Variation of the stress principal $\sigma 1, \sigma 2$, and $\sigma 3$ in the study region 100 


\begin{abstract}
The region encompassing the collision of northern Arabia with Eurasia is a tectonically heterogeneous region of distributed deformation. The northern Arabia plate is bounded to the west by the subducting Sinai plate and the left-lateral Dead Sea transform. This complexity suggests that there are multiple competing processes that may influence regional tectonics in northern Arabia and adjacent areas. Earthquake mechanisms provide insight into crustal kinematics and stress; however, reliable determination of earthquake source parameters can be challenging in a complex geological region, such as the continental collision zone between the Arabian and Eurasian plates. The goal of this study is to investigate spatial patterns of the crustal stress in the northern Arabian plate and surrounding area. The focal mechanisms used in this study are based on (1) first-motion polarities for earthquakes recorded by Syrian earthquake center during 2000-2011, and (2) regional moment tensors from broadband seismic data, from Turkey and Iraq. First motion focal mechanisms were assigned quality classifications based on the variation of both nodal planes. Regional moment tensor analysis can be significantly influenced by seismic velocity structure; thus, we have divided the study area into regions based on tectonic units. For each region, the velocity model is described using a waveform-modeling technique prior to the regional moment tensor inversion. The resulting focal mechanisms, combined with other previously published focal mechanisms for the study area, provide a basis for stress inversion analysis. The resulting deviatoric stress tensors show the spatial distribution of the maximum horizontal stress varies from NW-SE along the Dead Sea Fault to the N-S toward the east. We interpret this to reflect the eastward change from the transform to
\end{abstract}


collision processes in northern Arabia. Along the Dead Sea Fault, transposition of the sigma-1 and sigma-2 to vertical and horizontal, respectively, may relate to influences from the subducted part of the Sinai plate. This change in regional stress is also consistent with extensional strains observed from GPS velocities. 


\section{Chapter 1 : Introduction}

Continental collision is a fundamental plate tectonic process that often involves deformations distributed across a broad plate boundary zone. An example is the active collision involving the northern Arabian plate and the Anatolian/ Eurasian plates (Figure 1.1). Continental deformation in Northern Arabia is further complicated by proximity the Dead Sea transform fault and the continental collision. Hence, studying continental deformation in the Northern Arabia plate can help to understand the competing tectonic influences in the region, specifically, the collision on one side and the transform on the other.

This region is very active seismically, with earthquakes along the main tectonic boundaries. During the past two decades, many local seismic networks have been deployed in order to detect small earthquakes $(\mathrm{M}<3)$. Small earthquakes are helpful in

understanding the spatial pattern of deformation and the regional stress field. Earthquake focal mechanisms provide basic kinematic indicators. Additionally, groups of focal mechanisms allow analysis of the stress field patterns for a particular region.

\subsection{Scientific goals}

The main goals of this study is to address the present day tectonic crustal stress fields for the study area using focal mechanisms acquired by multiple methods, primarily first motion and moment tensor techniques. Additionally, the study examines the efficiency of these methods based on the geological setting and the available seismic data. In addition to relative plate motion and stress field orientation, the results of this 
study have implications for broader understanding of the orogenic processes as well as regional earthquake hazards.

To achieve this end, this study used wide temporal and spatial data ranges (1910 2012) and magnitudes (7-2ML). Expanding the data ranges allows for generating greater reliability and precision in focal mechanism solutions. When a set of reliable focal mechanism solutions is available for a homogenous area, the best estimate for stress field orientation will be achieved by applying a stress inversion algorithm (Angelier, J.et.al., 1979.). The main scientific questions include:

- What is the reliability and appropriateness of the regional moment tensor technique in a complex geological region?

- How we improve the effectiveness of RMT procedure?

- How does the stress field vary spatially within northern Arabia Plate? What is the effect of the competing mechanism between the collision and the transform?

- How do the seismotectonic results compare with global positioning system (GPS) measurements of the same area? 


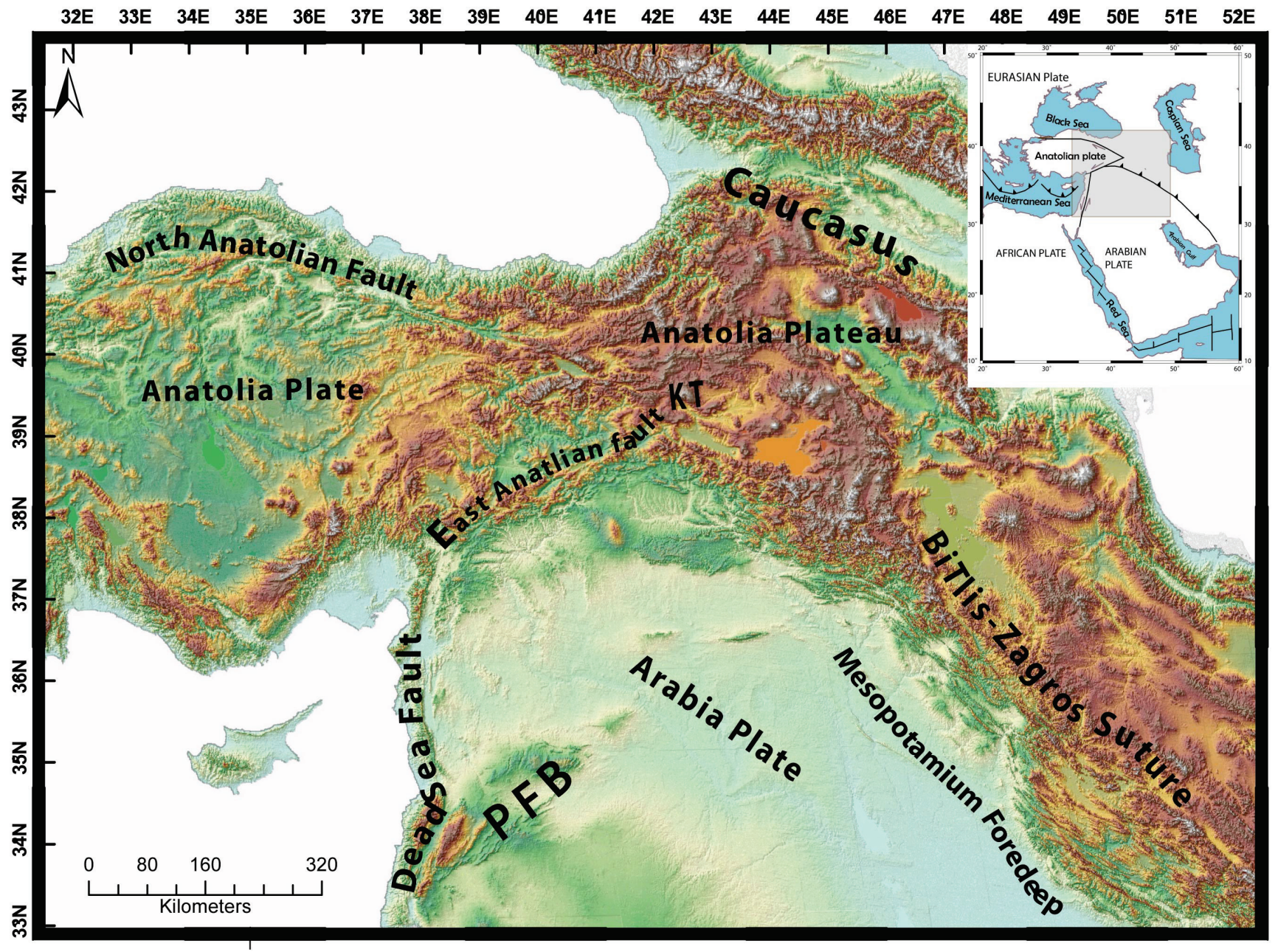

Figure 1.1. The studding region with the main tectonic settings, North Anatolian fault, East Anatolian Fault, Caucasus, Zagros Fold Belt, Dead Sea fault, Anatolian Plate, Arabian Plate, and Mesopotamium Foredeep 


\section{Chapter 2 : Geological Background}

\subsection{Introduction}

The geology of the study area reflects the history of the Tethys Ocean, the Paleotethys, the successive processes of Gondwana, separation of Arabia from Africa and a series of collisions culminating with the Mesozoic collision of Arabia and Eurasia which continues to the present day (Figure 2.1). The closure of the Neotethys Ocean during the Tertiary led to the formation of the Himalayan-Alpian belt, extending from the Atlantic Ocean to the Himalaya. The southeastern Anatolian orogenic belt forms an arcuate mountain belt that extends across Turkey towards t north western Iran ( Figure 1.1)

Along the southern margin of the Arabian plate, the opening of the Red Sea initiated during the Tertiary between 30 and 20 Ma (McQuarrie, et. Al., 2003). Consequently, the western edge of the Arabia plate separated from Africa (or rather, Sinai Plate) and started to move northward along the Dead Sea transform fault.

Because of continental collision between the Arabia and Eurasia plates, the Northern Anatolian fault and Eastern an orogenic domain boarder during the late Miocene to Pliocene age. The easternmost part of the Arabian plate still subducts beneath the Makran Mountains of present-day Iran (Figure 2.3).

\subsection{Tectonic settings}

The main tectonic units are as follows: 
The Zagros Fold-Thrust Belt (ZFTB) marks the southern side of the broad collisional zone of the Arabian and Central Iranian plate where the collision resulted in shortening and thickening. ZFTB consists of (1) Imbricate Zone, (2) High Folded Zone, and(3) Low Folded Zone. The belt was uniformly folded into a NW-SE fold system due to NE-SW compression applied from the Arabian Plate mainly during the late Miocene to Pleistocene. The intensity of deformation and the amplitude of the folds decreases to the southwest with distance from the high Zagros in the northeast.

The Mesopotamium Foredeep is the remnant of the Zagros foreland basin. It is characterized as an elongated $(\approx 900 \mathrm{Km}$ long and $200 \mathrm{Km}$ wide) terrestrial sedimentary basin, running parallel to the ZFTB and laying between the Zagros deformational mountain front and the stable interior of Arabian platform. The Mesopotamia foredeep comprises flat areas; in the southeastern part, which form the flood plains of the Tigris and Euphrates Rivers including their tributaries and distributaries.

The Bitlis Suture bounds the East Anatolian convergent zone. The suture zone consists of shallow dipping thrust faults / nappes that bound separate ophilitic massifs, mélange, and volcanic rocks. The nappes formed during the closure of the Southern Tethys between Arabia and the Anatolide-Tauride continental block. The whole massifs likely display a doubly plunging and multiply folded anticlinorium with overturned limbs both to the north and to the south (Dilek \& Moores 1990.)

The North Anatolian fault accommodates tectonic escape of the Anatolia block. It is one of the largest currently active strike-slip faults and forms dextral strike-slip deformation in northern Turkey. It initiated during the late Miocene as a result of continuing continental collision and resulting escaping of the Anatolian block to the west. 
The NAF extends from the Gulf of Saros in the northern Aegean Sea to the town of Karlıv in Eastern Turkey for approximately $1200 \mathrm{~km}$, paralleling roughly the southern Black Sea shores and keeping a regular distance of some $100 \mathrm{~km}$ to the coast.

The East Anatolian fault also accommodates tectonic escape of Anatolia via the left-lateral strike-slip fault. It meets the North Anatolian fault at the Karliova triple junction and extends to the southwest for about $600 \mathrm{~km}$ and extends the Mediterranean Sea. The EAF consists of several local parallel and sub-parallel left-lateral strike-slip faults with considerable normal components of movements. Moreover, the EAFZ consists of several distinct segments, based on fault stepovers, separation, or fault strike.

The East Anatolian Accretion Complex (EAAC) is a remnant of a large accretionary prism, located between the Pontide and the Bitlis massif. It forms a high plateau elevated at $2 \mathrm{~km}$, dynamically supported by asthenospheric doming (Sengor et.al., 2003). Crustal deformation is accommodated by intraplate and conjugate wrench

The Central Anatolian Crystalline Complex (CACC) occupies most of central Anatolia. The CACC consists of the Kirsehir, Akdag and Nigide metamorphic massifs, as well as many sedimentary basins, which initially evolved as peripheral foreland and forearc basins that outline the CACC. Two major suture zones surround the CACC in the north and the south. The Izmir-Ankara-Erzincan suture zone to the north and the InnerTauride suture (ITSZ) zone to the south marking the obliteration sites of the Tethyan seaways, which evolved between the Gondwana-derived continental fragments. Subduction of Tethyan oceanic lithosphere seaways resulted in the development of incipient arc-forearc complexes, that subsequently formed ophiolites, in the mantle heterogeneity beneath the continental fragments. Ophiolite complexes within the Izmir- 
Ankara-Erzincan suture zone include serpentinized upper mantle peridotites and gabbros that are crosscut by dolerite and plagiogranite dikes and overlain by pillow lavas (Tankut et al. 1998; Dilek \& Thy 2006). The Inner-Tauride ophiolites to the south (i.e. Alihoca, Aladag, Mersin) consist mainly of tectonized harzburgites, mafic-ultramafic cumulates and gabbros and commonly lack sheeted dykes and extrusive rocks.

The Tauride Block south of the CACC represents a ribbon continent rifted off from the northwestern edge of Gondwana (Robertson \& Dixon 1984; Garfunkel 1998). The Palaeozoic-Jurassic tectonic stratigraphic units in the Tauride block are tightly folded along major thrust faults, that developed during the obduction of the Inner-Tauride ophiolites from the north in the late Cretaceous and during the collision of the Tauride block with the CACC in the latet Palaeocene-Eocene. The entire Tauride block experienced gradual uplift in the footwall of a north-dipping frontal normal fault system along its northern edge starting in the Miocene, and developed as a southward-tilted, asymmetric megafault block with a rugged, alpine topography (Dilek, et. al., 1999b).

The Cappadocian volcanic province defines a c. $300 \mathrm{~km}$-long volcanic belt extending NE-SW across the CACC. The earliest volcanism in the province developed during the mid-Miocene (c. $13.5 \mathrm{Ma}$ ) and continued into the Quaternary. The volcanic edifices appear to have been built at the intersections of major strike-slip fault systems and NNW-SSE-oriented regional extension (Toprak et al. 1994; Dilek et al. 1999b). These relations indicate that faulting and volcanism in the Cappadocian volcanic province were spatially and temporally associated. The magma transport and extrusion were in part facilitated by crustal-scale fault systems (Dilek et al. 1999b). 
The Pontides comprise the region north of the İzmir- Ankara-Erzincan suture. They are fold and thrusts faulted during the Alpide orogeny, but they were not metamorphosed. The Pontides consist of three terranes, which show markedly different geological evolutions. These are the (1) Strandja (2) Istanbul and (3) Sakarya terranes. The Strandja terrane includes the Rhodope and Serbo-Macedonian massifs. (2) The İstanbul terrane is a $400 \mathrm{Km}$ long and $55 \mathrm{Km}$ wide continental fragment and lies on the south-western margin of the Black Sea. There are marked stratigraphic differences between the western and eastern parts of the Istanbul terrane. (3) The Sakarya terrane, intruded by a series of east-west trending Eocene and Oligo-Miocene granitoid plutons. The Kazdag massif within the western part of the Sakarya continent represents a metamorphic core complex.

The Dead Sea Fault System (DSFS) is a transform fault forming the Eastern margin of the Arabia plate and connecting Red Sea seafloor-spreading in the south with the collision zone in the north. Most researchers agree that a total of $\sim 107 \mathrm{~km}$ of sinistral motion has taken place on the southern portion of the fault, south of the Lebanese restraining bend. Concerning the episodic rifting in the Red Sea area (Hempton, 1987), many studies have suggested that the lateral motion on the DSFS occurred during two different episodes (e.g. Quennell, 1959; Freund, et. al., 1970; Beydoun, 1999). In this scenario, there was $\sim 65 \mathrm{~km}$ of movement during the Early to Middle Miocene, with the remaining $\sim 42 \mathrm{~km}$ from the earliest Pliocene until present. Rhomb-shape grabens, elongate pull apart basins, and steep normal faults have formed where the main fault segments step to the lift, and one of the largest of these steps is the Dead sea basin which filled with of $8.5 \mathrm{~km}$ of sediment. Gravity data and reflection profiles ensure the 
conclusion that the minimal effects of the extension process on the upper mantle, and they reveal the deep structure of the Dead Sea transform in the southern part of a thick upper crust $17-18 \mathrm{Km}$, lower crust $\sim 15 \mathrm{Km}$ and the Moho displaying as a small amount of topography.

The Palmyrides Fold Belt (PFB) is an extensive and prominent intraplate deformation zone in the Northern Arabia platform, about $400 \mathrm{~km}$ long and $100 \mathrm{~km}$ wide. The uplift in the Palmyrides is relatively recent and during most of the Phanerozoic the zone was a sedimentary depocenter (Palmyride / Sinjar trough), accumulating several kilometers of Paleozoic and Mesozoic strata through episodic rifting and broad subsidence. Since the Late Cretaceous, the Palmyrides have been subjected to episodic compression leading to folding and the currently observed topography. It can be divided into two distinct parts: the southwest Palmyrides, and the northeast Palmyrides, which in turn consists of the Bilas and Bishri blocks. These blocks have distinctly different Cenozoic histories.

The Euphrates Fault System (EFS) is a fault-bounded rift within the northern Arabian plate. Litak, et. al., (1997) demonstrated that the Euphrates Fault System extends southeast to the northwest. The Euphrates Fault System is weakly expressed topographically and seems to have experienced very little tectonic reactivation during the Cenozoic. Extension caused widespread redbed deposition (Litak et al., 1998) that graded into progressively deeper water carbonate facies. Transtensional deformation was increasingly dominant over time. The synrift carbonate deposition ended in the deposition of up to $2300 \mathrm{~m}$ of deep water marly limestone within the graben during the Maastrichtian. 


\subsection{Volcanic Activity}

In addition to these tectonic features, volcanic activity has characterized the past and present in much of the study area. The volcanic activity in northern Arabia, including successions, occurred in different locales of northern Arabia, partly correlated with different tectonic events, such as displacements along the Dead Sea Fault system or slab break-off beneath the Bitlis suture zone. The Syrian volcanic rocks are generally younger than lava in the southern Afro-Arabian region. Hence, that indicates a northward progression of the commencing volcanism since the arrival of the Afar mantle plume beneath Ethiopia/Djibouti 30 Ma ago (M.S.Krienitz, 2009).

The most extensive magnetic belt in Anatolian plate resulted from the complex Arabia-Eurasia collision and the Neotethys oceanic subduction beneath the Eurasia continental margins during the Albian Himalayan orogeny. These magmatic rocks have temporal, spatial, and compositional variability. The magmatism shows clearly transect from deep arc-type in the south to deeper eroded midcrustal plutons in the north to magmatism associated with slab rupture in the northeast.

Subduction of the Neotythys beneath the active continental margin of the Iranian block was established by arc magmatism and back-arc spreading formed from the late Triassic to Plio-Quaternary. This magmatism varied from SW-NE (Figure 2.5).

\subsection{Lithospheric structure}

Numerous seismic wave propagation studies have provided insight into the lithospheric structure of the study area (Al-Laski et al 2004). Seismic phases such as Lg, $\mathrm{Sn}$, and Pn have been particularly helpful. $\mathrm{Lg}$ is shown to be sensitive to lateral 
variations in the crustal thickness as well as the rheology of the crustal rocks. Whereas $\mathrm{S}_{\mathrm{n}}$ and $\mathrm{P}_{\mathrm{n}}$ are very sensitive to lateral variations in the mantle lid and to the presence of asthenospheric material very close to or below the crust. Generally, previous literature shows noticeably strong compatibility between increasing the seismic attenuation and decreasing the seismic wave velocity on one side and the volcanic distributions on the other. Gok et al (2003) documented strong attenuation of $\underline{S}_{\underline{n}}$ beneath the Anatolian and Iranian plateau where $\mathrm{S}_{\mathrm{n}}$ is blocked in the Anatolian plateau, and there is high attenuation in northern Anatolia (Pontides). In south western Turkey, high Sn attenuation was observed as well as low attenuation $\mathrm{S}_{\mathrm{n}}$ was observed in Eastern Arabia and along the Zagros fault and thrust belt. Ali Al Lazki, et. al., (2003) identified a broad region of low and smaller $\mathrm{P}_{\mathrm{n}}$ velocity anomalies beneath northwestern Iran, the eastern Anatolian plateau, the Caucasus, and most of the Anatolian plate, which are consistent with the $S_{n}$ results support the mantle lid instability beneath the Eurasia side of the collision (Figure2.5). Khaled Al-Damegh et.al.(2003) observed that the Lg was blocked through eastern Turkey, the Anatolian Plateau, the southern Black Sea, and the Zagros thrust belts. Khaled Al-Damegh et.al.(2003) also observed efficient Lg across the Arabia Plate and interpreted these results as a partially molten to eroded mantle lid. The regions underlain by low $P_{n}$ velocity and high attenuation of $S_{n}$ and the very low $P_{n}$ can be interpreted as an absence of the mantle lid. The instability in the upper mantle is evidenced by calc-alkaline and alkaline volcanism, which resulted in zones of blocked $\mathrm{S}_{\mathrm{n}}$ correlating with the volcanism or asthenospheric upwelling in the Turkish- Iranian plateau. The large zone of $S_{n}$ blockage extending from the eastern Mediterranean coast 
to Jordan, Syria and northwestern Iraq was imaged as very low $P_{n}$ velocity likely due to the widespread Neogene/Quaternary volcanics.

To estimate the crustal thicknesses in the northeastern part of the Arabian Plate, Gok et al. (2008) used combined P-wave receiver functions and surface (Rayleigh) waves. The thicknesses are interpreted to be $39 \mathrm{~km}$ beneath Mosul (near the Zagros Fold Belt) and $43 \mathrm{~km}$ at Baghdad (in the Mesopotamian Foredeep). In the northwestern part of the Arabian Plate, in Jordan, Mohsen et al. (2006) used receiver function analysis to suggest the depth of the Moho across the Dead Sea transform. They obtained depths ranging from $30 \mathrm{~km}$ to $34-38 \mathrm{~km}$, which is similar to the range of $35-37 \mathrm{~km}$ obtained from active seismic profiling (El-Isa et al., 1987). Moreover, to the north, in Syria, the crust appears to be significantly thinner. Al-Saad et al. (1992) used gravity modeling to estimate an $\sim 32 \mathrm{~km}$ thick crust, while Brew, et. Al., (2001) combined gravity modeling and receiver-function analysis to show that Syrian crust north of the Palmyrides is significantly thinner $(\sim 25 \mathrm{~km})$ than that to the south $(\sim 35 \mathrm{~km})$. The crust beneath the northernmost Arabia Plate thickens somewhat near the Bitlis suture, where a thickness of $\sim 40 \mathrm{~km}$ was determined by receiver function studies (Angus et al., 2006). In eastern Turkey, (R. GOK 2006) joint the inversion of surface wave group velocities (Rayleigh and Love) with Telesesimic receiver functions where used to assess the crustal thickness, with resulted showing the Anatolian plateau varies between 40 and $52 \mathrm{~km}$ with the thickest crust within the northeastern corner of the region. The Anatolian block, the western part of the plateau, bounded by the NAFZ and the EAFZ is thinner ( $40-45 \mathrm{~km})$

than the Anatolian plateau ( $48 \mathrm{~km}$ on average). 


\subsection{Active Tectonic Setting}

At the present-day, relative movement of Arabia and Eurasia are documented using GPS. The velocity ranges from $17.8 \pm 1.1 \mathrm{~mm} / \mathrm{yr}$ on the northernmost Arabian plate in southeast Turkey, to $20.6 \pm 0.8 \mathrm{~mm} / \mathrm{yr}$ in eastern and central Turkey, to $24.6 \pm$ $1.0 \mathrm{~mm} / \mathrm{yr}$ in western Turkey (Robert Reilinger, 2006). Additionally, the velocity field of the Zagros region relative to Eurasia can be characterized by north-south shortening from Arabia to Eurasia is $20-25 \mathrm{~mm} /$ year. The slip rate of the northern Dead Sea fault is estimated at $1.8-3.3 \mathrm{~mm} /$ year with a locking depth of 5-16 $\mathrm{km}$, with a lower slip rate in the south and the central DSF 4-6mm/year. This result was the basis of the suggestion that the DSFS does not behave as a simple transform, and the northern part is district from the central and southern parts. Furthermore, intraplate deformation in northern Arabia, mostly related to the Palmyride Fold Belt, has been suggested in the NNW-SSE

direction and demonstrated $1 \mathrm{mmyr}^{-1}$ of active, regional shortening (Alchalbi, et. al., 2009)(Figure 2.3).

Earthquake activity expresses active deformation throughout the study area (Figure2.3). Instrumental Seismicity was taken from the ISC catalogue where the earthquake magnitudes $>3$ are abundant in this area and confined along the main tectonic settings of the Bitlis-Zagros zone, Dead Sea Fault, NAF, and the EAF. However, scattered events were located over a wide region between theses settings. Because of the a scarcity of the seismic activity along the NDSF, which was demonstrated by the GPS result (Alchalbi, et. al., 2009), a seismic gap may exist which would suggest that the is a locked fault. Most of the hypocenters were located in the upper crust except for subduction zone events, which have a greater depth. For instance, in the transitional 
region between Zagros and the Makran, the seismicity extended to the lower crust 30$40 \mathrm{Km}$, consistent with the low angle thrusting of the Arabian basement beneath central Iran (Figure 2.4). 

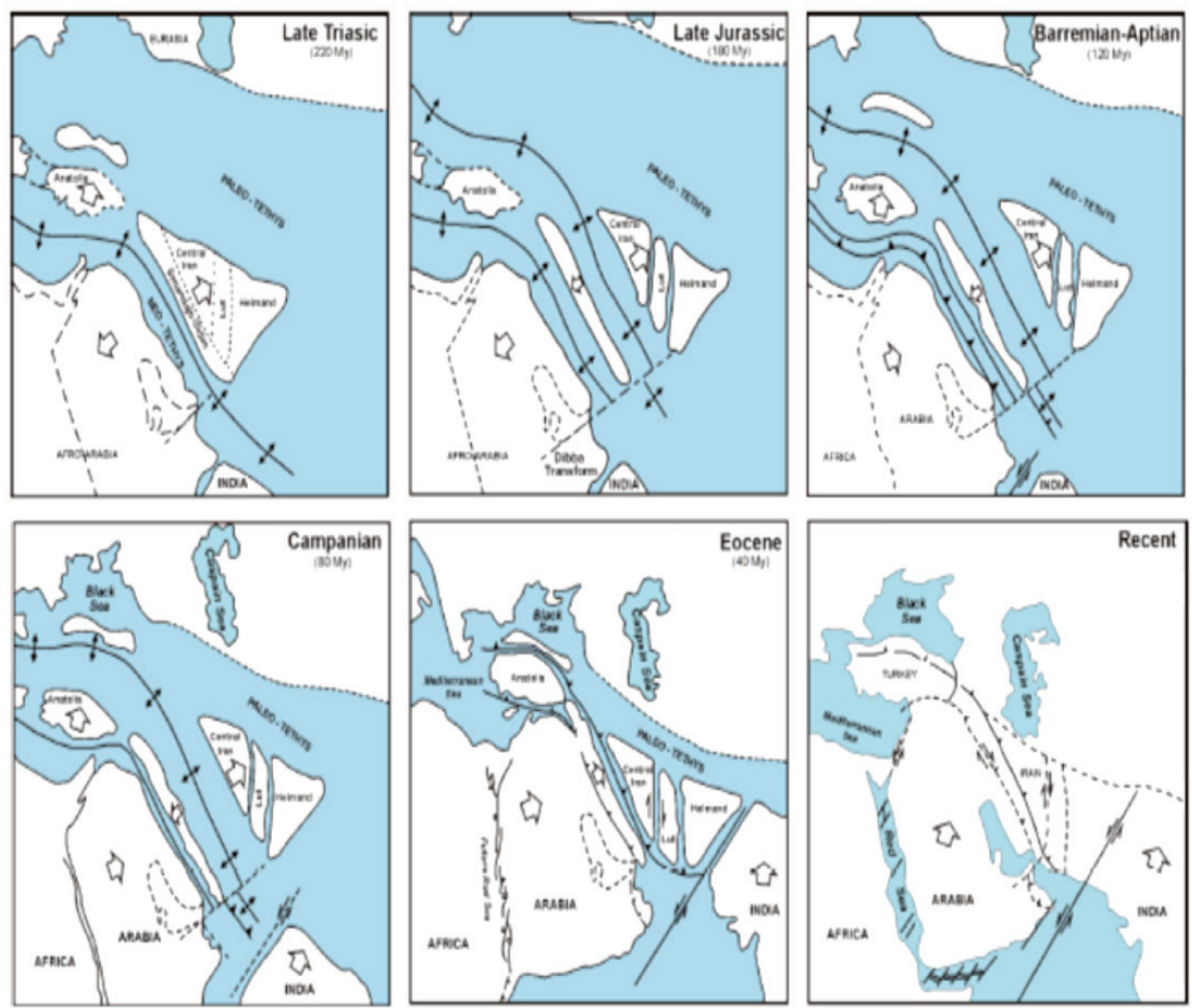

Figure 2.1. Continental drift of the Arabian plate beginning in late Triassic to present (modified from Glennie) 


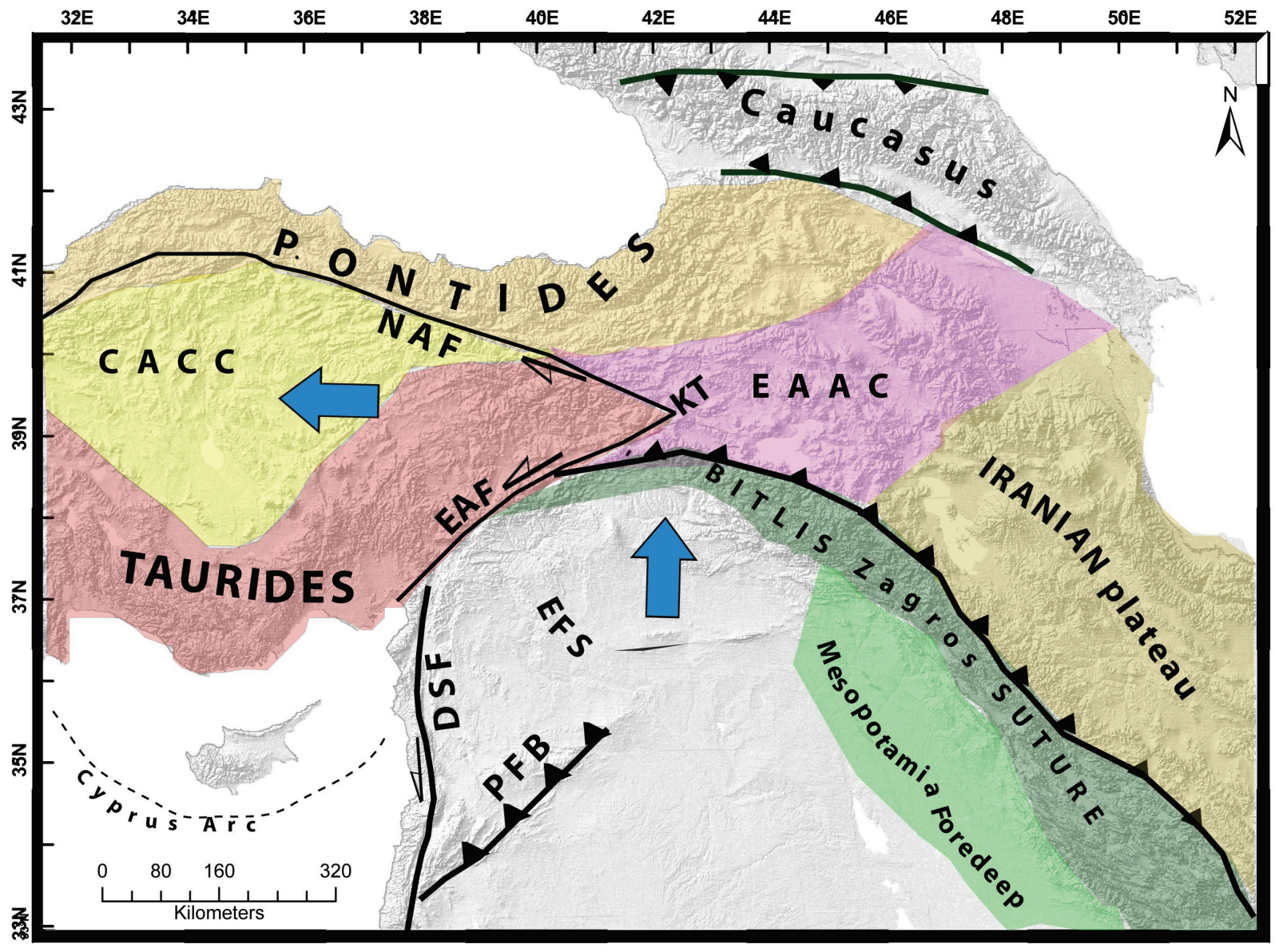

Figure 2.2. Tectonic map of the study area and the surrounding region with the Topographic feature(SRTM30), Abbreviations are North Anatolian fault (NAF), East Anatolia fault (EAF), Dead Sea fault (DSF), Caucasue, Cyprus arc, Karliova Triple junction (KT), Euphrates Fault System(EFS), Central Anatolian Crystalline Complex (CACC), East Anatolian Accretion Complex (EAAC), Palmyrides Fold Belt PFB. 


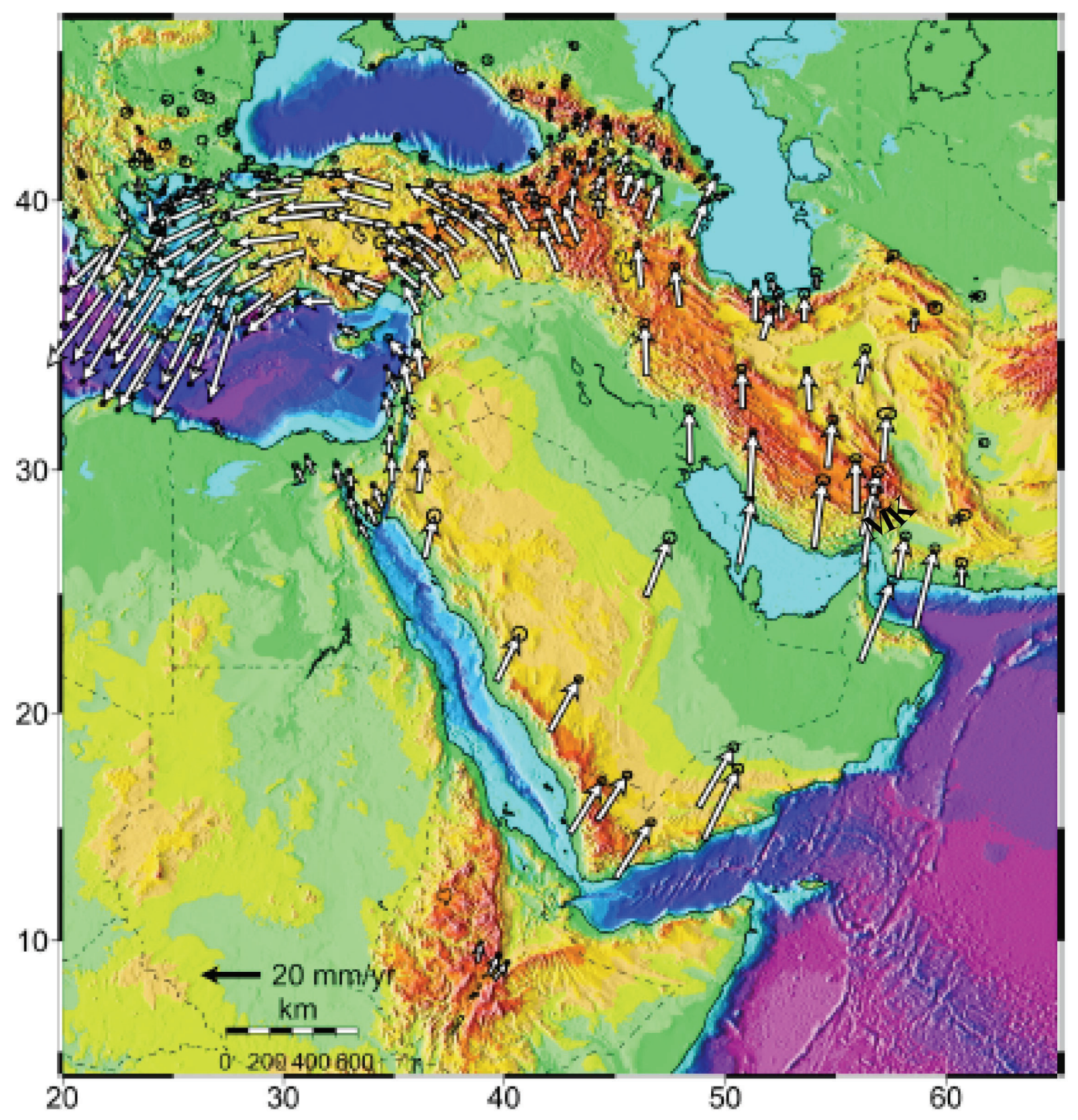

Figure 2.3. GPS velocities relative to Eurasia and Topography (Reilinger,et al 2006), MK: Makran mountain. 


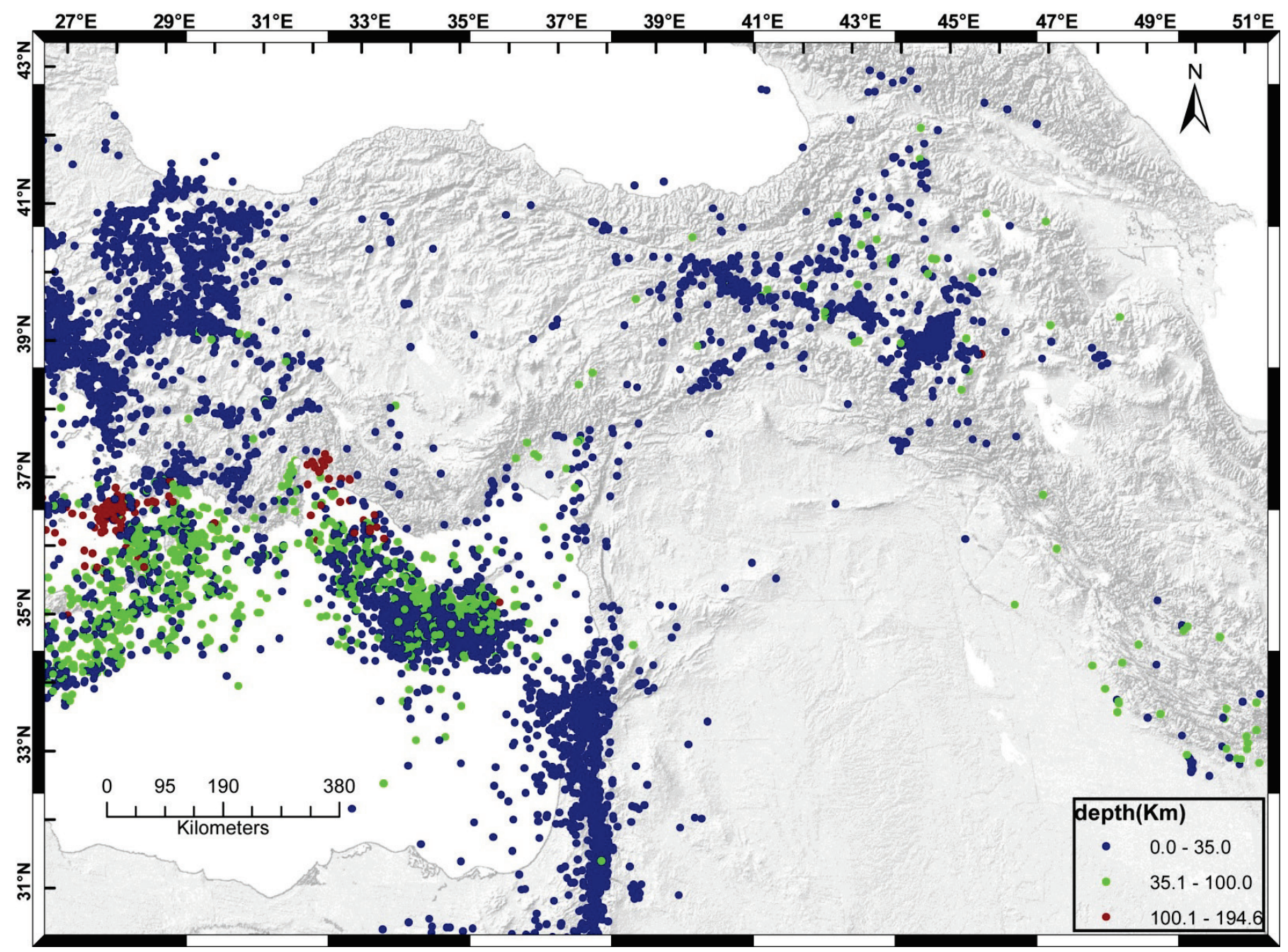

Figure 2.4. Seismicity map for 1980-2012 for studied region and the surrounded area, with color degradation represents the depth variation (ISC-GEM catalogue). 


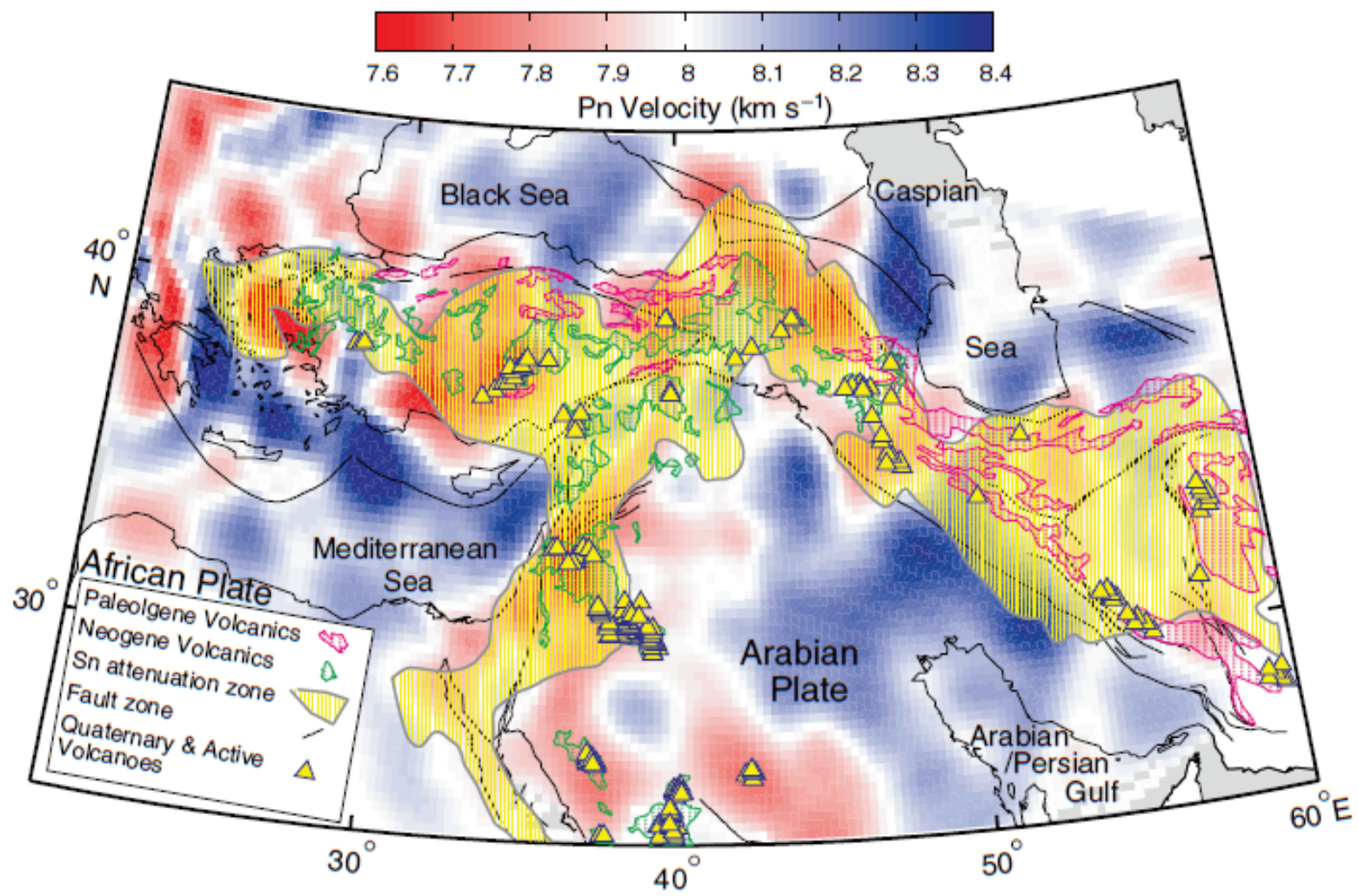

Figure 2.5. Comparative map showing Pn velocity with anisotropy (base map, red-blue colour, see Fig. 7a), volcanic outcrops as green and pink polygons filled with plus signs, Sn attenuation zones as yellow hatched areas enclosed by a solid grey line (after Khaled Al-Damegh, personal communication), and volcanoes as yellow triangles. (AL-lazki, 2004). 


\section{Chapter 3: Moment Tensor}

\subsection{Introduction and Methodology}

One of the most reliable methods used to determine the seismic source is the Centroid Moment Tensor (CMT) method, which estimates source parameters by modeling the equivalent forces producing dynamic displacements at the earth's surface. These forces are identical to those from the actual forces of the physical process of the source.

This study estimates the moment tensor using observed seismograms containing information about the source, earth structure and the instrument response. First, the path structure was determined in order to isolate the source parameters. Second, the synthetic seismogram, which is the theoretical time histories of ground motion at a particular location and distance from the source, is a function of many different parameters including the source mechanism, path velocity structure, and the instrument response. For example, some errors arise from approximations in the theory used to calculate the synthetic seismograms and other errors originate from using simplified earth and source model.

The earthquake sources, defined by the seismic moment tensor, were inverted by matching the observed and synthetic seismogram. This inversion can be done by several methods either in the time domain or the frequency domain.

Seismic waves can be divided into three different categories: (1) body waves method, (2) surface wave method, and (3) whole waveform method which combines both body and surface phases. For example, (Gillbrt et. al., 1975) used the normal modes of the free oscillations of the earth, (Scott and Kanamri, 1985) used long period surface waves, low pass filter with a corner period of 135s, and (Dziewonski, 1981) used moment tensor inversion for body wave data, and 
surface waves. We have chosen to use frequency domain approach where we can define the inverse problem using the standard formulation.

$$
\mathrm{D}=\mathrm{Gm} .(3.1)
$$

In the time domain, the $\mathrm{D}$ vector consists of values of the observed time history of ground displacement; $(\mathrm{G})$ is a matrix containing the Green's function calculated using earth model; $(\mathrm{m})$ is a vector containing the 6 independent moment tensor elements. For the frequency domain, (D) consist of real and imaginary part of the displacement spectra. In addition, the $\mathrm{G}$ and $\mathrm{m}$ contain the real and imaginary parts of the Green's function. The m contains a smaller number of moment tensor elements in case the constrained are applied.

\subsection{Green's function}

The Green's function is a representation of the displacements generated by simple sources localized precisely in space and time. The body forces are the quantities that originate from the applied displacements over a surface of an elastic body. The accurate the Greens function is, the robust determined source parameters become. The reliability of the Green's function depends on all of the propagation effects, attenuation, reflections, diffractions, scattering, mode conversions, and the Geometric spreading. There are three methods to calculate the Green's function and generalized rays in homogeneous layers:

- Cagniard De Hoop Algorithm.

- Extension of Cagniards approach.

- Reflectivity method: double integration over real slowness and real frequency Fuchs(1968,1970,1971). 
- Double integration over real or complex slowness and real frequency.

\subsubsection{Reflectivity method}

The reflectivity method, originated from Fuchs $(1968,1970,1971)$, determines the ground motion for seismic wave propagating within a medium composed of very many homogenous layers. This approach is based upon on matrix methods developed in seismology by Haskell and utilized numerical integration over a limited range of ray parameters. Then numerical inverse Fourier transform was applied on the frequency choice

\subsection{Global Centroid Moment Technique}

The GCMT method determines both the location and the source typically using very long period surface and body waves, smaller periods surface waves, and short period body wave phases. Using the body waves helps to extend efficiency of the technique to smaller earthquakes since these events typically do not produce low frequency seismic waves. In 1981, Dziewonski, Chou, and Woodhouse introduced The CMT method and illustrated the applications of modeling and fitting both the body wave and surface wave portions of the seismograms ( $T>45 \mathrm{~s}$ ). In 1983, Dziewonski and Woodhouse extended the method by applying period longer than $135 \mathrm{~s}$, which called mantle phase. In 1991, (Dziewonski, et. al., 1992) used the whole mantle shear-velocity model that well accounting for 3-D Earth structure and improved variance reduction and; consequently, the quality of the CMT determinations. In addition, in 1994, the model QL6 of Durek and Ekstrom (1996) was used to compute the decay of amplitude of seismic waves.

\subsection{Regional Moment Tensor (RMT) Method}

The regional moment tensor method developed by Douglas S. Dreger and designed to obtain reliable solutions using a minimal number of stations. According to (Dreger and 
Helmberger, 1993), they studied only three-component broadband station, which required to obtain a unique solution. Moreover, they used the complete time-domain waveform inversion technique which fits the complete seismogram rather than breaking it up into parts (i.e. surface and body wave parts).

\subsubsection{Methodology}

The RMT method was originally proposed by Dreger and Helmberger (1993) and later was implemented by Dreger (2003). The algorithm inverts complete, three-component broadband displacement waveforms to estimate a point-source solution. The solution is determined by fitting the synthetic seismograms to the observed data, and its quality is measured through the variance reduction (VR) parameter. The inversion does not solve for the isotropic component, which is constrained to be zero (Jost and Hermann, 1989). The MT solution provides the percentage of double couple (DC) and compensated linear vector dipole (CLVD). For any fixed depth, the procedure attempts to find the best fit by aligning automatically the data with the Green's functions. For each station, the resulted shift interval (in seconds) was shown through a specific output parameter, Zcor. The other output parameters are the Strike, Rake and Dip for the two possible double-couple planes, the scalar seismic moment, and Mw. Information about the moment tensor decomposition in terms of percent double-couple (DC), CLVD, and isotropic (ISO) are also listed. Moreover, fitting parameters, such as the variance, the variance reduction (Var. Red), and the variance modulated, are listed in terms of the percent doublecouple (RES/Pdc). The output parameters VAR, VR, Var/Pdc and Quality are used to gauge the success of the inversion.

Specifically, ZCOR is the sample offset obtained from cross correlating the data with the fundamental Green's functions for the best oriented double-couple mechanism. This offset 
adjustment procedure minimizes the error of MT solutions due to both slight velocity structure misfit (i.e., Green's functions inaccuracies) and to centroid location error. Dreger (2003) suggests that a reasonable search interval for improving fits is +-3 samples (i.e., in this case the corresponds to $3 \mathrm{sec}$ because the waveforms are down sampled to 1 sample per second (sps)) from the value obtained automatically. This is usually sufficient for determining the optimal.

If the data are noisy or the velocity model used to construct the Green's functions is incorrect, a larger search interval may be necessary. On another hand, the variation reduction VR is a quantity of comparing the data $\mathrm{d}$ with the synthetic source data $\mathrm{s}$, and the fit for each comparison.

$$
V R=1-\sum \sqrt[2]{\left(\text { data }_{i}-\text { synthetic }_{i}\right)^{2} /\left(\text { data }_{i}\right)^{2}}
$$

Where data and synth are the data and Green's function time series, respectively, and the summation is performed for all stations and components. The source location was found iteratively by finding the depth that minimizes the misfit between the observed and synthetic waveforms.

The Dreger, et. al., 1992 approach utilizes frequency-wavenumber integration Code (FKRPROG) written by Chandan Saikia, which uses the reflectivity methods to generate synthetic Greens function for laterally homogeneous layered velocity structures using the flat Earth approximation. The Green's functions are computed for a sample rate that is the same as the observed data sample rate. We also applied the same filter on both the synthetic Green's Function. Jost and Herrmannn, (1989) computed the complex spectra of eight Green's function components associated with slip on the fundamental faults. The Zss, Rss, Tss, ; Rds, Zds, Tds; Zdd, Rdd, Rexp, Zexp, are the Green function components required to calculate the full wave 
field due to an arbitrary point dislocation source located in a layered medium. For each distance and azimuth, the PUTMECH program was used to generate the synthetic double couple mechanism. Then a level of noise, $35 \%$ of the maximum synthetic amplitude was added to the synthetic data. Once all the last steps were done, the synthetic data was inverted to generate the moment tensor solutions.

\subsubsection{Signal to noise ratio:}

The method of Dreger, et. al., (1993) takes into account the SNR of the data and station coverage as a function of event location and magnitude. Hence, SNR analysis is performed on two 100 second time windows starting and ending at $\mathrm{P}$-wave arrival time for signal and noise, respectively. For each component, the root mean square of the noise and the data were computed, and the stations will be chosen to use in the analyzing in case their three components are SNR $>3$. This step will avoid the unstable solutions.

\subsubsection{Velocity models}

Since the moment tensor inversion results strongly depend on the velocity structure, various methods were applied to search for the optimal velocity model used to generate the synthetic waveforms; then we tested the models by using GCMT solution for $5 \mathrm{Mw}$ event located in Eastern Turkey (Figure 3.1). 55 body waves, and 93 surface waves have been used to calculate the centroid moment tensor.

\subsection{Using the Grid search and Modeling methods to determine the crustal structure in Zagros region.}

Since the waveforms have a strong sensitivity to the crust and lithospheric structure, the synthetic seismograms were computed by using different computational tools. To minimize the 
trade off between the source location and the mechanisms and the velocity structure, the events that had well constrained source mechanism were only used. The waveform modeling method considers an efficient method to determine the seismic velocity, crustal structural, and the attenuation. The waveform modeling of a whole seismogram, including body and surface waves, allows using information contained in higher modes, and it does not need to many seismic stations. Moreover, modeling the three components of seismograms reduces the chance of modeling coherent noise. In some cases, to develop one dimensional velocity model, waveform modeling is more efficient method than the traditional method, travel time of seismic phases, which can be effected by the error in origin times and hypocenter location arising due to low signal to noise ratio and lack of density of the waveforms.

\subsubsection{Methodology}

This method compares the entire observed seismogram against the synthetic seismogram in order to determine the optimal set of 1-D model parameters; moreover, it follows the steps: (1) a forward-modeling approach, which requires Green's functions to generate the synthetic waveforms for a particular distance and azimuth, was adopted, (2) the synthetic and the observed seismic data were aligned by applying the cross correlations, (3) the waveforms were matched to calculate the agreement using L1norm relationship, (4) the models that have the best fit were selected. The synthetic seismograms are computed by using frequency-wavenumber integration Code written by Chandan Saikia (1994), depending on reflectivity methods.

To determine which parameters produced the best fit between the observed and synthetic waveforms, a grid search algorithm was chosen to analyze many combinations of crustal thicknesses and P- wave crustal velocity. The Grid search method has the advantage of being the last model is independent of the starting model. The viability of this method depends on the 
number of the unknowns and the computational time it takes to compute the Green's function. Therefore, we fixed the depth of the event at $15 \mathrm{Km}$, the moment tensor solution reported by Global Centroid Moment Tensor GCMT, and the attenuation Qp, Qs. Furthermore, we used empirical relationships for density and shear velocity Vs, respectively to further reduce the number of required model parameters.

$$
\rho=0.32 * V p+0.77 \quad V s=V p / 1.83 \quad(3.3)
$$

The resulted receiver function in Northern Iraq (Roland Gritto, et. al., 2008), $\mathrm{V}_{\mathrm{p}} / \mathrm{V}_{\mathrm{s}}=1.83$ were used for KESM station. The grid search searches over the layer thickness and velocity. Specifically, we have 6 model parameters, three for P-wave velocity and three for thickness of three layers over the half space. The first layer, V1 varies between 3 and 4.5, thickness varies between 2 and $10 \mathrm{Km}$. The second layer, V2 varies between 45 and 55Km, and thickness 4 and 30, for the third layered V3 varies between 5.7 and $7.2 \mathrm{Km}$, the thickness for third layer trades off with thickness of the second layer. After this division, a smoothing algorithm was applied to the three -layer model in order to obtain a smoother model consisting of 9 layers with a fixed 4 $\mathrm{km}$ interval.

\subsubsection{Modeling Parameter Perturbations:}

- S wave velocity: Empirically calculated

- P wave velocity: $0.2 \mathrm{~km} / \mathrm{s}$

- Layer thickness: $2 \mathrm{Km}$

- Density: Empirically calculated

- Attenuation: Fixed. 


\subsubsection{Data and Analysis}

Moderate sized earthquake was used, 5.2 Mw 20070825 22:05:47.34 latitude $39.266 \mathrm{~N}$, longitude 41.1122 E, as well as used seismic waveforms of KESM station from NISN North Iraqi Seismographic Network (Figure 3.2), with distance of 240Km and an azimuth132.

The observed seismograms are firstly deconvolved; then integrated the velocity to displacement; then a butterworth bandpass filter with corner periods between 10-50s. This bandwidth was chosen for two reasons: (1) the high frequency features in the seismogram are a function of the lateral variation of seismic velocity and not the source, which is what this study focused on, (2) the moderate size earthquakes relatively are low signal to noise ratios for periods greater than $50 \mathrm{~s}$.

The vertical components have a better signal to noise ratio comparing with the radial and tangential components; therefore, vertical component have more weight than the horizontals.

\subsubsection{Result and Discussion}

In this study, the whole waveform was modeled and compared to both body and surface modeled waveforms. Then the probability density of well-fit models of each of the nine layers were calculated (Figure 3.3). Holt \&Wallace, (1990) and Rodgers \& Schwartz, (1997) both suggested that the surface waves are sensitive to the perturbation of both P- and S-wave velocities of the shallow crust. In contrast, in the deeper crust, the S-wave velocity primarily controls the $\mathrm{S}_{\mathrm{V}}$ wave, and the $\mathrm{P}_{\mathrm{n}}$ wave has a relatively uniform sensitivity to the $\mathrm{P}$ - and S-wave velocities between the surface and bottom layers of the crust.

Figure 3.4 shows that the crust is $\sim 38 \mathrm{Km}$ and consists of $\sim 8-11 \mathrm{~km}$ sediments with $\mathrm{V}_{\mathrm{p} \sim}$

4-4.4 km/s and overlaying thick crystalline layer with $\mathrm{V}_{\mathrm{p}} \sim 8.1 \mathrm{Km} / \mathrm{s}$. The upper crust thickness 
of $\sim 20 \mathrm{Km}$ with a velocity is between 5 and $5.6 \mathrm{Km} / \mathrm{s}$. It is lower than the velocity of the usual continental crust. The lower crust thickness is $\sim 8$ with high velocity $6.2-7.2 \mathrm{~km} / \mathrm{s}$.

Trial and error method was used to develop a unique model fits all the NISN stations. Because of the complex geology and the variable sedimentary layer thickness, the area was divided into two regions based on the thickness of the crust. (R2) contains the Zagros fold belt, and (R1) contains the Mesopotamian Foredeep which is a deep sedimentary basin

Figure 3.2) (Figure 3.5).

\begin{tabular}{|l|l|l|l|l|l|l|l|}
\hline \multicolumn{2}{|l|}{ Thickness(Km) } & \multicolumn{2}{l|}{ P-waves (Km/s) } & \multicolumn{2}{l|}{ S-waves $(\mathrm{Km} / \mathrm{s})$} & \multicolumn{2}{l|}{ Density $\left(\mathrm{gcm}^{-3}\right)$} \\
\hline R1 & R2 & R1 & R2 & R1 & R2 & R1 & R2 \\
\hline 14 & 1 & 4.8 & 3.2 & 2.6 & 1.8 & 2.3 & 1.7 \\
\hline 10 & 4 & 5.6 & 4.7 & 3.1 & 2.7 & 2.5 & 2.2 \\
\hline 17 & 4 & 6.5 & 5.1 & 3.6 & 3 & 2.8 & 2.4 \\
\hline & 12 & & 6.1 & & 3.6 & & 2.7 \\
\hline & 25 & & 6.8 & & 4 & & 2.9 \\
\hline & 10 & & 7.3 & & 4.3 & & 3.1 \\
\hline Pn & & 8.1 & 7.9 & & & & \\
\hline Qp,Qs & & & & & & & \\
\hline 600,300 & 400,200 & & & & & & \\
\hline
\end{tabular}

Table3.1. Thickness, P- wave velocity, S -wave velocity and density for the first and second Zagros regions

\subsubsection{Testing 1-D velocity models}

In the first region, the seismic waveforms of seismic station (KESM) were used in the analysis. In the second region, two stations KSSS, KSJS (Figure 3.6) were used. 20-50sec filter was applied, and then the Global moment tensor solution (GCMT) and Regional moment tensor solution (RMT) were compared by using the method of Dreger, 2003 (Figure 3.7). 


\subsection{Anatolian plate velocity models:}

The Anatolian plate consists of a series of geological complex terrains. Thus, using a unique one-dimension velocity model is likely a very poor approximately for the velocity structure. In order to overcome this problem, we have divided the Anatolian plate into four subregions. Each sub-region almost has a homogenous crustal structure. The optimal 1-D velocity models were calculated by using the grid search approach for each of the following sub-regions:

The first sub-region contains the Pontide (Eastern and Central Pontide), the second subregion contains the Eastern Anatolian plateau, the third sub-region contains the Central Anatolian, the fourth contains Tauride block, and finally the fifth sub-region is the foreland of the Arabian plate. The 1-D velocity model of Skolbetsyn et. al., 2013 (in review) for Eastern Anatolian plateau was used for the second sub-region, and as initial model for the first and the fourth sub-regions. By applying a trial and error method, we were able to improve the models for the first and fourth sub regions. The observed and synthetic waveform is well-matched for second sub-region. Furthermore, the study region of Skolbetsyn et al 2013 totally contains the second sub-region.

\begin{tabular}{|c|c|c|c|c|c|c|c|c|c|c|c|c|c|c|c|}
\hline \multicolumn{4}{|c|}{$\begin{array}{l}\text { Thickness }(\mathrm{Km}) \\
\text { (Region } 1-4) \text { respectively }\end{array}$} & \multicolumn{4}{|c|}{$\begin{array}{l}\text { P-wave velocity } \\
(\mathrm{Km} / \mathbf{s})\end{array}$} & \multicolumn{4}{|c|}{$\begin{array}{l}\text { S-wave velocity } \\
(\mathrm{Km} / \mathbf{s})\end{array}$} & \multicolumn{4}{|c|}{$\begin{array}{l}\text { Density } \\
\left(\mathrm{g} / \mathrm{cm}^{3}\right)\end{array}$} \\
\hline 15 & 20 & 2 & 3 & 6.110 & 5.8 & 5.2 & 3.5 & 3.232 & 3.35 & 2.9 & 2.02 . & 2.725 & 2.62 & 2.7 & 1.8 \\
\hline 10 & 10 & 9 & 13 & 6.110 & 6.4 & 6.4 & 5 & 3.232 & 3.7 & 3.6 & 3.07 & 2.725 & 2.81 & & 2.23 \\
\hline 23 & 12 & 29 & 20 & 6.395 & 6.9 & 7.4 & 6.29 & 3.677 & 4 & 4.2 & 4.2 & 2.816 & 2.91 & 2.8 & 2.7 \\
\hline $\mathrm{Pn}$ & & & & & & & & & & & & & & & \\
\hline 7.6 & 7.6 & 8 & 7.6 & & & & & & & & & 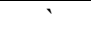 & & & \\
\hline
\end{tabular}

Table 3.2.1-D velocity models for the Anatolian plate used in this study (1-4)region, respectively. 


\subsubsection{Testing the models}

First region: The seismic data of stations BCA, BZA, ESPY, DIKM, KTUT, PZAR was used to calculate the RMT solution separately and as a group (Figure 3.6). The result is acceptable for all stations except the PZAR because it has poor fit waveforms. Therefore, PZAR was not used in the group solution RMT.

Second region: The RMT solution for CLDR station was calculated (Figure 3.6), the distance from the source $240 \mathrm{~km}$ and azimuth $92^{\circ}$. The fitness between the observed and theoretical seismograms was satisfactory, and it is compatible with the GCMT solution.

Fourth region: In this region, BNN, GAZ, CORM, KARA, KOZT, BZK, MERS, SARI used to calculate RMT with the distances from the source,460,415,566,577, 504,673, 638,420 $\mathrm{Km}$, and the Azimuth $265^{\circ}, 237^{\circ}, 282^{\circ}, 249^{\circ}, 248^{\circ}, 298^{\circ}, 247^{\circ}, 258^{\circ}$, respectively, Figure 3.8 shows that the result is acceptable except for station SARI. Furthermore, the moment tensor solution for a set of stations shows a strike-slip focal mechanism, $M w=5.1, C L V D=49, D C=51$.

Third region: Stations CANT, CORM, SVSK, RSDY, with distances of, 363.36 , $349.499,566.988,659.407 \mathrm{Km}$ and the azimuth 285, 282, 282, 292, respectively. All of these stations are separable by faults and located in diverse tectonic unites (Figure 3.6). CANT located in Cankiri Basin, RSDY located in Sakarya continent zone and CROM located in Kirsehir massif and SVSK located in Ophiolitic mélange, which is surrounded by the basin from the west, north and east. The result of the waveform modeling is shown in Table3.2 and (Figure 3.9). Moment tensor solution is acceptable for both separate station solution and for a group solution (Figure $3.10)$. 


\begin{tabular}{|l|l|l|l|l|l|l|l|}
\hline \multicolumn{2}{|c|}{ CANT } & \multicolumn{3}{c|}{ CORM } & \multicolumn{2}{c|}{ SVSK } & RSDY \\
\hline $\begin{array}{l}\text { Thickness } \\
(\mathrm{Km})\end{array}$ & $\begin{array}{l}\mathrm{P}_{\text {Velocity }} \\
(\mathrm{Km} / \mathrm{s})\end{array}$ & $\begin{array}{l}\text { Thickness } \\
(\mathrm{Km})\end{array}$ & $\begin{array}{l}\mathrm{P}_{\text {Velocity }} \\
(\mathrm{Km} / \mathrm{s})\end{array}$ & $\begin{array}{l}\text { Thickness } \\
(\mathrm{Km})\end{array}$ & $\begin{array}{l}\mathrm{P}_{\text {Velocity }} \\
(\mathrm{Km} / \mathrm{s})\end{array}$ & $\begin{array}{l}\text { Thickness } \\
(\mathrm{Km})\end{array}$ & $\begin{array}{l}\mathrm{P}_{\text {Velocity }} \\
(\mathrm{Km} / \mathrm{s})\end{array}$ \\
\hline 5 & 5.2 & 2 & 5 & 2 & 5.2 & 2 & 4.4 \\
\hline 6 & 6.2 & 12 & 6.4 & 9 & 6.4 & 6 & 6.2 \\
\hline 29 & 7.2 & 26 & 7.2 & 29 & 7.4 & 32 & 7.4 \\
\hline
\end{tabular}

Table 3.2. 1-D velocity models for the third region

\subsubsection{Discussion result of the velocity models of the third region.}

All the resulting models indicate high upper crust velocity overlays by variable thin sedimentary layer. Seda Yolsal-Cevikiblen, et. al., (2010) obtained the 1-D velocity model for Central Turkey using VELEST code, which inverts for both velocity and hypocenter locations (Figure 3.12). Comparing the Seda model to the resulted model, substantial differences were founded. In this study result, the sedimentary layer is thin, and its $\mathrm{P}$ velocity is high. Whereas the upper and middle crust $\mathrm{P}$ velocity is high, the lower crust has a slightly consistent $\mathrm{P}$ velocity with Seda model.

According to Yolsal-Cevikiblen, et. Al., (2010), the 3-D P-wave velocity structure and the $\mathrm{Vp} / \mathrm{Vs}$ variations from 5 to $30 \mathrm{Km}$ depth were imaged in Central Anatolian. They recognized a high velocity block which they interpreted as a continental basement fragment. The top of the block has been identified as the basement of Cankri basin. They argue that the velocity in this region was high, and it associated with low $\mathrm{Vp} / \mathrm{Vs}$ ratio because of a dominant felsic rock composition. On the other hand, the accretionary geologic units have a low $\mathrm{P}$ wave velocity, and a high $\mathrm{Vp} / \mathrm{Vs}$ ratio, because either they have more mafic rocks or contain more fluids or partial melt. Furthermore, they identified a large variation in the $\mathrm{Vp} / \mathrm{Vs}$ ratio over the entire region that can be related to variations in the fluid content of the crust. This result is extremely useful 
because it explained the lateral variable of the crustal structure and emphasized effects of the velocity lateral variation on the moment tensor result.

Ardeleanu, et. al., (2010) investigated the effect of the incorrectly modeling of the crust for the moment tensor solution by randomly perturbing the parameters of 1-D models and observing the deviation in the mechanism. They concluded that a 5\% model perturbation preserves the agreement of the mechanism with the regional stress field, but $20 \%$ uncertainty makes the moment tensor unreliable. In addition, the content of the double couple and Compensated Linear Vector Dipole (CLVD) resulting from the decomposition of the moment tensor is quite sensitive to the miss-modeling of the earth structural. Consequently, the result for this region seems relatively reliable because the model, which used in the inversion, has less than a $20 \%$ perturbation from the GCMT models.

\subsection{Arabian Platform velocity model:}

Ibrahim et. al., (2008) used seismic data form Syrian national seismological network to explore the crust and uppermost mantle under Syrian stations by using inversion method for structure and hypocenters (Table 3.3) (Figure 3.5).

\begin{tabular}{|l|l|l|}
\hline Thickness $(\mathrm{Km})$ & P-velocity $(\mathrm{Km} / \mathrm{sec})$ & $\mathrm{V}_{\mathrm{P}} / \mathrm{Vs}$ \\
\hline 4 & 5.68 & 1.89 \\
\hline 6 & 5.87 & 1.69 \\
\hline 8 & 6.18 & 1.78 \\
\hline 19 & 6.74 & 1.7 \\
\hline Pn & 8.1 & 1.72 \\
\hline
\end{tabular}

Table3.3. Thickness, $\mathrm{P}-$ wave velocity, and $\mathrm{V}_{\mathrm{p}} / \mathrm{V}_{\mathrm{S}}$ of Arabian platform. 


\subsubsection{Test of the model}

Two stations TOTH, ORFA have recorded this event within the stable Arabian plate with a signal to noise ratio higher than 3 . Figure 3.13 shows the result of the RMT using 20-50sec filter, which seems acceptable comparing with GCMT result.

\subsection{Moment Tensor inversion analysis data:}

\section{January 2007, Mw= 5.4}

This event was large enough for the Global CMT project to calculate a solution, which provides an opportunity to compare Dreger code moment tensor solution RMT with a Global CMT solution. Its location is $(39.60 \mathrm{~N}, 42.72 \mathrm{E})$, recorded at three stations with $\mathrm{SNR}>3$, CUKT, KESM, KVT with source-receiver distances 269, 312, $605 \mathrm{Km}$ and azimuth $166,158,289$, respectively, the depth $15 \mathrm{Km}$ (Figure 3.15). The observed and synthetic waveforms were bandpass-filtered between $0.02-0.05 \mathrm{~Hz}$. The matching between the synthetic and observed data seems good, and the GCMT and RMT solutions are very similar. Moreover, the P-axis trending NNW-SSE is consistent with what is known about the Arabian-Eurasian collision and trend of the fold and thrust belt (Figure 3.16).

\section{September 2008, Mw=5}

This event located in (38.69 N, 45.79E), recorded at four stations KSBB, KSWW, KESM, ROOS within distances of 420,284,235,912 and azimuths of 181,190,218,299 km (Figure 3.17). The SNR for the chosen stations is above 3.0 at frequencies higher than $0.02 \mathrm{~Hz}$. The waveforms were filtered with a bandpass filter with corner frequencies of $0.02-0.05 \mathrm{~Hz}$, and the agreement between the synthetic and observed waveforms is good. Comparing the Regional moment tensor solution with first motion focal mechanism resulted from $33 \mathrm{P}$ - wave arrivals 
(Figure 3.14). Comparing the GCMT with RMT solutions seems convenient with NNW-SSE trending $\mathrm{P}$ axis, which consists with collision process (Figure 3.18).

\section{October 2006, Mw=3.9}

This event is an example of the earthquakes that Regional moment tensor analysis is well suited to resolve. Earthquakes with Ml 4.0-5.0 do not generate energy at low-enough frequencies for Global moment tensor methods, but they do generate sufficient low-frequency energy for reliable moment tensor solutions at regional distances. The SNR for the chosen stations is above 3 at frequencies higher than $0.02 \mathrm{~Hz}$. This event was located in $35.824 \mathrm{~N}$, 35.600E, recorded at three stations TOTH, KMRS, KOZT, within $\sim 289,219,184 \mathrm{~km}$ of the epicenter and azimuth $\sim 164$ (Figure 3.19). The waveforms were filtered at $0.03-0.06 \mathrm{~Hz}$. The high degree of agreement between the synthetic and observed waveforms is acceptable (Figure 3.20). By comparing the moment tensor solution with first motion solution resulted from $33 \mathrm{P}-$ wave arrivals (Figure 3.14), the NW-SE trending P-axis for the first motion solution is consistent with the RMT solution. Another frequency was examined, 0.02-0.05 Hz, and the result is similar to RMT solution (Figure 3.21).

\section{July 2008, Ml 4.6 Ms=3.6}

This event was located in $(38.4925 \mathrm{~N}, 43.0966 \mathrm{E})$ and recorded at three stations, KARS, KTUT, PTK, with distances from the epicenter of 243, 420, 351km, and azimuth 354, 314, 280, respectively (Figure 3.22). The SNR $>3$ at frequencies higher than $0.02 \mathrm{~Hz}$. The waveforms were filtered at $0.02-0.05 \mathrm{~Hz}$, and the agreement between the synthetic and observed waveforms is good (Figure 3.23). The first motion solution was calculated using 22 polarities (Figure 3.14). The two methods have a consistent result, and the orientation of the P-axis is consistent with the tectonic trend of this region. 


\section{5 may 2007, $\mathrm{Ml}=4.2, \mathrm{Ms}=3.7$}

This event was recorded at two stations, CUKT, PTK, within a distance from epicenter, 207,2250 km, and azimuth 145,273 (Figure 3.24). The SNR for the chosen stations is above 3 at frequencies higher than $0.02 \mathrm{~Hz}$. The waveforms were bandpassed filtered between $0.02-0.05$ $\mathrm{Hz}$, and the agreement between the synthetic and observed waveforms is good (Figure 3.25). The depth was fixed at $15 \mathrm{~km}$, first motion solution was calculated using 18 polarities (Figure 3.14), and fairly consistent results were observed using both methods.

\section{October 2007, $\mathrm{Ml}=4.2, \mathrm{Ms}=3.5$}

This event was located in $(39.035 \mathrm{~N}, 41.115 \mathrm{E})$, recorded at three stations URFA, KARS, ROOS within $\sim 264,248,635, \mathrm{~km}$ of the epicenter and azimuth 22 (Figure 3.26). The SNR $>3$ at frequencies higher than $0.02 \mathrm{~Hz}$. The waveforms were filtered at $0.02-0.05 \mathrm{~Hz}$, and the fit between the synthetic and observed waveforms is good (Figure 3.27). The depth is fixed at 15 $\mathrm{km}$. First motion solution was calculated using 28 polarities. Similar to the other events, both methods resulted consistent results.

\section{June 2007, $\mathrm{Ml}=4.1, \mathrm{Ms}=3.3$}

This example examines RMT solutions for small events. This event located in $(38.962 \mathrm{~N}$, 43.8826E)(Figure 3.28), recorded at two stations AGRB,CUKT, within $~ 107,190$, km and azimuth 311 of the epicenter. The SNR $>3$. The waveforms were filtered at $0.02-0.05 \mathrm{~Hz}$, and the agreement between the synthetic and observed waveforms is good (Figure 3.29). The first motion solution was calculated using 16 polarities (Figure 3.14). The matching between the two results is good with NNW-SSE trending P-axes. 


\subsection{Result and conclusion}

In a complex geological region, lithospheric heterogeneity plays an essential role in obtaining a reliable Regional Moment Tensor solution. Hence, different velocity models for every geologic setting are required for a robust result. The small magnitude event waveforms are usually more affected by the heterogeneity of the crust and scattering since the associate waveforms have little energy at the longer periods. Consequently, the most influential factors on the moment tensor inversion are the following factors: (1) the complexity of the velocity structures along source-station paths, (2) the amount of the dislocation of the epicenter, and (3) the number of stations used in the inversion and their azimuthal distribution. Using well-fit velocity models and choosing small frequency ranges consider the keys for reliable focal mechanisms.

In the Anatolian plate, the radial components mostly shows misfit between the synthetic and the observed waveforms even with using the optimal velocity models. It is known that the radial components and Rayleigh waveforms are strongly sensitive to the SV component of the shear wave velocity. The changing $\mathrm{Vp}$ of the top layer can change the amplitude and the period of the Rayleigh waves (Song, et. al., 1995). Due to the strong heterogeneity in the Anatolia, the $\mathrm{Vp}$ has high lateral variation. Moreover, the attenuation plays a big role in this region. Whereas the Q values used in waveform modeling is 200, the Q in Eastern Turkey is variable, and it is less than 100 in some locations (Bao et al., 2010; Zor et al., 2007).

Likewise the GMT solution used in waveform modeling, the RMT solution of the analyzed events shows that the CLDV percent is high because of the lateral variation of the crustal structure and the anisotropic media that characterize the Anatolian plate. Usually the moment tensor technique neglects the anisotropic effects (Rossler, et. al., 2003). The improved 
velocity structure along the propagation paths or using 3-D velocity model contributes in decreasing CLVD values.

Focal mechanisms derived from moment tensors inversions well agree with all focal mechanisms obtained using first motion polarities. First motion solutions require a large number of stations with good azimuthal distribution to calculate a reliable mechanism. However, sometime is possible to get a well constrained $\mathrm{P}$ and $\mathrm{T}$ axis even when the coverage is poor and the focal mechanism is not constrained. The uncertainties for first motion solutions are large when station coverage is sparse. However, estimating the uncertainty in moment tensor is difficult but (Frolich and Davis,1999) most likely 5-10 degree or less.

Earthquakes $\mathrm{Mw}<3.5$ shows a lack of seismic energy at frequencies as low as $0.02 \mathrm{~Hz}$. Dreger (2003) method shows a strong dependency on the band pass filter, so applying the inversion on a broad frequency range instead of a narrow frequency range can result in an incorrect source mechanism because, in this case, the modeling is more sensitive to details of crustal structure.

Most of the computed moment tensors have small non- double -couple components (20\%-50\%) considered being introduced by noise and problems with the $1-\mathrm{D}$ velocity models. Using many seismic stations in RMT resulted in a low VR. However, the solution is reliable. 
Region name: TURKEY

Date $(\mathrm{y} / \mathrm{m} / \mathrm{d}): 2007 / 8 / 25$

Information on data used in inversion

$\begin{array}{lrrc}\text { Wave } & \text { nsta } & \text { nrec } & \text { cutoff } \\ \text { Body } & 55 & 89 & 40 \\ \text { Mantle } & 0 & 0 & 0 \\ \text { Surface } & 93 & 178 & 50\end{array}$

Timing and location information

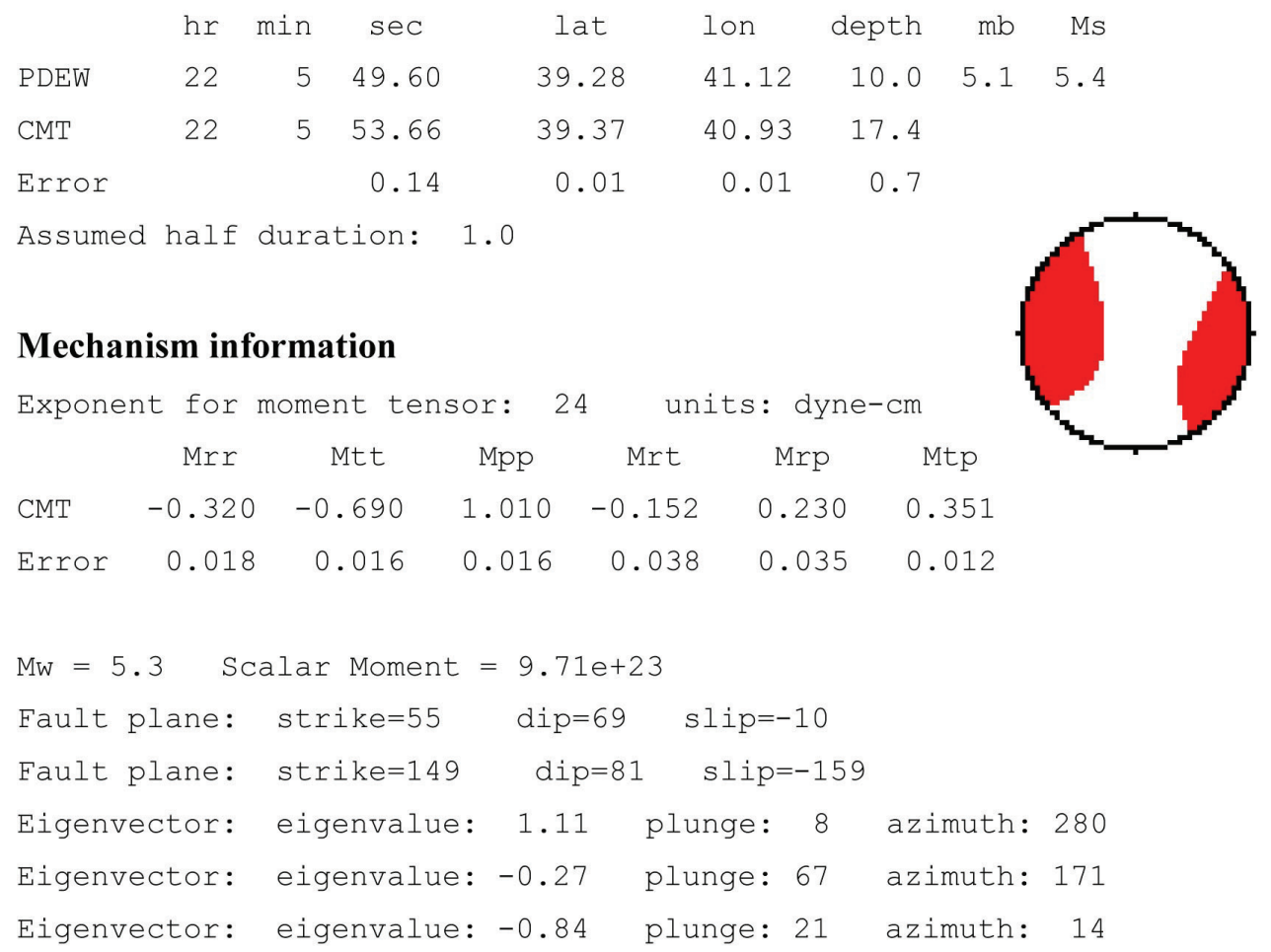

Figure 3.1. The GCMT solution for earthquake located in Eastern Turkey 


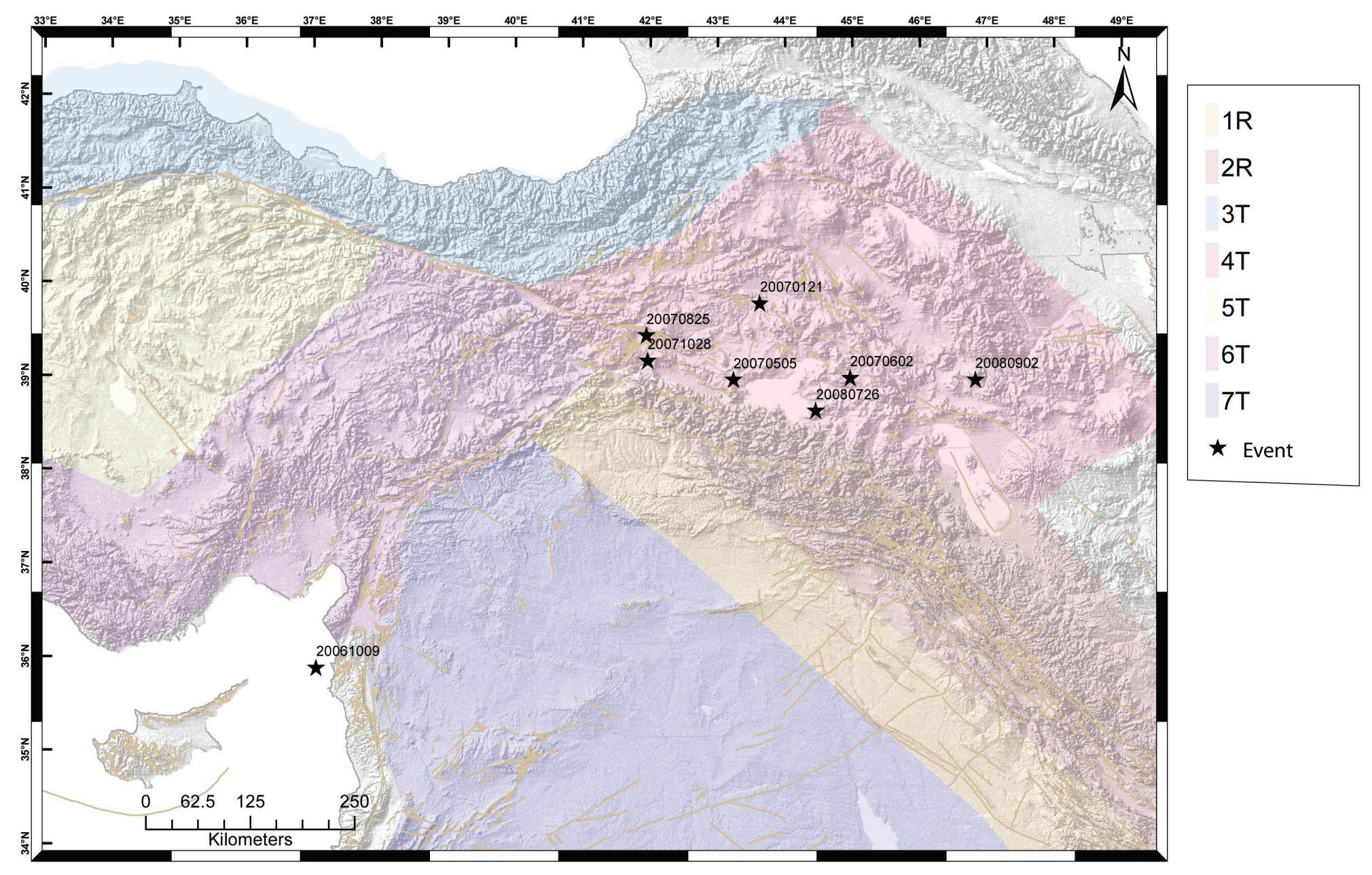

Figure 3.2. Map showing the subregions of the study area which compatible with geological settings, earthquakes location of the events used in this study(USGS-NIES) and topography, tectonic and geographic features are located. Black stars represent the earthequakes used in this study. 


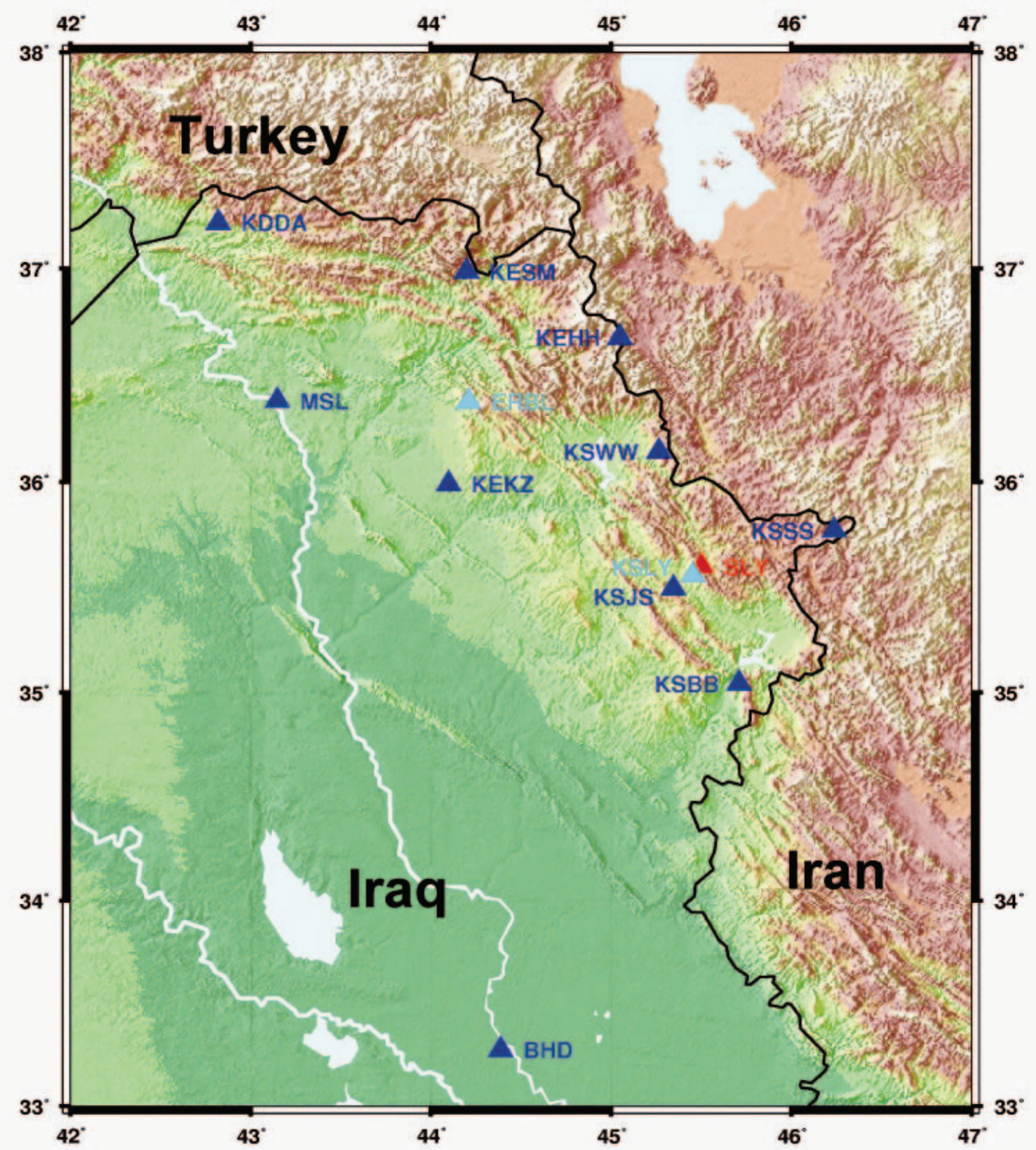

Figure 3.3. Zagros region and NIES seismic network distribution.(blue Triangle), geographic features and topography, white line is Euphrates and Tigris rivers. 

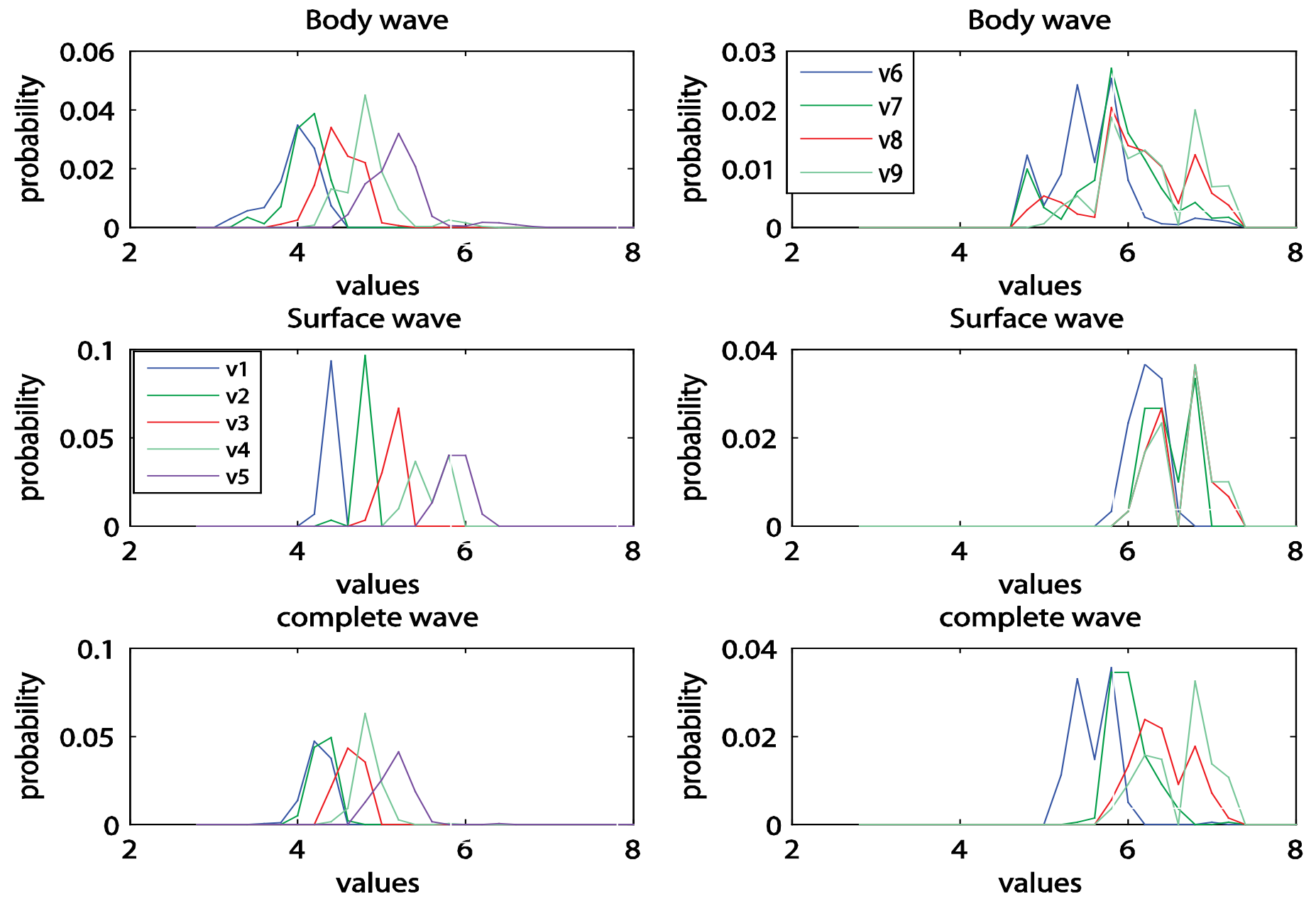

Figure 3.4. Body, Surface and all waves probability of nine layers of the best well -fit models resulting of waveform modeling. Left side represents first five layers, and right site shows the last four layers. The value is velocity $\mathrm{Km} / \mathrm{s}$. 
P-wave Velocity $(\mathrm{km} / \mathrm{s})$

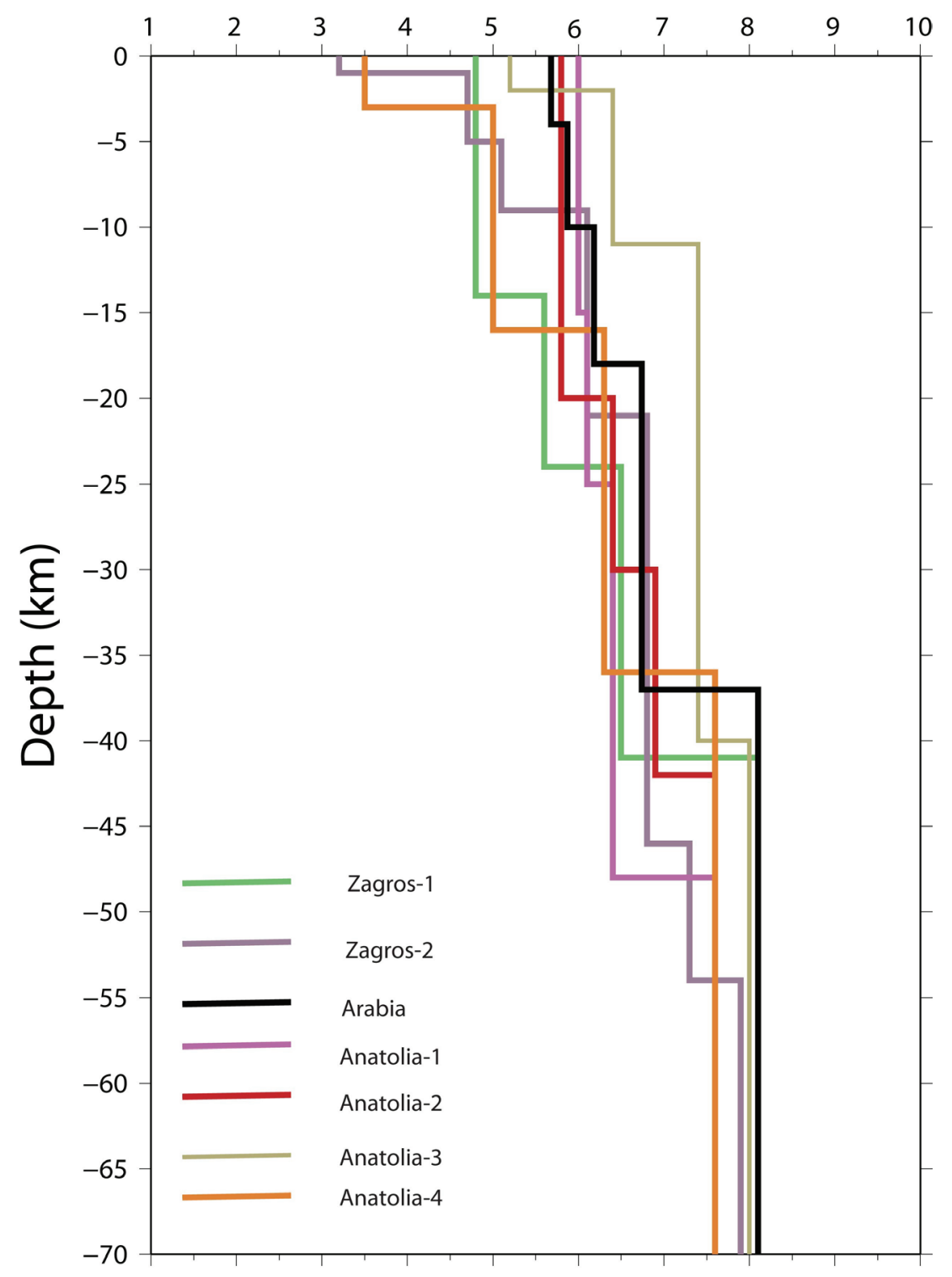

Figure 3.5. Velocity models of all the sub-regions in the study area, Zagros, Anatolia, Arabia. 


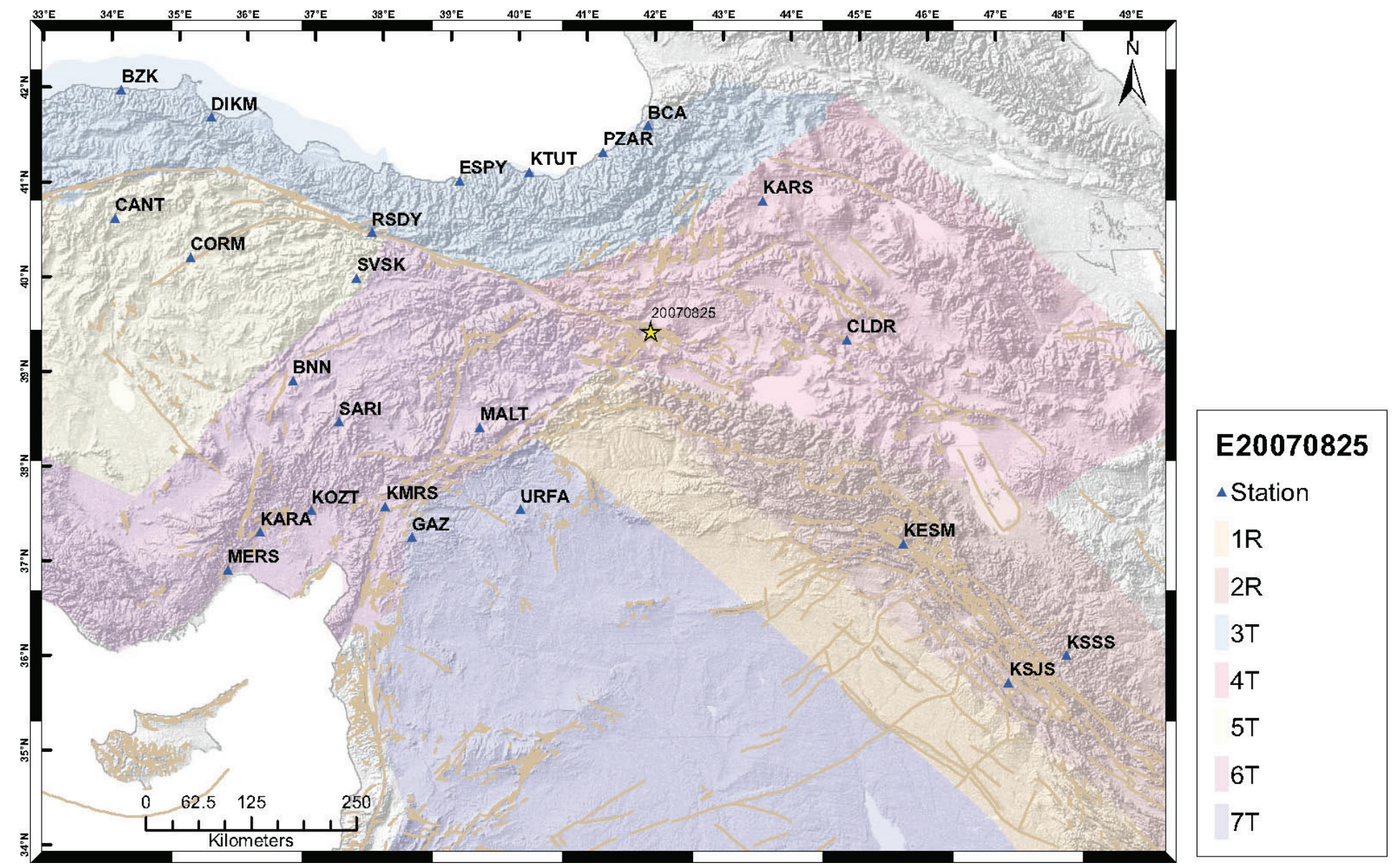

Figure 3.6. Map shows all stations used in testing the velocity models for all the all the sub-regions, as well as the sub-regions. 


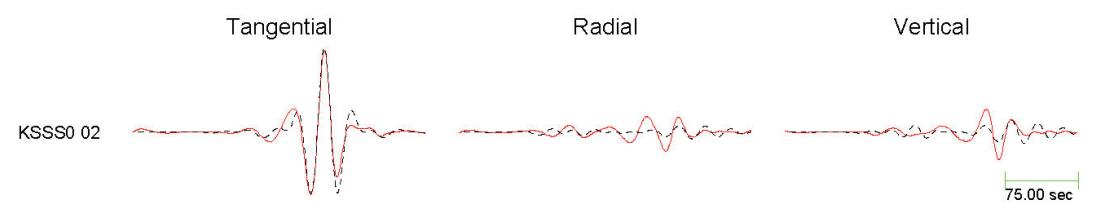

Distance $=595 \mathrm{~km}$ Azimuth $=129 \mathrm{Max}$ Amp $=1.07 \mathrm{e}-02 \mathrm{~cm}$ Zcorr $=22 \mathrm{VR}=80$

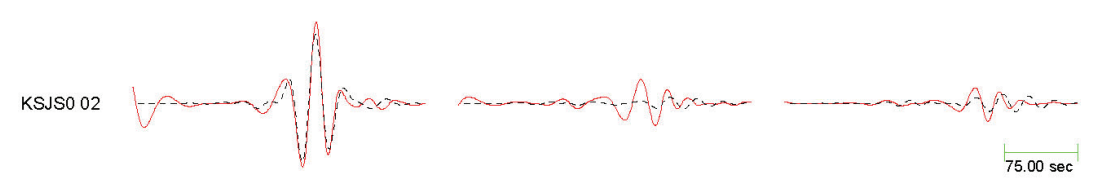

Distance $=560 \mathrm{~km}$ Azimuth $=137$ Max Amp $=1.27 \mathrm{e}-02 \mathrm{~cm} \mathrm{Zcorr}=20 \mathrm{VR}=76$

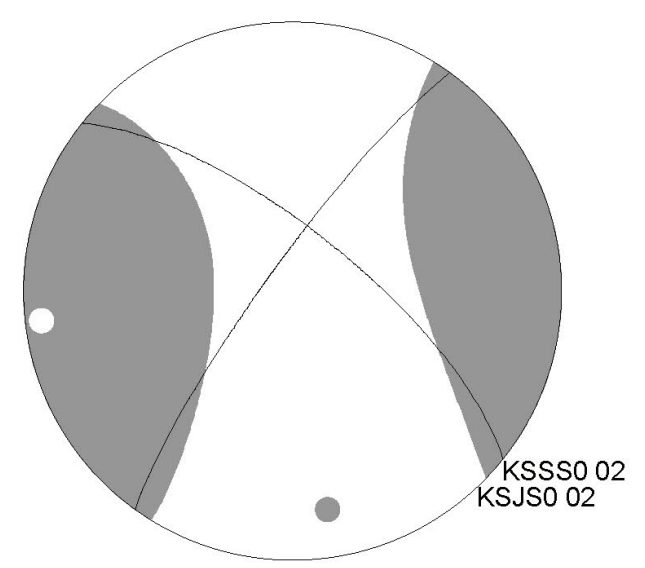

$\begin{array}{ll}\text { Depth }=15 & \text { Percent } D C=35 \\ \text { Strike }=216 ; 309 & \text { Percent } C L V D=65 \\ \text { Rake }=-19 ;-171 & \text { Percent ISO }=0 \\ \text { Dip }=82 ; 72 & \text { Variance }=6.42 \mathrm{e}-07 \\ M 0=8.70 \mathrm{e}+23 & \text { Var. Red. }=77.9 \\ M w=5.23 & \text { RES/Pdc }=1.84 \mathrm{e}-08\end{array}$

Figure 3.7. Moment tensor solutions for a group of stations together for first and second Zagros regions. The red line is the observed waveforms, and the dashed line is the synthetic waveforms. 


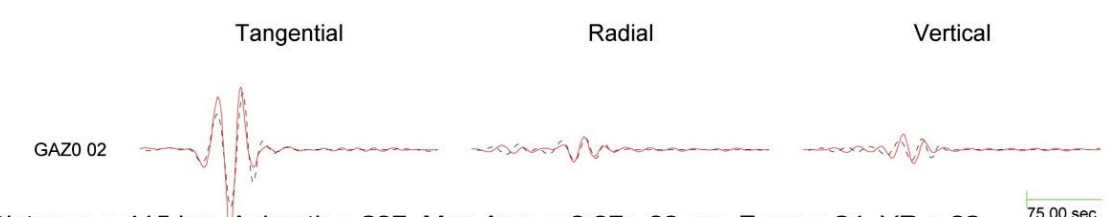

Distance $=415 \mathrm{~km}$ Azimuth $=237$ Max Amp $=3.97 \mathrm{e}-03 \mathrm{~cm} \quad$ Zcorr $=24 \quad \mathrm{VR}=82 \quad 75.00 \mathrm{sec}$

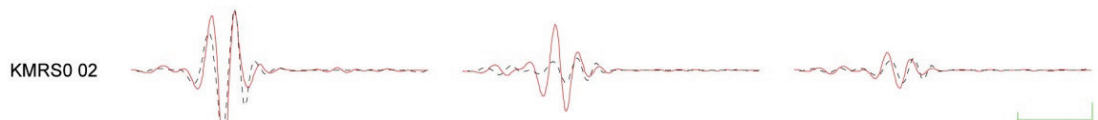

Distance $=419 \mathrm{~km}$ Azimuth $=244$ Max Amp $=3.54 \mathrm{e}-03 \mathrm{~cm} \quad$ Zcorr $=26 \quad \mathrm{VR}=64 \quad 75.00 \mathrm{sec}$

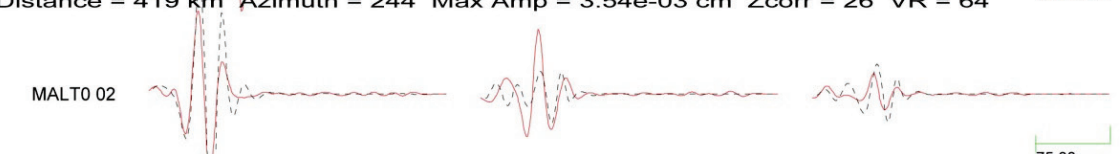

Distance $=258 \mathrm{~km}$ Azimuth $=247$ Max Amp $=2.20 \mathrm{e}-03 \mathrm{~cm} \quad$ Zcorr $=28 \quad \mathrm{VR}=40 \quad 75.00 \mathrm{sec}$

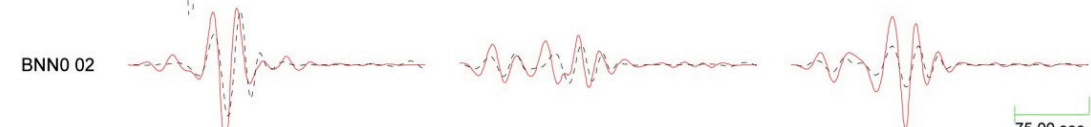

Distance $=460 \mathrm{~km}$ Azimuth $=266$ Max Amp $=1.96 \mathrm{e}-03 \mathrm{~cm} \quad$ Zcorr $=42 \quad \mathrm{VR}=55 \quad 75.00 \mathrm{sec}$

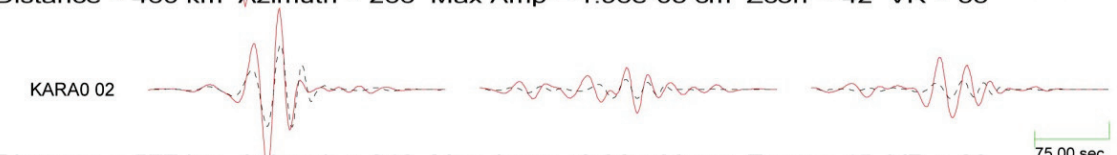

Distance $=577 \mathrm{~km}$ Azimuth $=249 \mathrm{Max} A \mathrm{Amp}=3.36 \mathrm{e}-03 \mathrm{~cm} \quad$ Zcorr $=45 \mathrm{VR}=60 \quad 75.00 \mathrm{sec}$

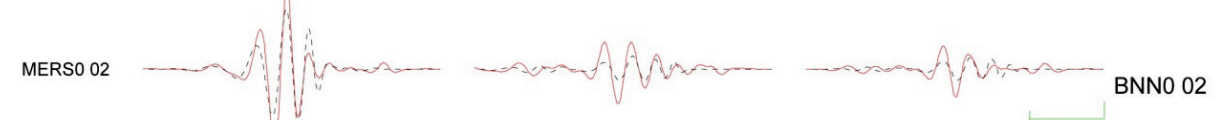

Distance $=639 \mathrm{~km}$ Azimuth $=247$ Max Amp $=2.28 \mathrm{e}-03 \mathrm{~cm}$ Zcorr $=42$ VR $=70 \quad 75.00 \mathrm{sec}$ KARA0 02

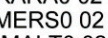

MALTO 02

KMRSO 02 GAZO 02
Depth $=15$

Strike $=144 ; 53$

Rake $=-161 ;-4$

Dip $=86 ; 71$

$\mathrm{Mo}=4.80 \mathrm{e}+23$

$\mathrm{Mw}=5.06$

Percent DC $=51$

Percent CLVD $=49$

Percent ISO $=0$

Variance $=6.75 \mathrm{e}-08$

Var. Red. $=63.4$

$\mathrm{RES} / \mathrm{Pdc}=1.32 \mathrm{e}-09$

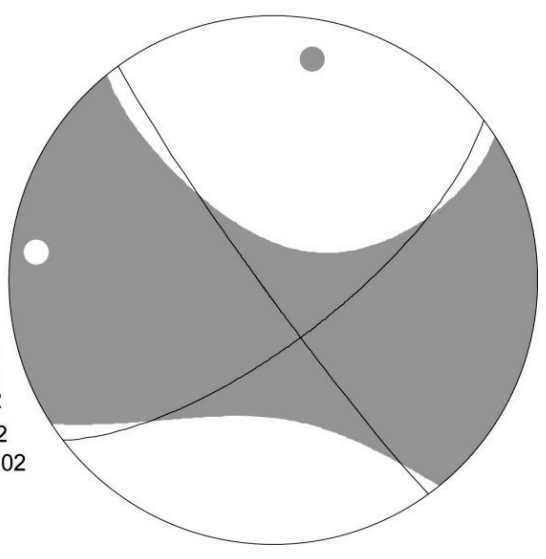

Figure 3.8. Moment tensor solution of the fourth region in the Anatolian plate as group solution. The red line represents the observed waveforms, the dashed line represents the synthetic waveform. 


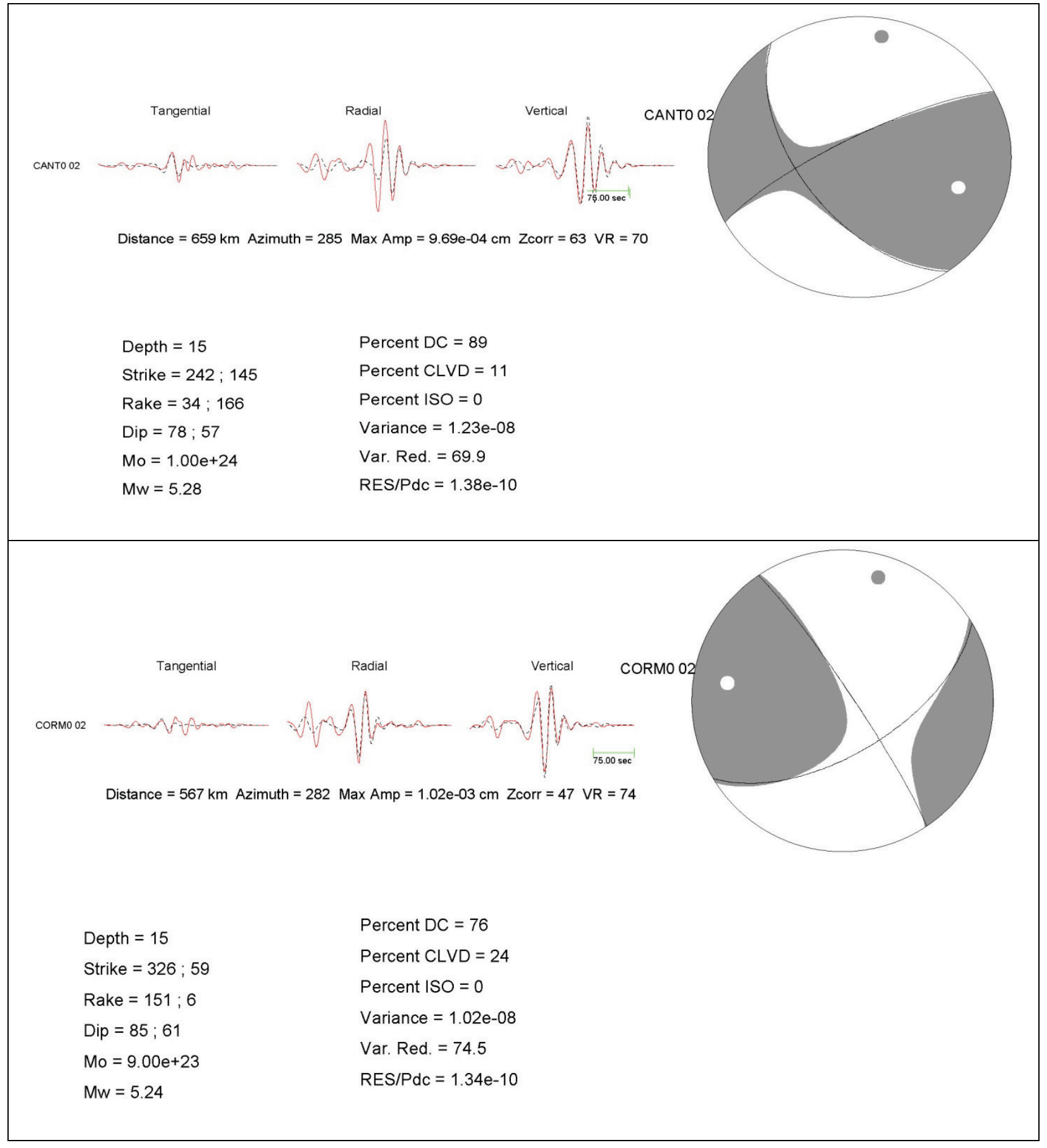




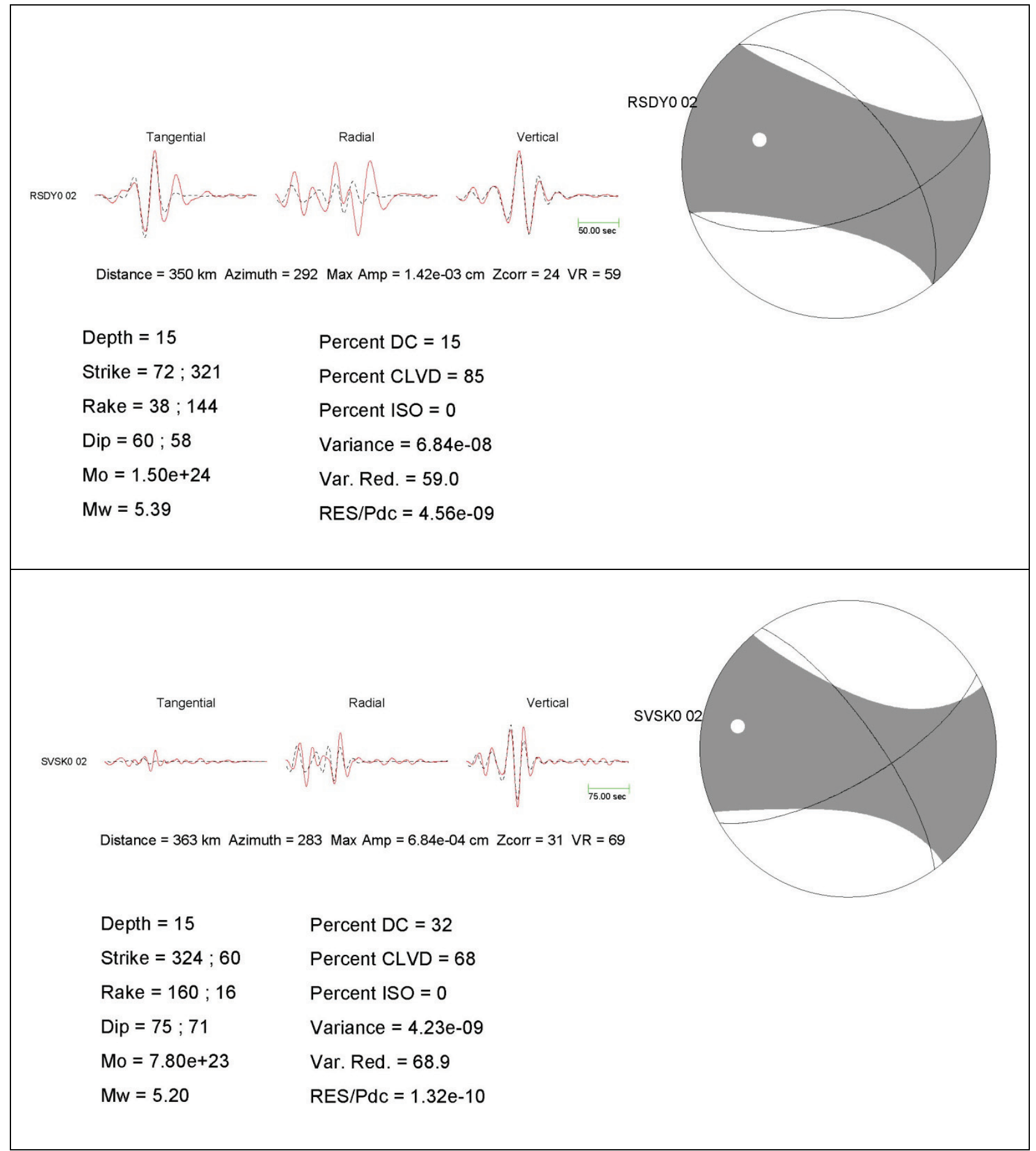

Figure 3.9. Moment tensor solution for the third region in the Anatolian plate per station. The red line represents the observed waveforms; the dashed line represents the synthetic waveforms. 


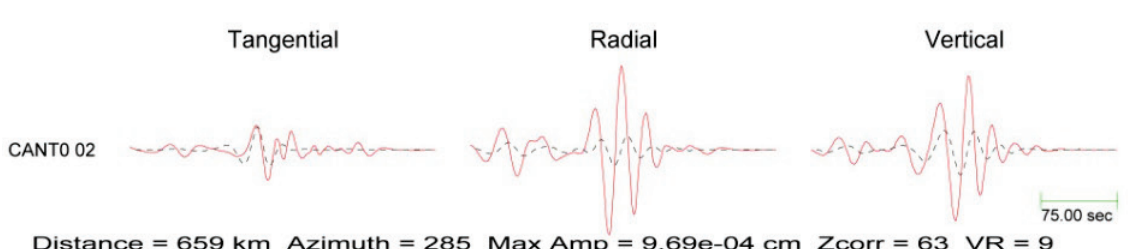

Distance $=659 \mathrm{~km}$ Azimuth $=285$ Max Amp $=9.69 \mathrm{e}-04 \mathrm{~cm}$ Zcorr $=63$ VR $=9$

CORMO 02
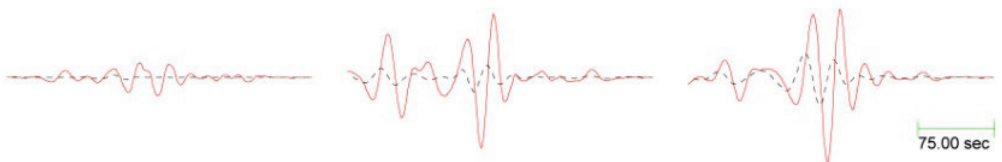

Distance $=567 \mathrm{~km}$ Azimuth $=282$ Max Amp $=1.02 \mathrm{e}-03 \mathrm{~cm} \quad$ Zcorr $=47 \mathrm{VR}=-2$

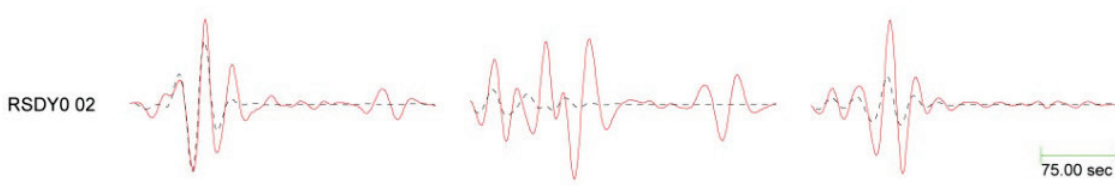

Distance $=350 \mathrm{~km}$ Azimuth $=292 \mathrm{Max} A m p=1.42 \mathrm{e}-03 \mathrm{~cm} \quad \mathrm{Zcorr}=24 \mathrm{VR}=37$

svSko 02
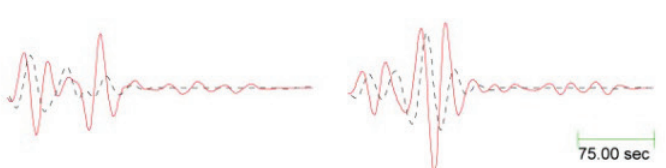

Distance $=363 \mathrm{~km}$ Azimuth $=283 \mathrm{Max} A m p=6.84 \mathrm{e}-04 \mathrm{~cm}$ Zcorr $=41 \quad \mathrm{VR}=-45$
Depth $=15$

Strike $=237 ; 147$

Rake $=3 ; 180$

Dip $=90 ; 87$

$\mathrm{Mo}=7.50 \mathrm{e}+23$

$\mathrm{Mw}=5.19$

Percent $\mathrm{DC}=22$

Percent CLVD = 78

Percent ISO $=0$

Variance $=4.29 \mathrm{e}-08$

Var. Red. $=15.8$

$\mathrm{RES} / \mathrm{Pdc}=1.95 \mathrm{e}-09$

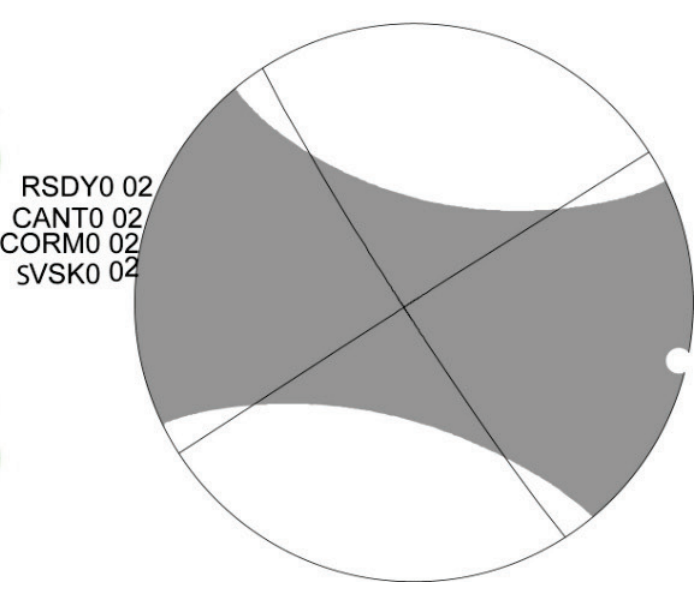

Figure 3.10. Moment tensor solution of the third region in the Anatolian plate as group solution. The red line represents the observed waveforms, the dashed line represents the synthetic waveform. 


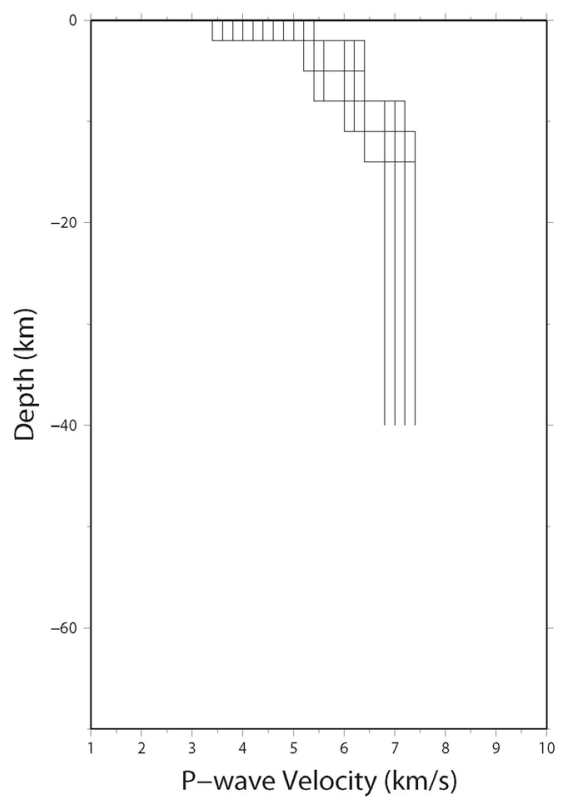

A.CANT

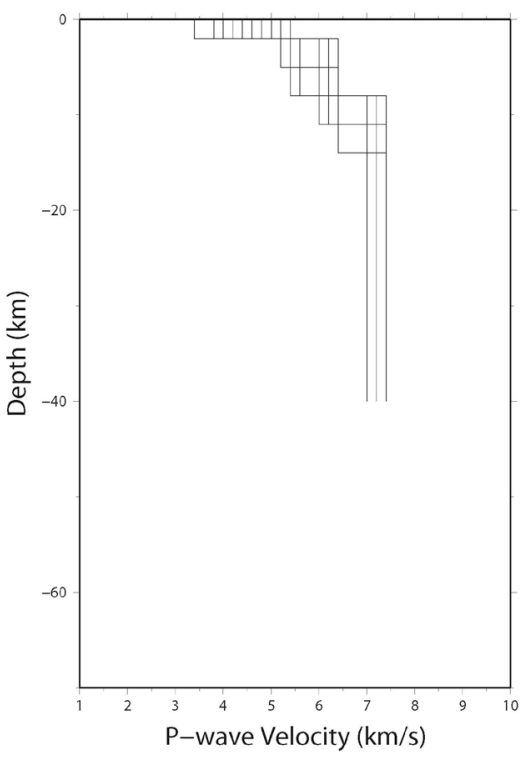

C.CORM

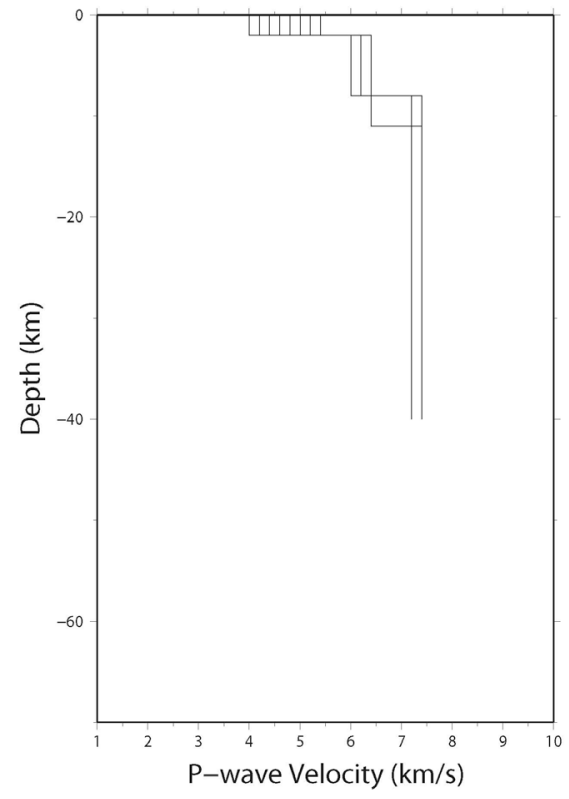

B.RSDY

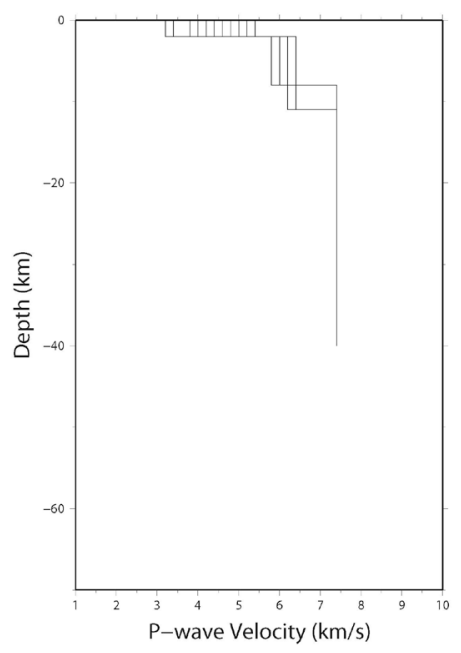

D.SVSK

Figure 3.11. P-waves velocity models for third region in Anatolian plate, CANT,RSDY,CORM and SVSK stations. 


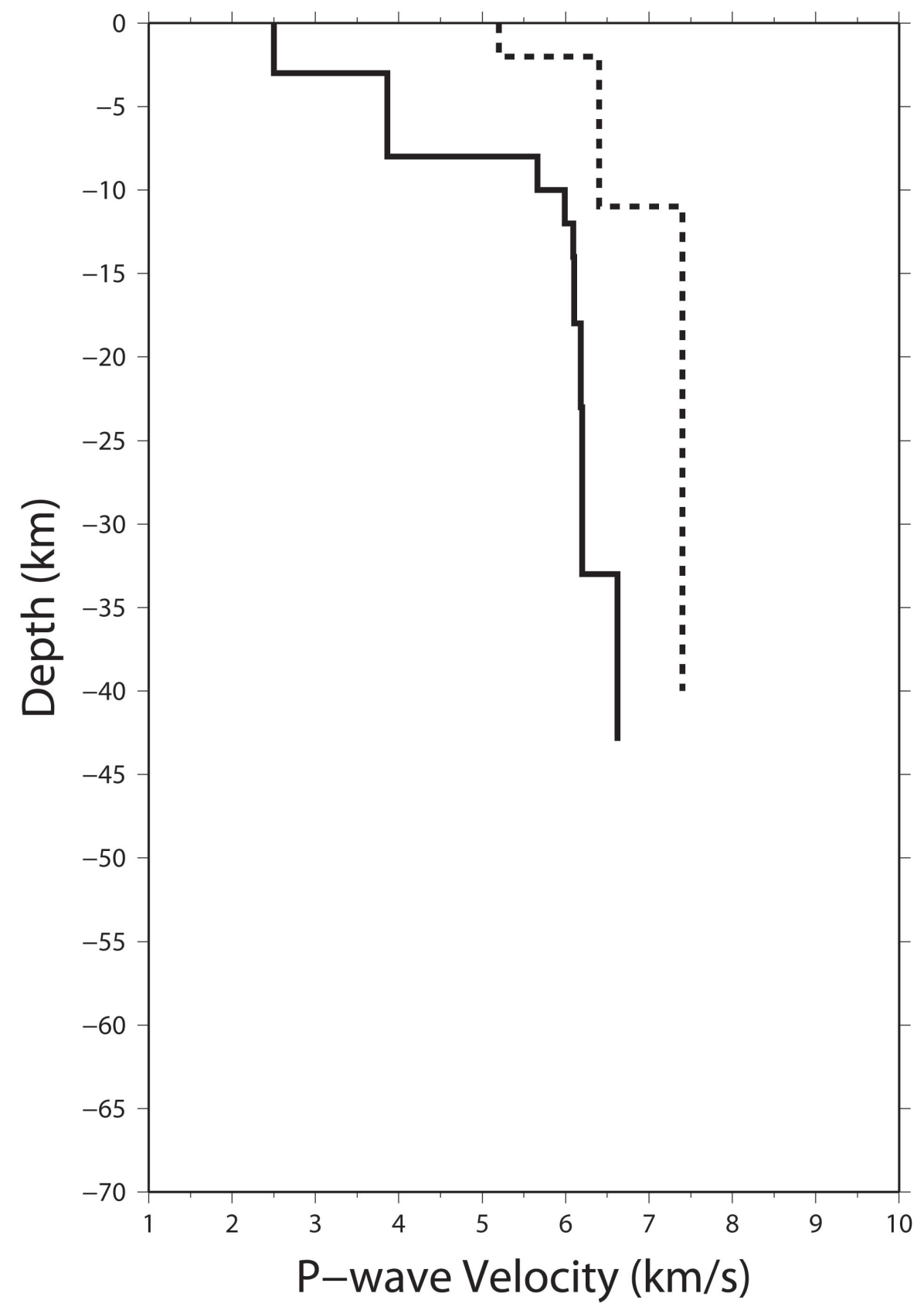

Figure 3.12. Comparing resulted velocity model (dashed line) with previous 1-Dvelocity model for the Central Anatolian(Seda, et. al., 2010) (Bold line). 


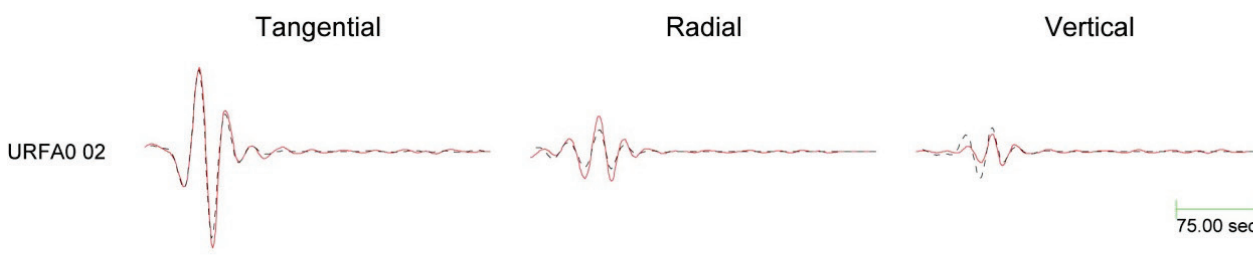

Distance $=287 \mathrm{~km}$ Azimuth $=226$ Max Amp $=4.01 \mathrm{e}-03 \mathrm{~cm}$ Zcorr $=33$ VR $=92$

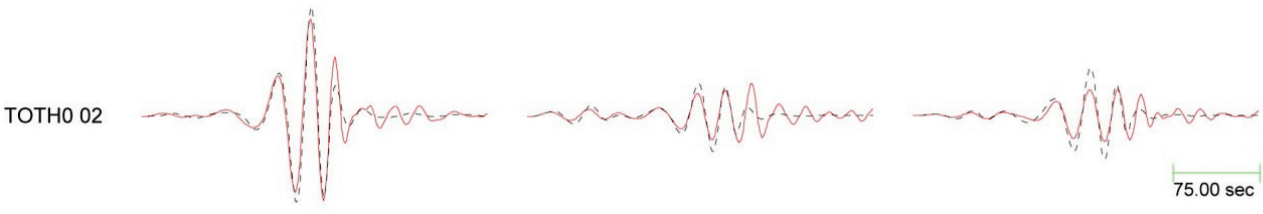

Distance $=780 \mathrm{~km}$ Azimuth $=214$ Max Amp $=1.03 \mathrm{e}-03 \mathrm{~cm}$ Zcorr $=85$ VR $=82$

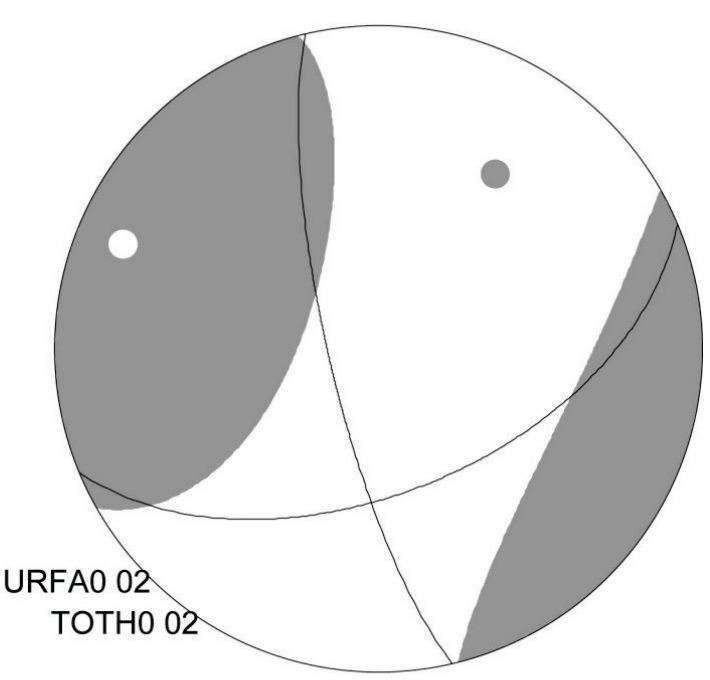
Depth $=15$
Percent $D C=13$
Strike $=167 ; 67$
Percent CLVD $=87$
Rake $=-142 ;-16$
Percent ISO $=0$
Dip $=77 ; 53$
Variance $=1.31 \mathrm{e}-08$
$\mathrm{Mo}=1.10 \mathrm{e}+24$
Var. Red. $=90.1$
$\mathrm{Mw}=5.30$
$\mathrm{RES} / \mathrm{Pdc}=1.01 \mathrm{e}-09$

Figure 3.13. Moment tensor solution for Arabia plate as a group solution. The red line represents the observed waveforms, and the dashed line represents the synthetic waveforms 


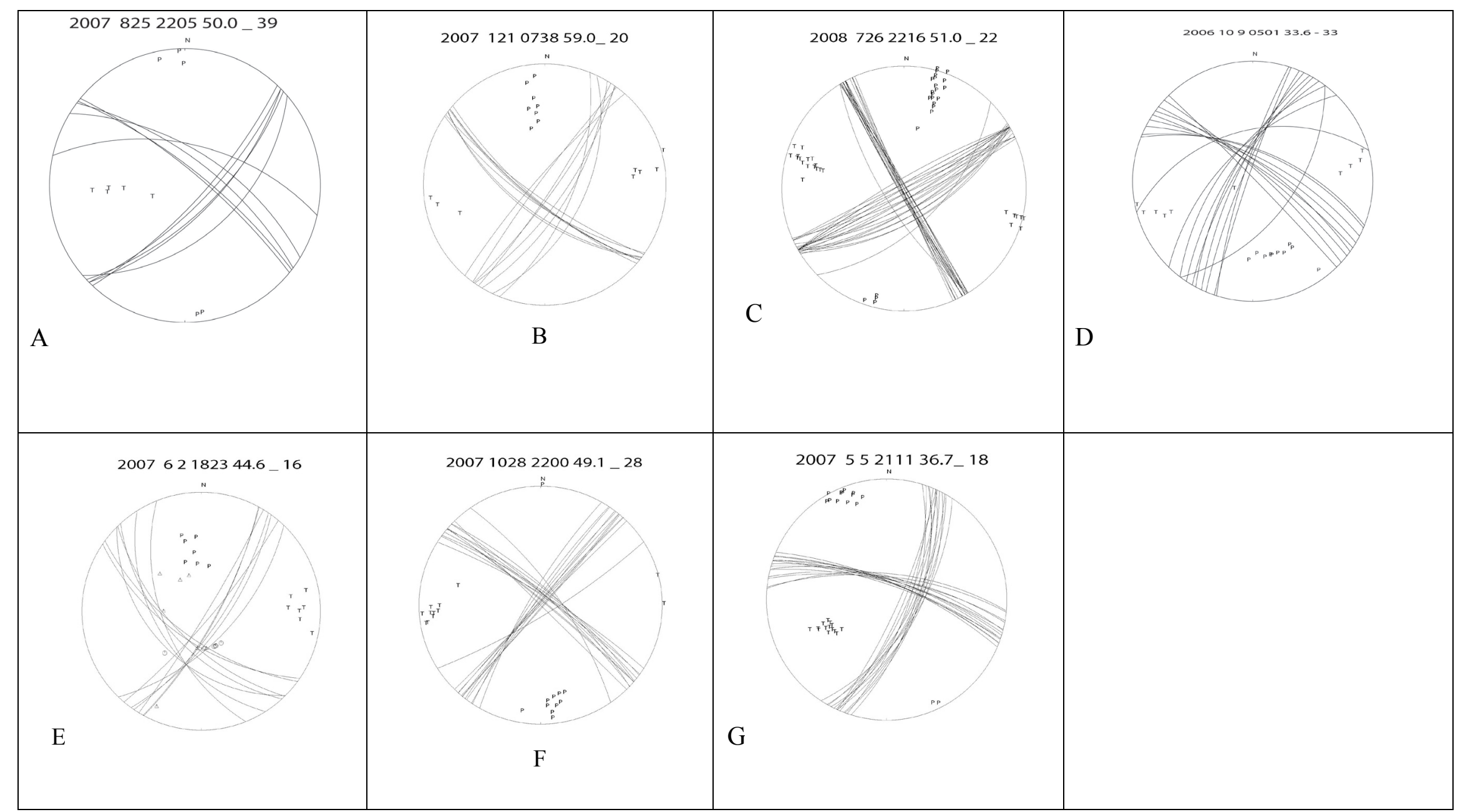

Figure 3.14. Focal mechanisms of all the events used in this study with the ranges of acceptant solutions, using first motion method, circle is positive and triangle is negative. And P,T B axis. 


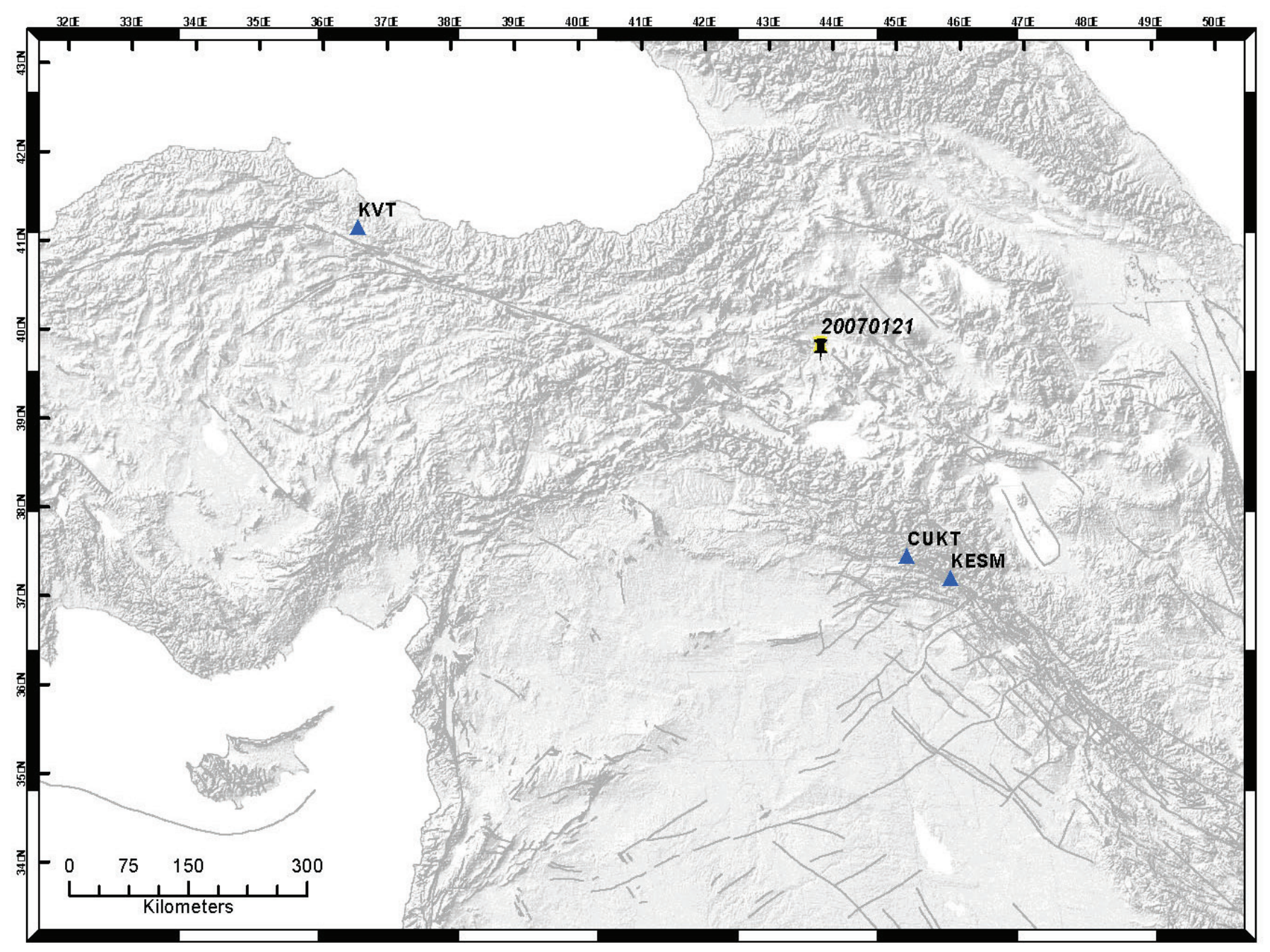

Figure 3.15. Map shows the study area. Triangles are stations used in inversion for 20070121 Event. The landmark is the epicenter of the event. 


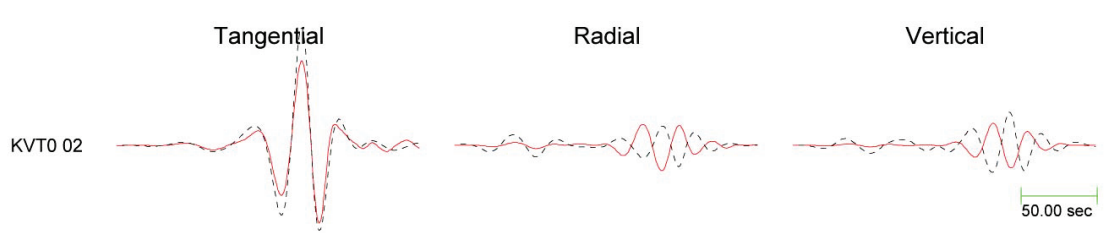

Distance $=604 \mathrm{~km}$ Azimuth $=288 \mathrm{Max}$ Amp $=1.69 \mathrm{e}-03 \mathrm{~cm}$ Zcorr $=55 \mathrm{VR}=21$

CUKTO 02

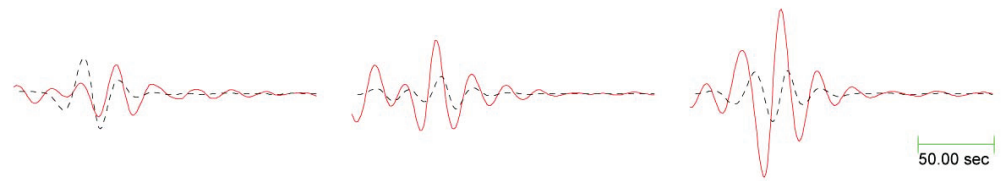

Distance $=268 \mathrm{~km}$ Azimuth $=166$ Max Amp $=2.77 \mathrm{e}-03 \mathrm{~cm}$ Zcorr $=94$ VR $=4$

KESMO 02
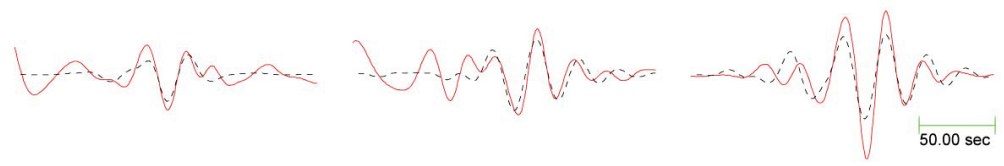

Distance $=312 \mathrm{~km}$ Azimuth $=158 \mathrm{Max}$ Amp $=6.68 \mathrm{e}-03 \mathrm{~cm}$ Zcorr $=26$ VR $=60$

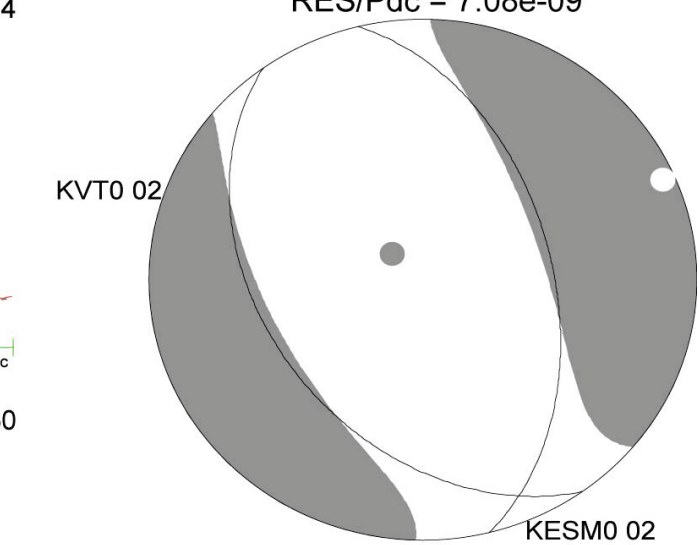

Figure 3.16. Focal mechanisms of 20070121 event, observed and synthetic waveforms are shown by solid and dashed line, respectively. The parameters o the focal mechanism and moment tensor are shown on the right side. 


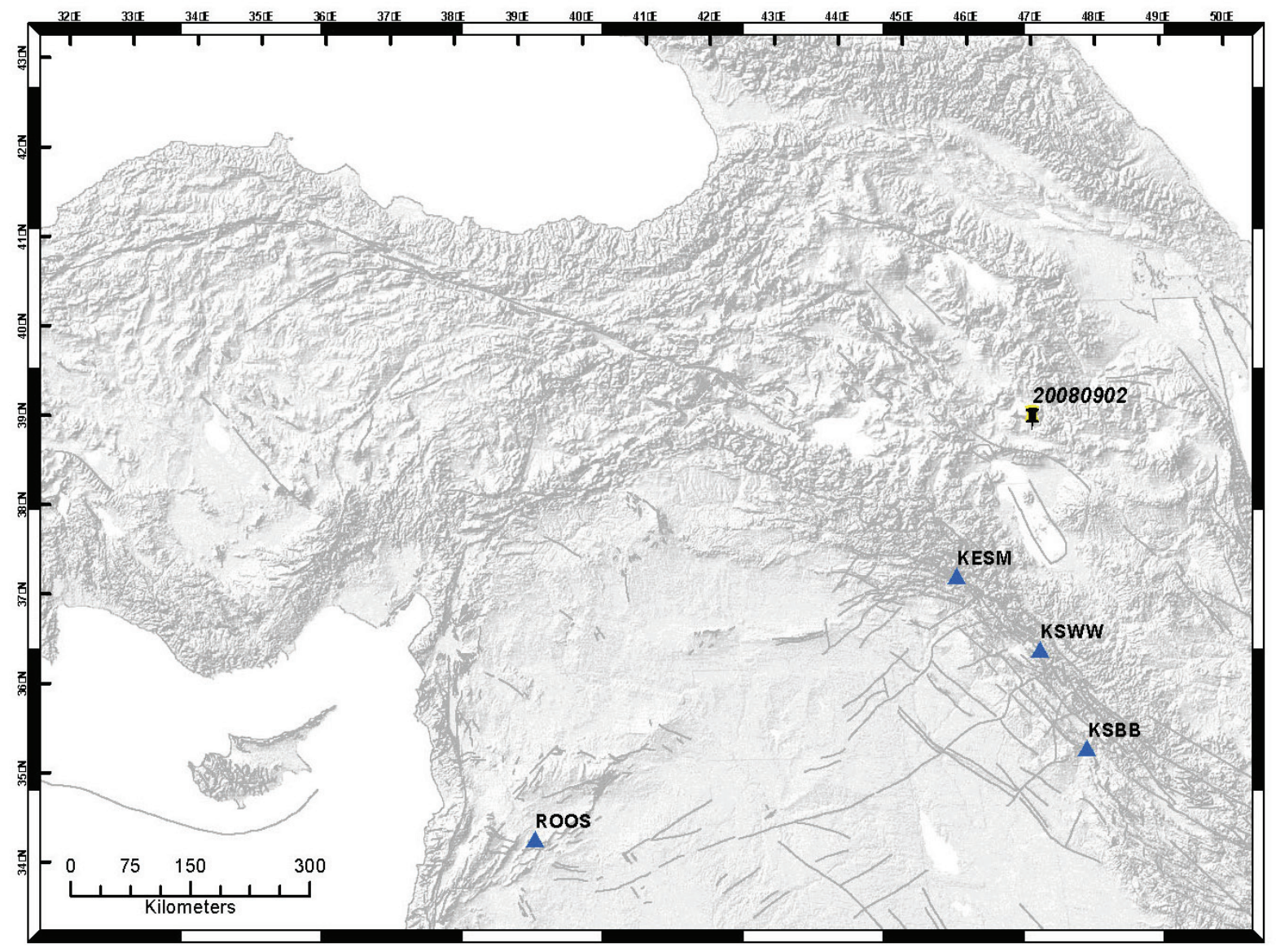

Figure 3.17. Map showing, triangles are stations used in for 20080902Event. The landmark is the epicenter of the event. 


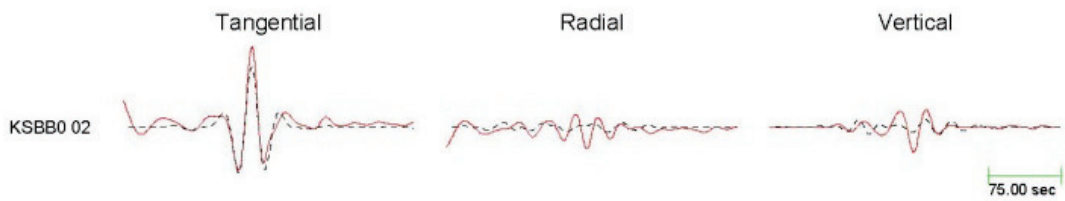

Distance $=402 \mathrm{~km}$ Azimuth $=181$ Max Amp $=6.46 \mathrm{e}-03 \mathrm{~cm}$ Zcorr $=86$ VR $=69$

KSWW0 02
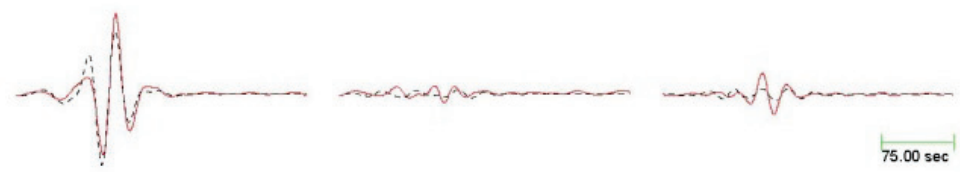

Distance $=284 \mathrm{~km}$ Azimuth $=190$ Max Amp $=7.63 \mathrm{e}-03 \mathrm{~cm}$ Zcorr $=100$ VR $=83$

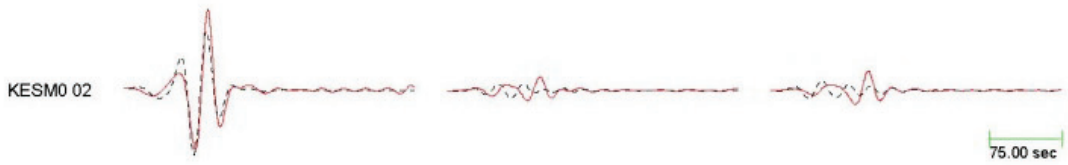

Distance $=235 \mathrm{~km}$ Azimuth $=218$ Max Amp $=9.14 \mathrm{e}-03 \mathrm{~cm}$ Zcorr $=88$ VR $=73$
Depth $=15$

Strike $=201 ; 293$

Rake $=-10 ;-171$

Dip $=81 ; 80$

$\mathrm{Mo}=3.90 \mathrm{e}+23$

$\mathrm{Mw}=5.00$

Percent DC $=91$

Percent CLVD $=9$

Percent ISO $=0$

Variance $=2.42 \mathrm{e}-07$

Var. Red. $=75.0$

$\mathrm{RES} / \mathrm{Pdc}=2.65 \mathrm{e}-09$

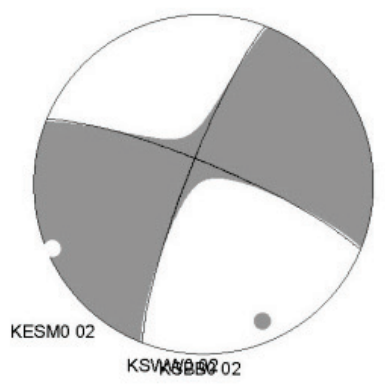

Figure 3.18 Focal mechanism of 20080902 event. Observed and synthetic waveforms are shown by solid and dashed line, respectively. The parameters of the focal mechanism and moment tensor are shown on the right side. 


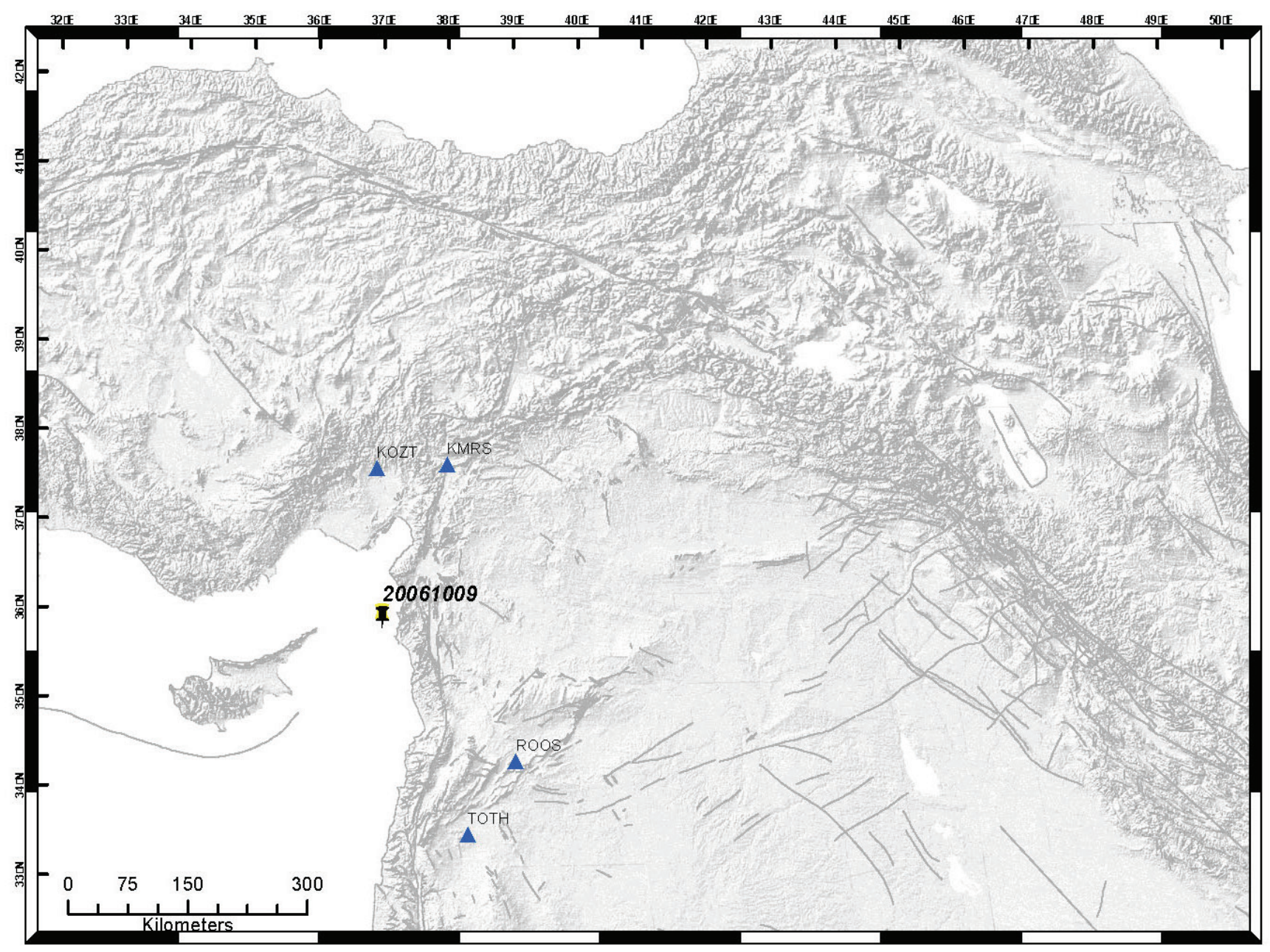

Figure 3.19. Map shows the study area. Triangles are stations used in for 200601009 Event. The landmark is the epicenter. 


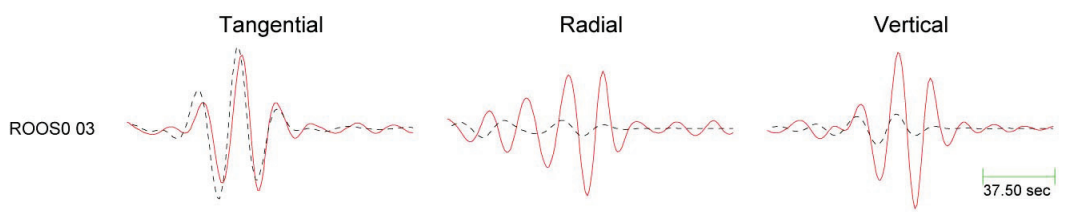

Distance $=245 \mathrm{~km}$ Azimuth $=140$ Max Amp $=4.73 \mathrm{e}-05 \mathrm{~cm}$ Zcorr $=47$ VR $=31$

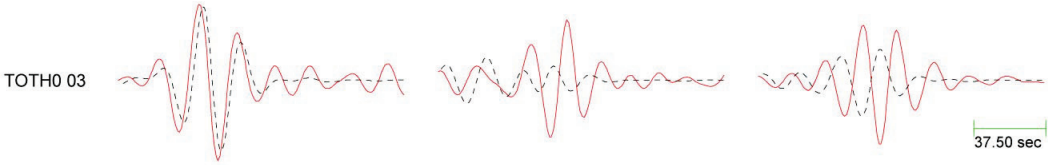

Distance $=289 \mathrm{~km}$ Azimuth $=164$ Max Amp $=2.85 e-05 \mathrm{~cm}$ Zcorr $=93$ VR $=-13$

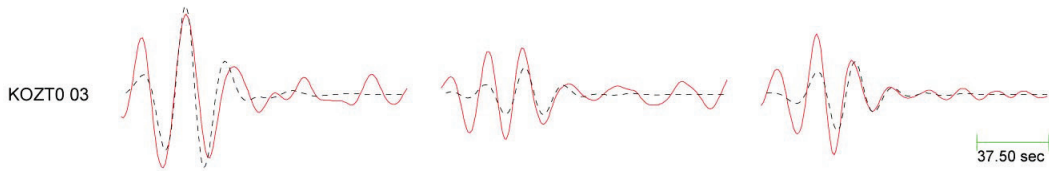

Distance $=185 \mathrm{~km}$ Azimuth $=6$ Max Amp $=9.33 \mathrm{e}-05 \mathrm{~cm}$ Zcorr $=138$ VR $=64$
Depth $=15$

Strike $=299 ; 203$

Rake $=-145 ;-10$

Dip $=82 ; 56$

$\mathrm{Mo}=1.60 \mathrm{e}+22$

$M w=4.07$

Percent DC $=15$

Percent CLVD $=85$

Percent ISO $=0$

Variance $=1.47 \mathrm{e}-10$

Var. Red. $=49.4$

$\mathrm{RES} / \mathrm{Pdc}=9.81 \mathrm{e}-12$ KOZTO 03

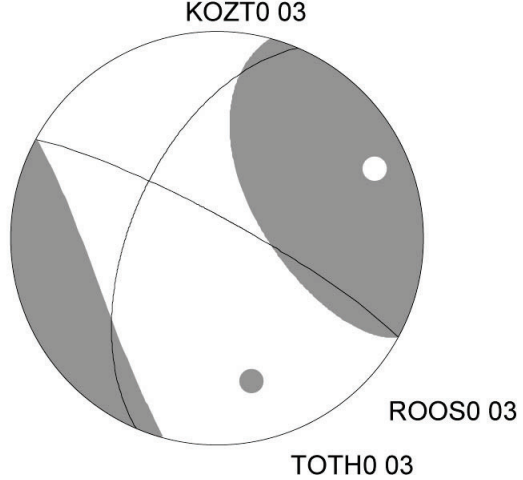

Figure 3.20. Focal mechanism of 200601009 event. The observed and synthetic waveforms are shown by solid and dashed line, respectively. The parameters of the focal mechanism and moment tensor are shown on the right side, bandpass filter $0.03 \_0.06 \mathrm{~Hz}$. 


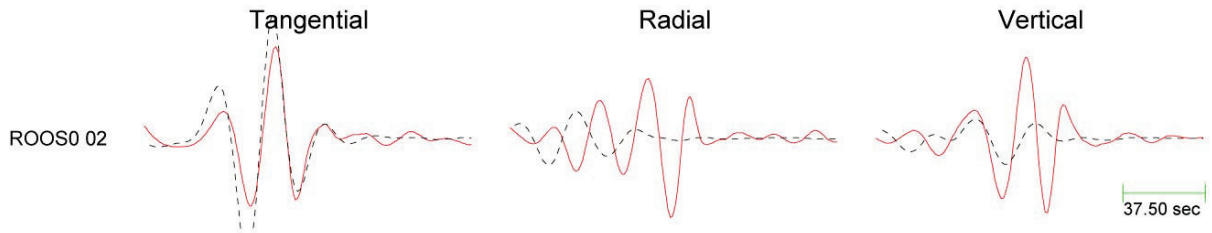

Distance $=245 \mathrm{~km}$ Azimuth $=140$ Max Amp $=3.00 \mathrm{e}-05 \mathrm{~cm}$ Zcorr $=47$ VR $=15$

TOTH0 02
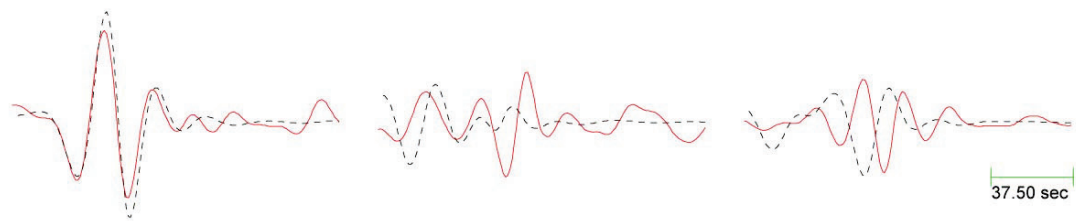

Distance $=289 \mathrm{~km}$ Azimuth $=164$ Max Amp $=2.28 \mathrm{e}-05 \mathrm{~cm}$ Zcorr $=93$ VR $=-0$

KOZTO 02
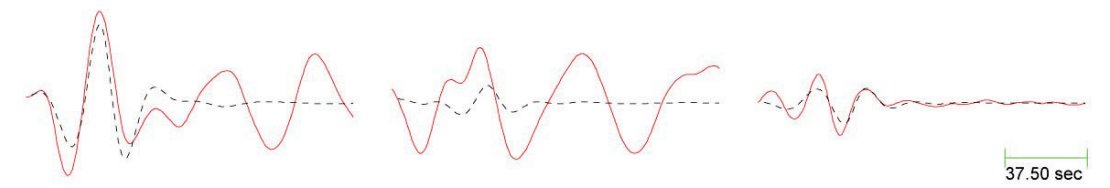

Distance $=185 \mathrm{~km}$ Azimuth $=6$ Max Amp $=1.35 \mathrm{e}-04 \mathrm{~cm}$ Zcorr $=139 \mathrm{VR}=29$
Depth $=15$

Strike $=111 ; 201$

Rake $=161 ; 1$

Dip $=89 ; 71$

$\mathrm{Mo}=1.80 \mathrm{e}+22$

$\mathrm{Mw}=4.11$

Percent DC $=38$

Percent CLVD $=62$

Percent ISO $=0$

Variance $=4.45 \mathrm{e}-10$

Var. Red. $=27.9$

$\mathrm{RES} / \mathrm{Pdc}=1.17 \mathrm{e}-11$

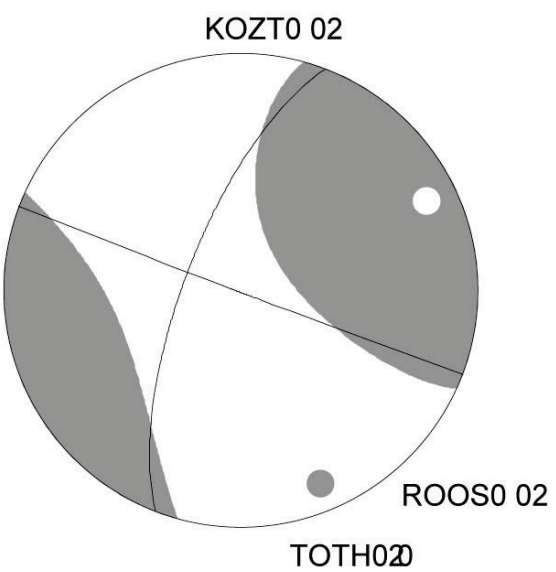

Figure 3.21. Focal mechanism of 200601009 event, observed and synthetic waveforms are shown by solid and dashed line, respectively. The parameters of the focal mechanism and moment tensor are shown on the right side, bandpass filter0.02_0.05Hz. 


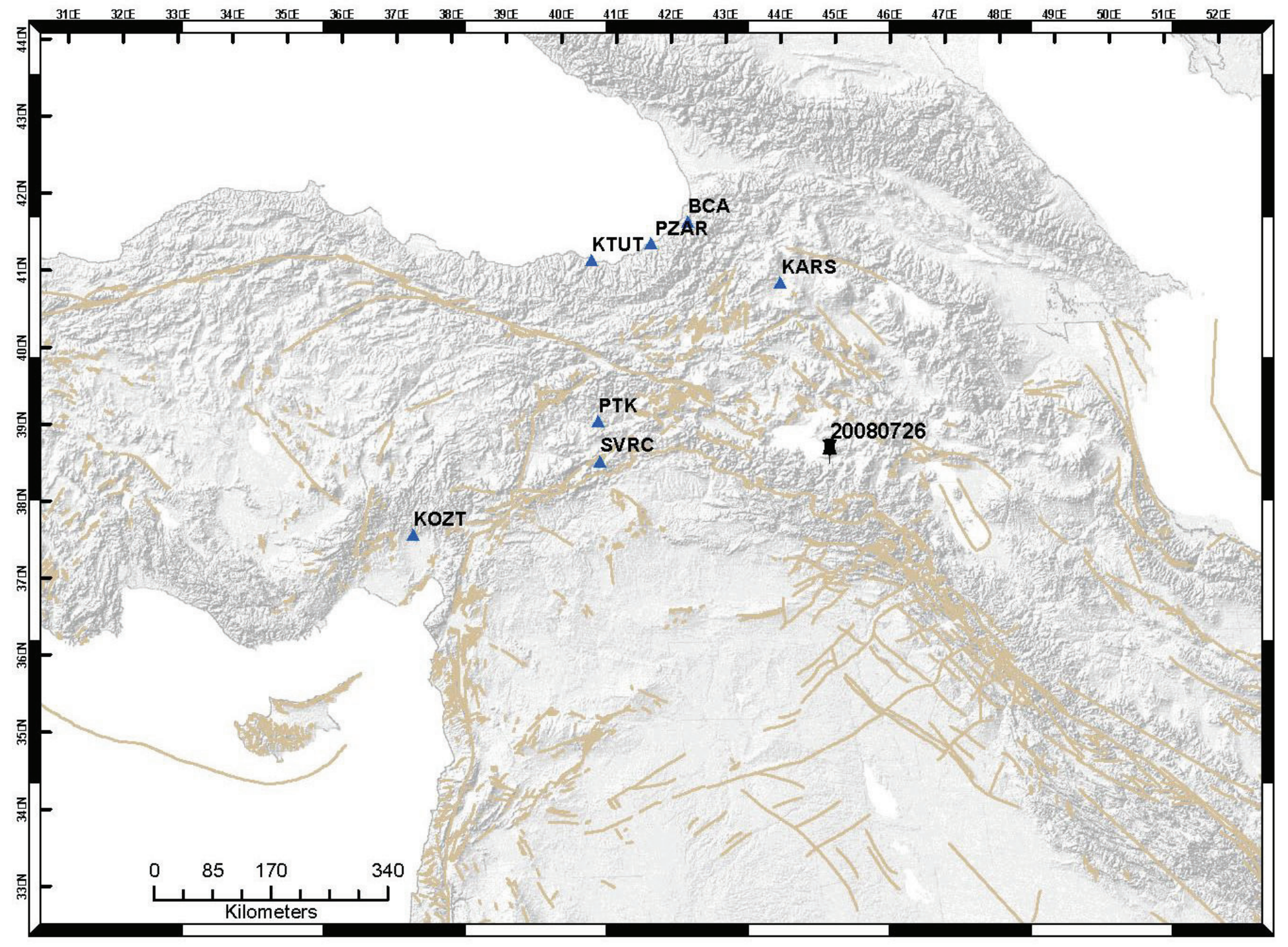

Figure 3.22. Map shows the study area, Triangles are stations used in for 20080726 Event. The star is the event epicenter 


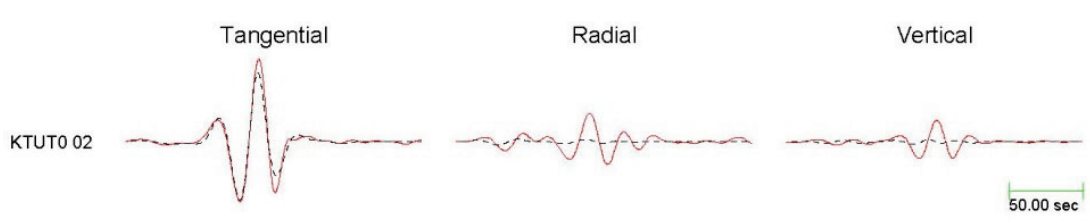

Distance $=420 \mathrm{~km}$ Azimuth $=314$ Max Amp $=2.89 \mathrm{e}-04 \mathrm{~cm} \mathrm{Zcorr}=88$ VR $=79$

KARSO 02
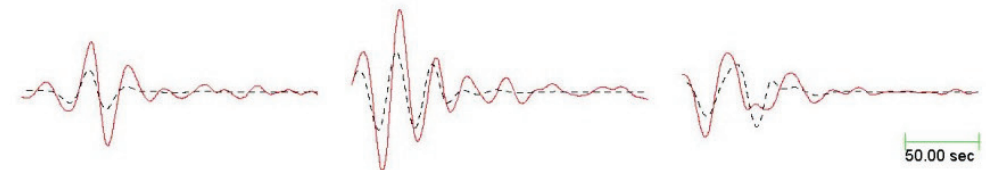

Distance $=243 \mathrm{~km}$ Azimuth $=354 \mathrm{Max}$ Amp $=1.50 \mathrm{e}-04 \mathrm{~cm}$ Zcorr $=76$ VR $=54$

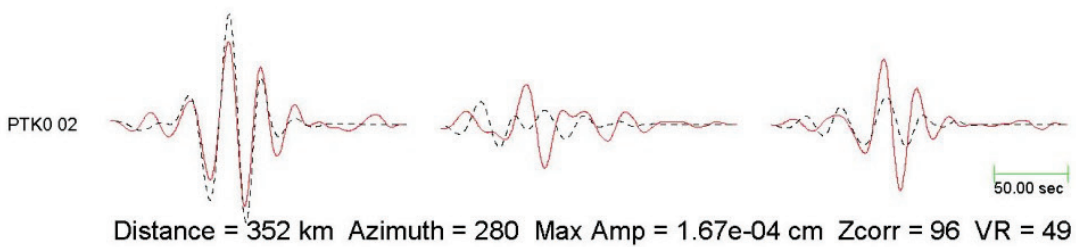

Depth $=15$

Strike $=306 ; 216$

Rake $=-171 ; 0$

Dip $=90 ; 81$

$\mathrm{Mo}=5.20 \mathrm{e}+22$

$\mathrm{Mw}=4.41$

Percent DC $=83$

Percent CLVD $=17$

Percent ISO $=0$

Variance $=5.94 \mathrm{e}-10$

Var. Red. $=65.9$

RES $/$ Pdc $=7.16 \mathrm{e}-12$

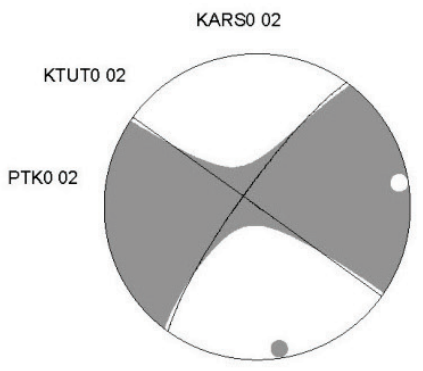

Figure 3.23. Focal mechanism of 20080726 event. Observed and synthetic waveforms are shown by solid and dashed line, respectively. The parameters of the focal mechanism and moment tensor are shown on the right side. 


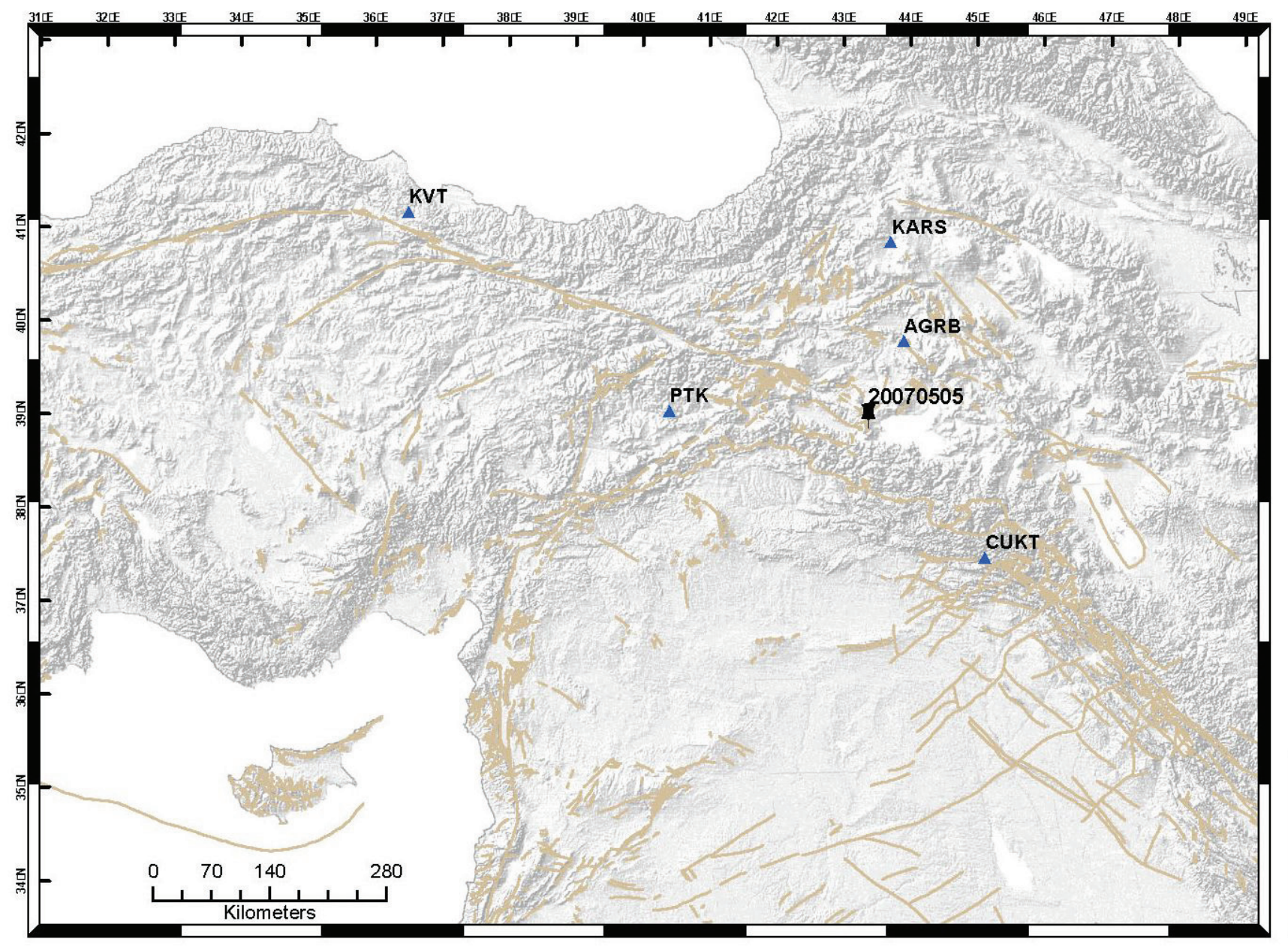

Figure 3.24. Map shows the study area. Triangles are stations used in for 20070505 Event. The landmark is the epicenter of the event 


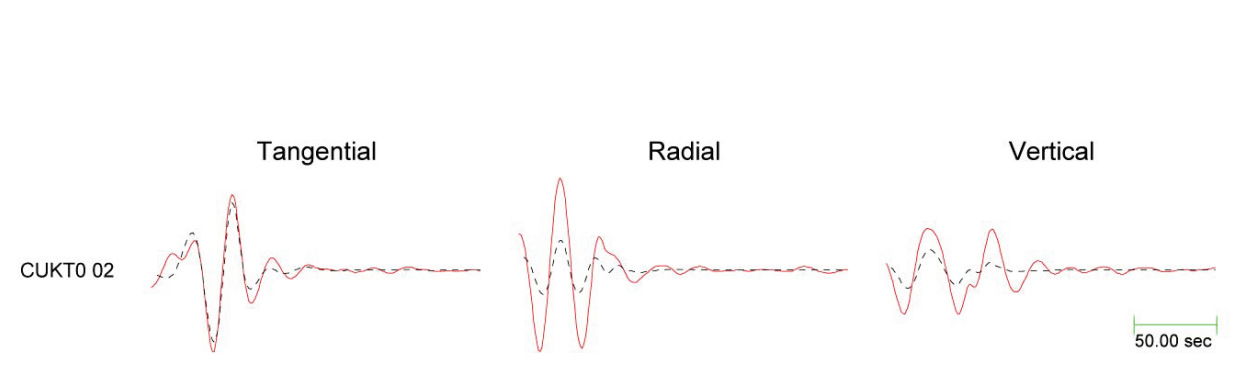

Depth $=15$

Strike $=302 ; 32$

Rake $=170 ; 3$

Dip $=87 ; 80$

$\mathrm{Mo}=2.90 \mathrm{e}+22$

$\mathrm{Mw}=4.25$

Distance $=208 \mathrm{~km}$ Azimuth $=145$ Max Amp $=1.87 \mathrm{e}-04 \mathrm{~cm}$ Zcorr $=63$ VR $=59$

Percent DC $=19$

Percent CLVD = 81

Percent ISO $=0$

Variance $=5.94 \mathrm{e}-10$

Var. Red. $=51.2$

$\mathrm{RES} / \mathrm{Pdc}=3.13 \mathrm{e}-11$

Distance $=250 \mathrm{~km}$ Azimuth $=273$ Max Amp $=9.83 e-05 \mathrm{~cm}$ Zcorr $=63$ VR $=18$

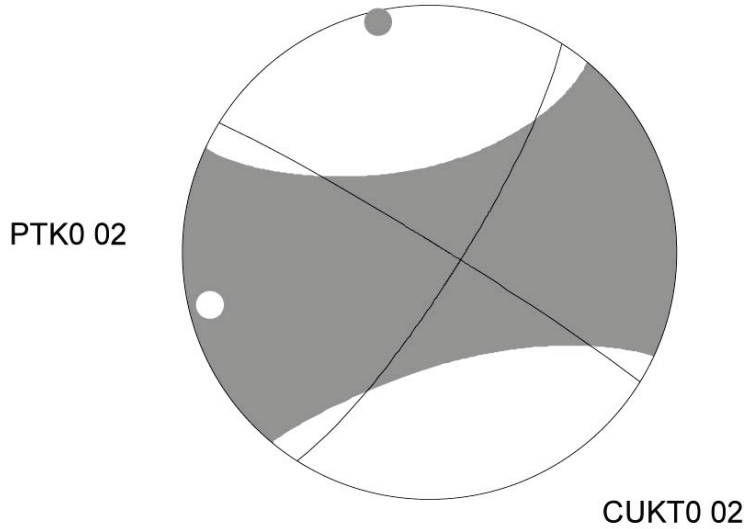

Figure 3.25. Focal mechanism of 20070505 event. Observed and synthetic waveforms are shown by solid and dashed line, respectively. The parameters of the focal mechanism and moment tensor are shown on the right side. 


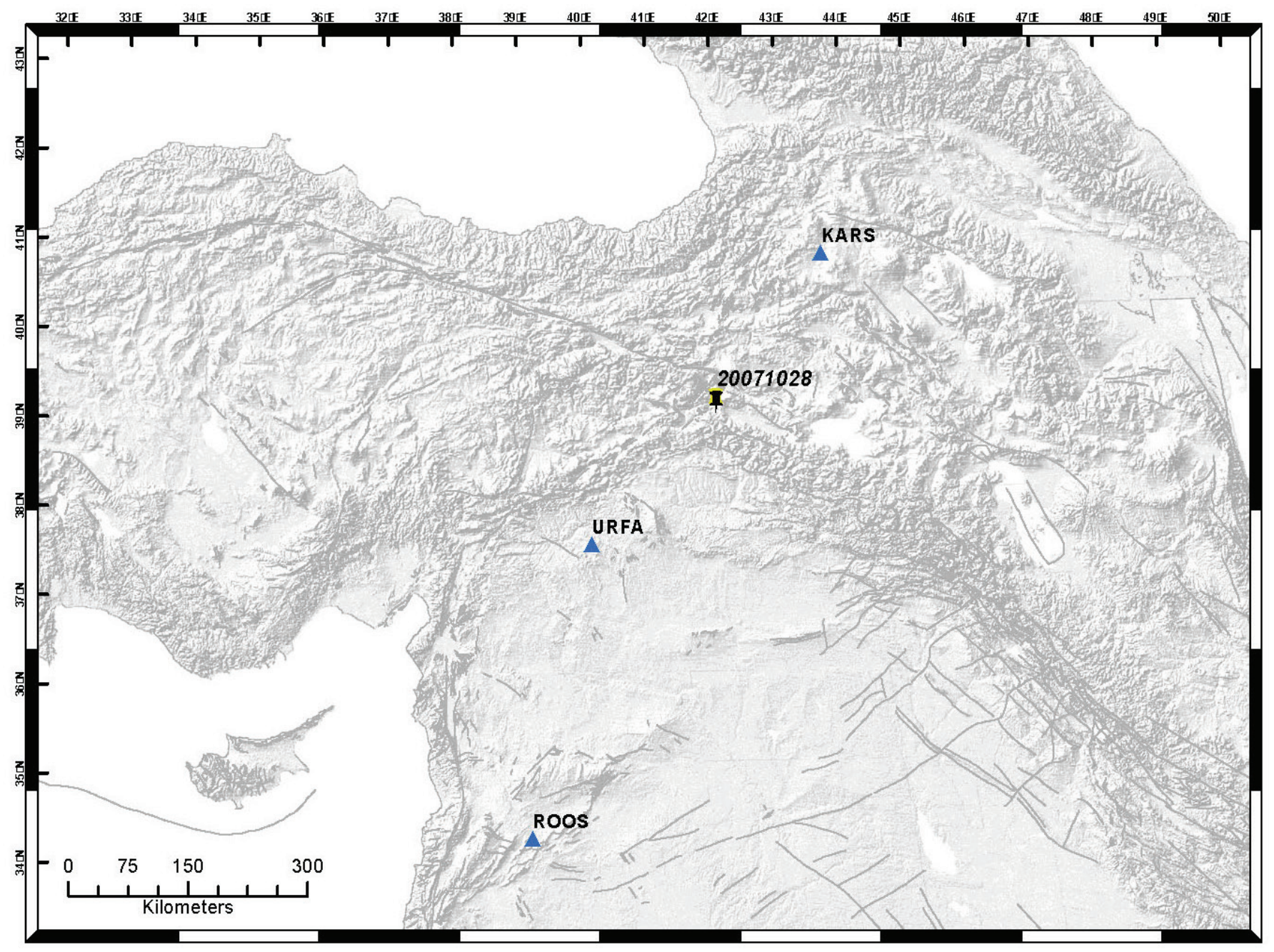

Figure 3.26. map showins the study area. Triangles are stations used in for 20071028 Event. The landmark is the epicenter of the event. 


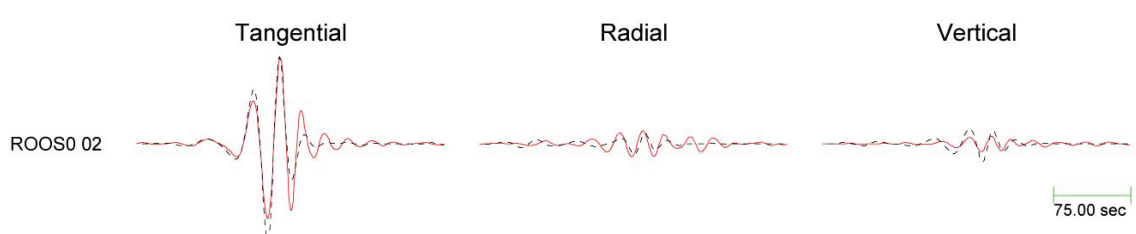

$$
\begin{aligned}
& \text { Depth }=15 \\
& \text { Strike }=325 ; 55 \\
& \text { Rake }=167 ; 1 \\
& \text { Dip }=89 ; 77 \\
& \text { Mo }=3.40 \mathrm{e}+22 \\
& \text { Mw }=4.29 \\
& \text { Percent DC }=41 \\
& \text { Percent CLVD = 59 } \\
& \text { Percent ISO }=0 \\
& \text { Variance }=1.12 \mathrm{e}-10 \\
& \text { Var. Red. }=79.8 \\
& \text { RES/Pdc }=2.73 \mathrm{e}-12
\end{aligned}
$$

Distance $=248 \mathrm{~km}$ Azimuth $=44$ Max Amp $=1.87 \mathrm{e}-04 \mathrm{~cm}$ Zcorr $=79$ VR $=71$

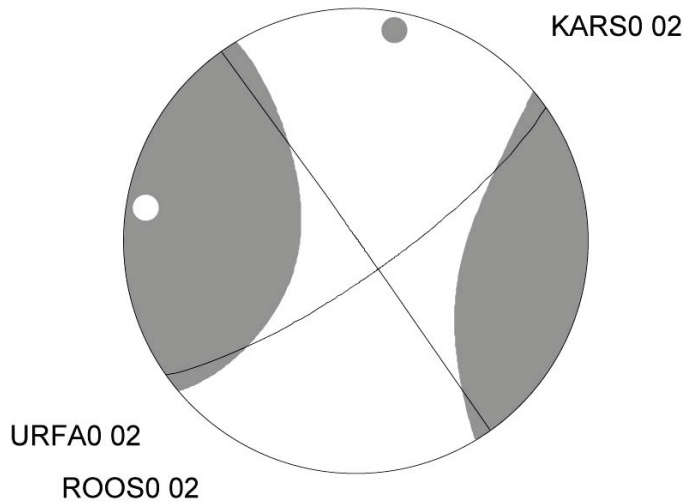

Figure 3.27. Focal mechanism of 20071028 event. The observed and synthetic waveforms are shown by solid and dashed line, respectively. The parameters o the focal mechanism and moment tensor are shown on the right side 


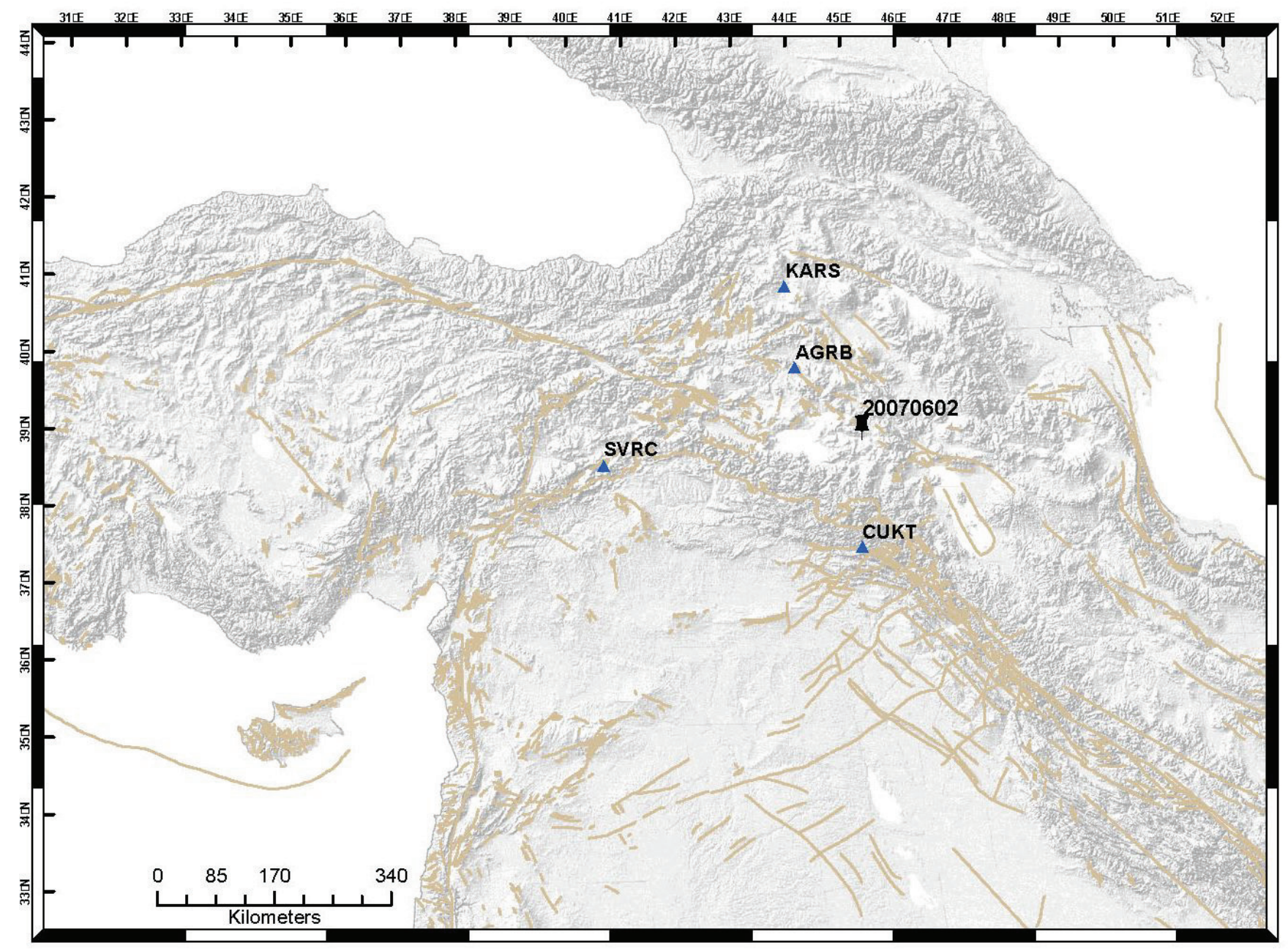

Figure 3.28. Map shows the study area. The triangles are stations used in for 20070206 Event. The landmark is the epicenter of the event 

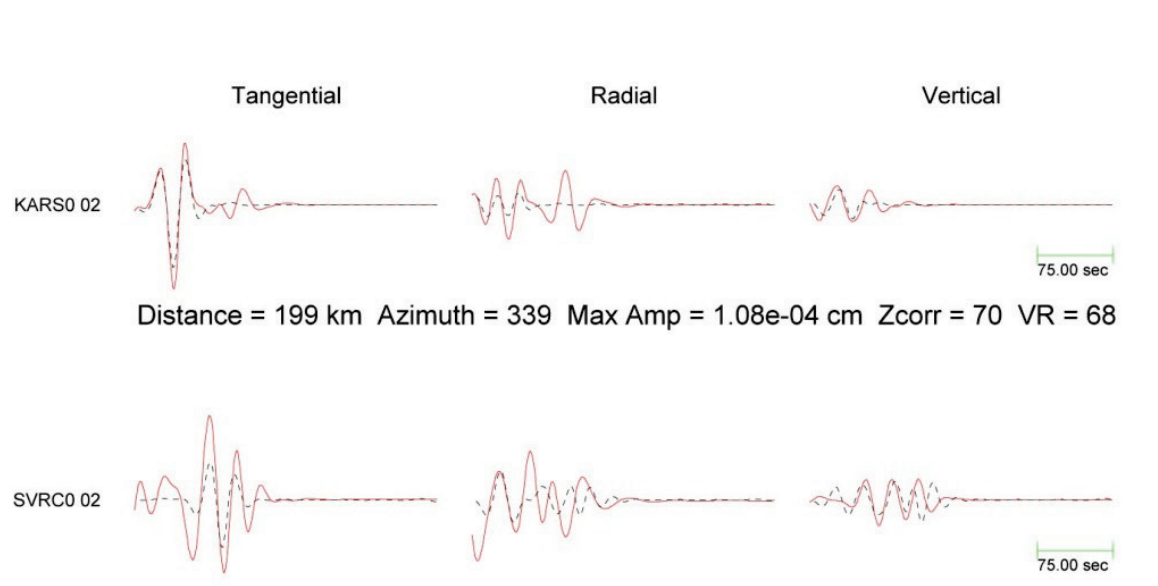

Depth $=15$

Strike $=314 ; 224$

Rake $=-174 ;-3$

Dip $=87 ; 84$

$M o=1.40 \mathrm{e}+22$

$\mathrm{Mw}=4.04$

Percent DC $=83$

Percent CLVD $=17$

Percent ISO $=0$

Variance $=2.49 \mathrm{e}-10$

Distance $=408 \mathrm{~km}$ Azimuth $=262$ Max Amp $=3.50 \mathrm{e}-05 \mathrm{~cm}$ Zcorr $=57$ VR $=33$

Var. Red. $=46.6$

$\mathrm{RES} / \mathrm{Pdc}=3.00 \mathrm{e}-12$
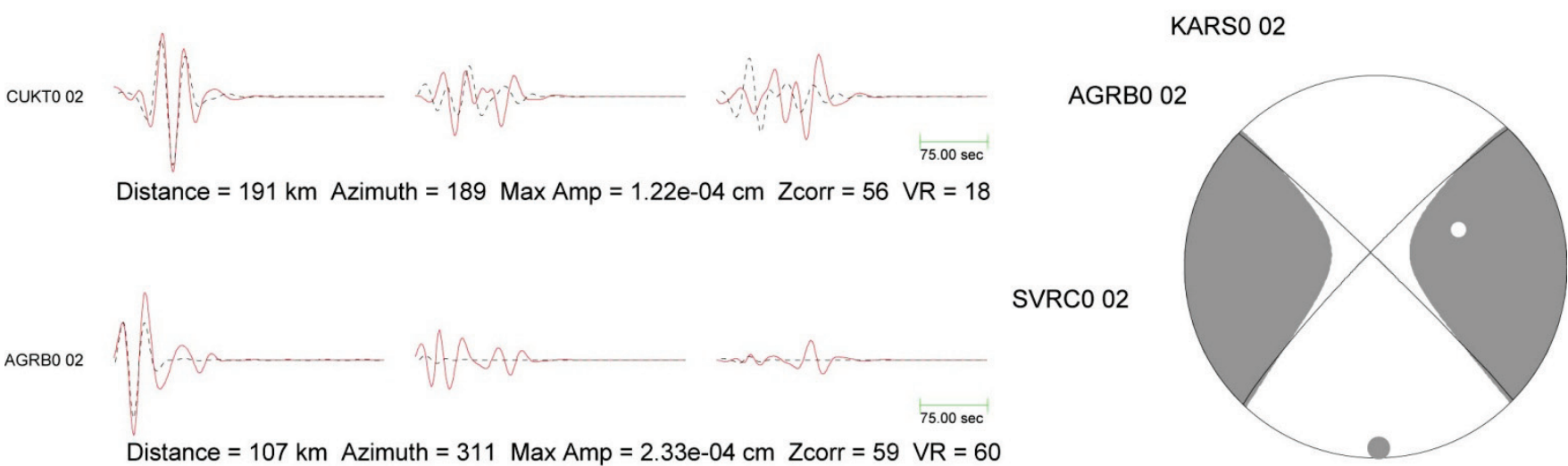

CUKTO 02

Figure 3.29. Focal mechanism of 20070602 event. The observed and synthetic waveforms are shown by solid and dashed line, respectively. The parameters of the focal mechanism and moment tensor are shown on the right side. 


\section{Chapter 4 : First motion focal mechanisms}

\subsection{Introduction \& Methodology:}

First-motion polarities have been used extensively for determining earthquake focal mechanism. This is the classical approach for calculating fault-plane solutions (Mckenzie, 1969). First-motion polarity indicates whether the seismic station moves away (up) or toward (down) the earthquake source. To relate this to the focal mechanism, the position of the seismic station relative to the source (hypocenter) and the take-off angle (i.e., angle at which the ray leaves the source) are necessary. The hypocenter is computed based on the earthquake location. The take-off angle is computed by using an assumed seismic-velocity model and the distance between the hypocenter and the seismic station. A double couple source defines four quadrants; two contraction and two dilatation. The quadrants are bounded by nodal plane geometry (strike, dip), depending on source fault geometry and sense of the slip (Figure 4.1).

Errors in first-motion observations may occur because of station polarity reversals or incorrect direct P-arrival picks due to low signal-to-noise ratios. First-motion observations are usually divided into two classes: impulsive, for which polarities are easily determined; and emergent, for which the polarities are more ambiguous. Impulsive-polarity observations are higher quality but still may contain errors. The stability of a focal mechanism with respect to polarity errors can be tested by changing a single polarity datum and observing the change in the best-fitting mechanism. 
Reliable focal mechanism solutions strongly depend also on the accuracy of the source parameters, such as the location and the depth. Estimating an accurate hypocenter location depends on the network geometry, available phases, accuracy of arrival-time, and the crustal structure (Pavlis, 1986; Gomberg et al., 1990). In addition, the accurate reading of the arrival time plays a critical role in estimating the hypocenter location. The methodology for the hypocenter location is also important. Each hypocenter location method can give slightly different result and accuracy. Moreover, the earthquake locations outside the network coverage will have substantially larger errors.

\subsubsection{Hypocenter program:}

The program HYPOCENTER (Lienert et al., 1986; Lienert and Havskov, 1995) was used to determine hypocenter location and origin time of the earthquakes. The program calculates the location and origin time for a single event by tracing the rays through a given 1-D velocity (both direct and refracted waves) model and adjusting earthquake parameters using a conventional least-squares approach. There are two weighting options: The first weighting option is related to the accuracy of the arrival times. User specified weights $\left(\omega_{i}\right)$ are assigned by a single integer value in the range 0 to 4 for a given phase. These numbers correspond to weighting factors of $1,0.75,0.5,0.25$ or 0.0 for that phase. The second option is a distance weighting given by the following relationship

$$
\mathrm{W}_{\mathrm{I}}=\left(\mathrm{X}_{\text {far }}-\mathrm{D}_{\mathrm{i}}\right)\left(\mathrm{X}_{\text {far }}-\mathrm{X}_{\text {near }}\right)
$$

where $\mathrm{x}_{\text {near }}$ is the distance at which distance weighting starts and $\mathrm{x}_{\text {far }}$ is a distance at which distance weighting is zero (beyond $\mathrm{x}_{\text {far }}$, the phase is not used) and $\mathrm{D}$ is the 
epicenter distance. The residual time is defined as the difference between the observed times $\mathrm{t}_{\mathrm{i}}$ and predicted arrival times $\left(\mathrm{T}_{\mathrm{i}}(\mathrm{x}, \mathrm{y}, \mathrm{z})+\mathrm{t}_{0}\right)$ (Havskov and Ottemöller, 2003)

$$
\Delta \mathrm{t}=\mathrm{t}_{\mathrm{i}}-\mathrm{T}_{\mathrm{i}}(\mathrm{x}, \mathrm{y}, \mathrm{z})
$$

where $T_{i}(x, y, z)$ is the travel time from the source to the receiver (function of the coordinates) and $t_{0}$ is the origin time. The weighted residual is (Havskov and Ottemöller, 2003)

$$
\tau_{\mathrm{I}}=\omega_{\mathrm{i}}\left(\mathrm{t}_{\mathrm{i}}-\mathrm{T}_{\mathrm{i}}(\mathrm{x}, \mathrm{y}, \mathrm{z})-\mathrm{t}_{0}\right)
$$

here $\omega_{\mathrm{i}}$ is the product of all weighting factors (the first and second weighting options combined). This program uses the least squares solution which minimizes the sum of the weighted squared residuals from n observation (Havskov and Ottemöller, 2003).

A crustal velocity model is required for obtaining the hypocenter location and ultimately the focal mechanism, 1-D layered velocity model for Syria proposed by (Ibrahim, et. al., 2010), mentioned previously in the last chapter, was used and resulted a convenient result for this region.

\subsection{Data and Analysis}

Over the past 15 years, earthquakes were monitored in Syria by the National Earthquake Center with two networks: the analog and digital networks based on data transmitting way between the seismic stations and the main center. The analog network has been deployed since 1995 and consists of 26 short-period stations $(1 \mathrm{~Hz})$ - five of them three components stations, vertical north -south, east -west, whereas the other have vertical seismometers, only. The digital network, consisting of 24 short-period, three- 
component stations, Gurlap 4oT sensor, GMC-24 digitizer, has been operational since late 2008 .

Between 1995 and 2010, the Syrian network recorded approximately 3600 earthquakes in Syria and adjacent regions. $\sim 1910$ events were located within Syrian land. Most of the seismicity concentrated in the west along the Dead Sea Fault; however, comparing with historical seismicity, a seismic gap was noticeable. The hypocenter and magnitude were calculated using hypocenters 3.2 (Barry R, Lienert) implemented in SEISAN 8.1 (Jens Havskov and Lars Ottemöller). Among 1910-recorded events, the reliable located earthquakes were selected and calculated the fault plane solutions. The dataset consists of 128 events identified according to many criteria, and the phase picks were chosen carefully and manually. Each event had at least a minimum of 6 clear polarities. Azimuthal gaps range between 97 to 330 degrees, and RMS ranges between 01.7, and average location horizontal and vertical errors are 0.2 and $0.6 \mathrm{~km}$, respectively. Local magnitude estimates (ML) range from 1 to 4 . In addition, we have used the available focal mechanisms data from international seismological Catalog (ISC), besides the events collected from (Salmon, et. al., 1996) (Figure 4.2)

The focal mechanisms were determined using the FPFIT algorithm (Reasenberg and Oppenheimer, 1995) for the first motion analysis. FPFIT finds the double couple fault plane solution (source model) that best fits a given set of observed first motion polarities for an earthquake. The inversion is accomplished through two stages grid search procedures. These procedures determine the source model minimizing a normalized weighted sum of the first motion polarity discrepancies. Not only can we 
search for the best solution, but also multiple solutions. That gives an idea of uncertainty. The Focal mechanisms statistics calculated by FPFIT base on: QF, STDR, and Qp.

QF: Quality code summarizing the Degree to which the solution fits the data $(0=$ complete misfit, $1=$ excellent fit $)$

STDR: Estimator sensitive to distribution of the data on the focal sphere relative to the radiation pattern the closer the data are to the nodal planes, the less robust the solutions is, involving values of STDR $<0.5$.

Qp: Quality code that summarizes the range of uncertainties of the strike, dip, and rake in the solution.

\subsection{Results}

128 fault plane solutions were determined and classified into three different categories $(\mathrm{A}=$ very good, $\mathrm{B}=$ good, $\mathrm{C}=$ poor $)$ of quality, based on how tightly constrained each nodal plane.

\begin{tabular}{|c|c|c|c|c|}
\hline \multicolumn{2}{|c|}{ Quality parameter } & A.good & B.fair & C.poor \\
\hline QF & Degree of the misfit & 0.025 & $0.025 \leq \mathrm{QF} \leq 0.1$ & $0.1<$ \\
\hline STRD & Station distribution & $0.55<$ & $0.55 \leq \mathrm{STRD} \geq 0.45$ & $0.45>$ \\
\hline QP & Range of the solution & $20>$ & $20 \leq \mathrm{QP} \leq 40$ & $40<$ \\
\hline NUM & & 42 & 78 & 8 \\
\hline
\end{tabular}

Table 4.1 shows a sample of first motion solution for each quality.

The final single solution of the fault plane solutions for the earthquakes analyzed in this study is given in Table 4.4. In addition, Figure 4.4 shows a map of the focal mechanisms. In Northern Dead Sea Fault, majority of resulted mechanisms have normal 
and oblige normal mechanisms. In addition, the focal mechanism solutions in Central Dead Sea Fault are different and show more thrusting and strike-slip faulting; the most pressure axes orientation strikes SSW or EEN with a variable plunge. Toward the east, the events in Palmyrides have variable nodal planes strike, but the main trend is ESE. The pressure axes are mostly subhorizontal and have an average NNE trend $\left(\sim \mathrm{N} 50^{\circ}\right)$. Northeastern Syria has variable nodal planes, normal, reverse, and strike-slip faulting, because few mechanisms are located in this area (Figure 4.5-Figure 4.7) and (Figure 4.8). 



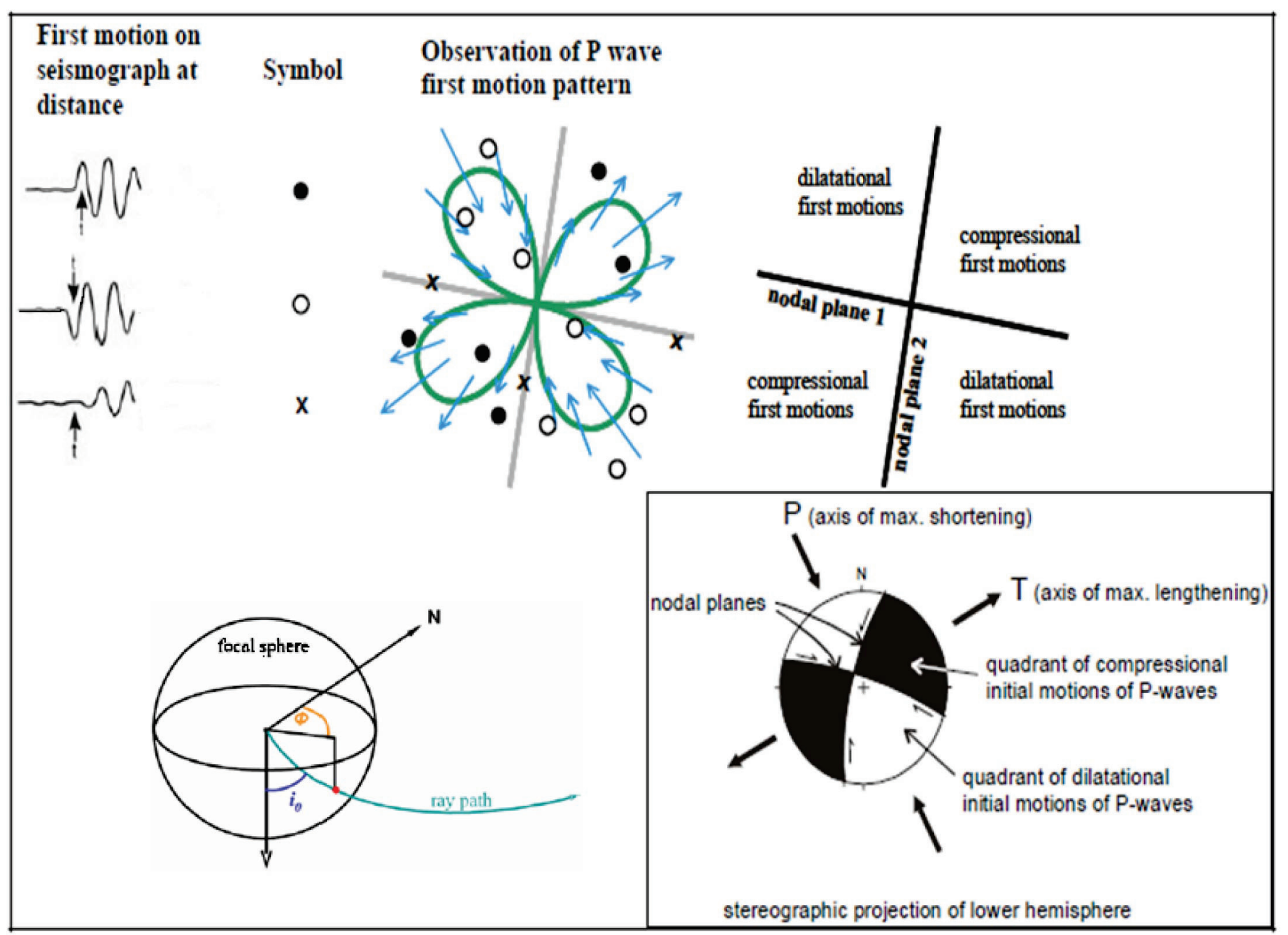

Figure 4.1. Earthquake source and mechanism, and the stereographic projection of the hemisphere. 


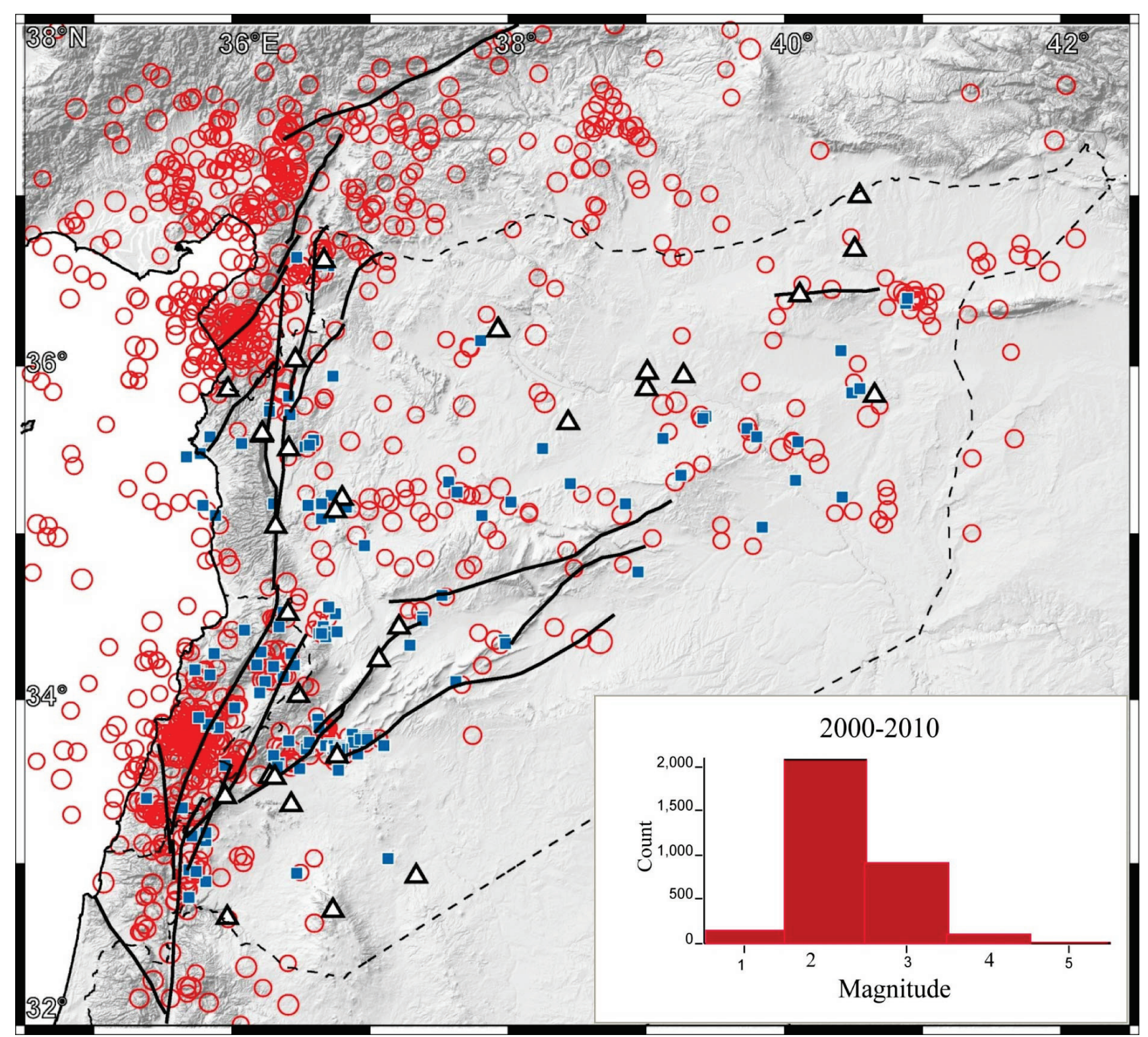

Figure 4.2. Seismicity map of Syria and surrounded area 2000-2010(red circle). Location of seismic stations (white triangle). selected events (blue squares), and the seismicity histogram (2000-2010). 

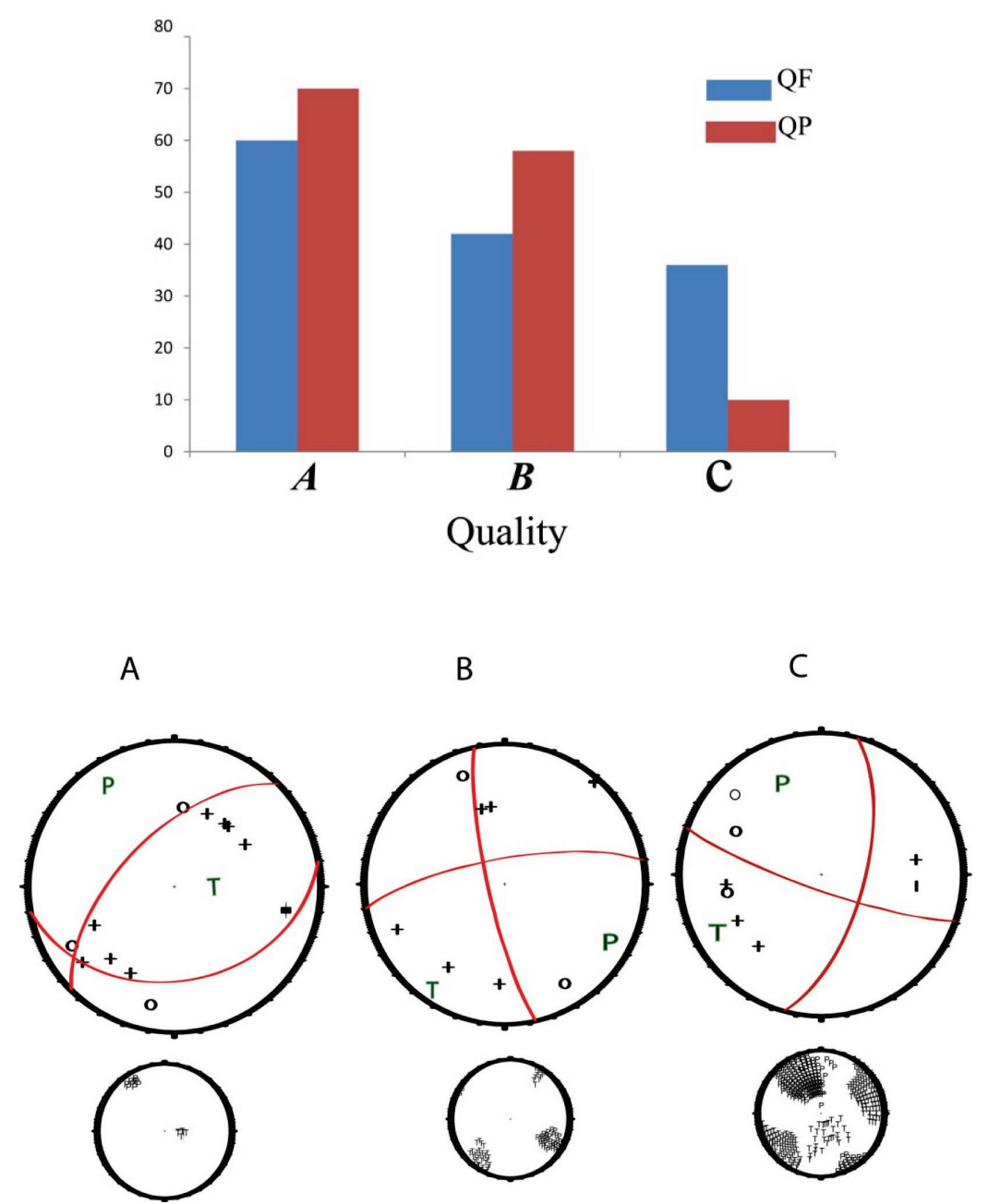

Figure 4.3. Samples of focal mechanism solutions with different qualities: $A=$ Excellent solution; $B=$ Very good solution; $C=U s a b l e ~ s o l u t i o n$.

T: Tension axis; P: Compression axis), and histogram represents all the qualities. 


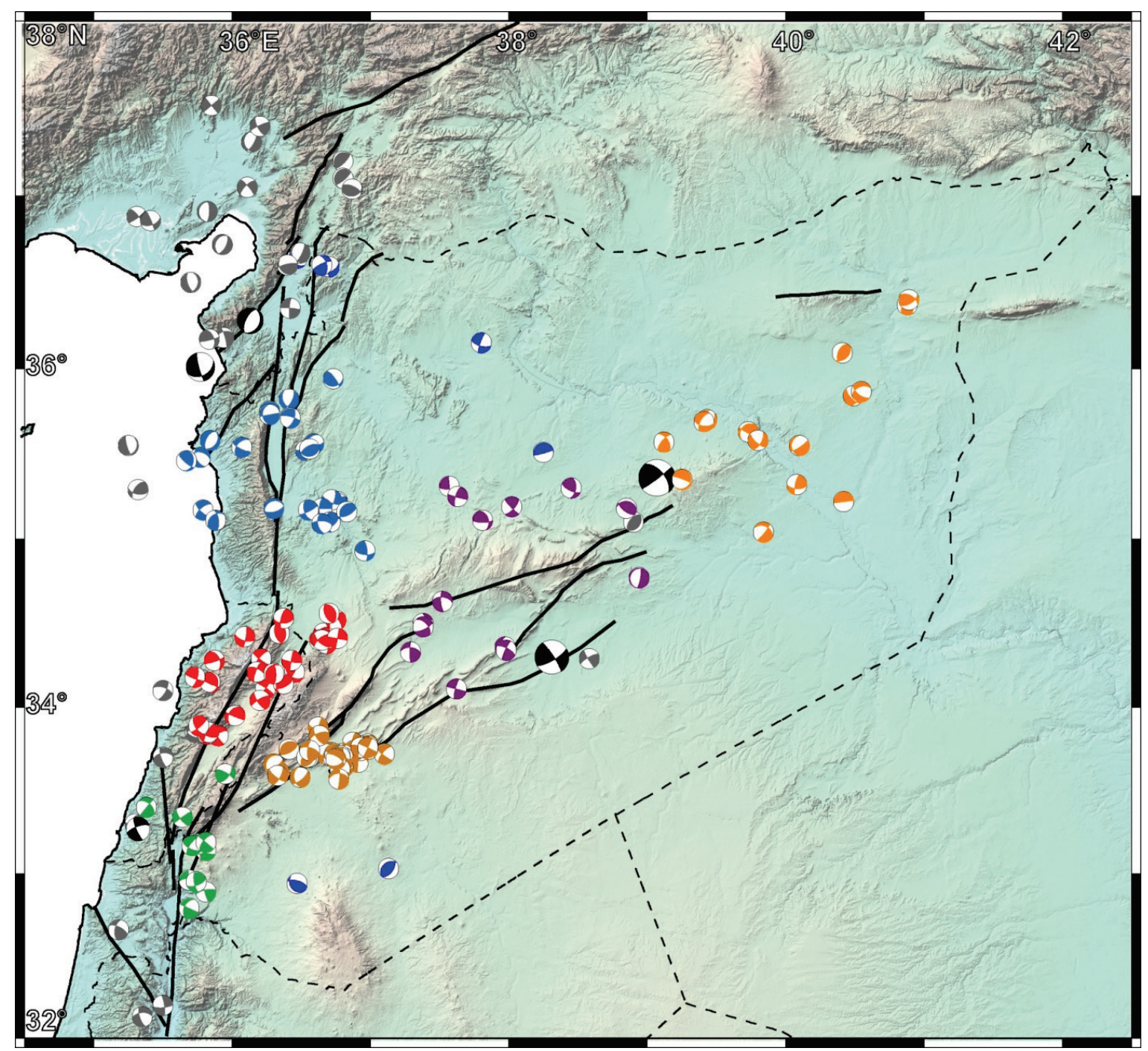

Figure 4.4. First plane solutions for all the regions, dark blue beachball=NDSF, red beachball $=$ CDSF, greed beach ball=SCDSF, dark orange beachball=SPLM, light orange beachball= NESyria. Black beachball=ISC catalog, gray beachball= $($ Salmon, et al 1996$)$ 
North Dead Sea Fault.

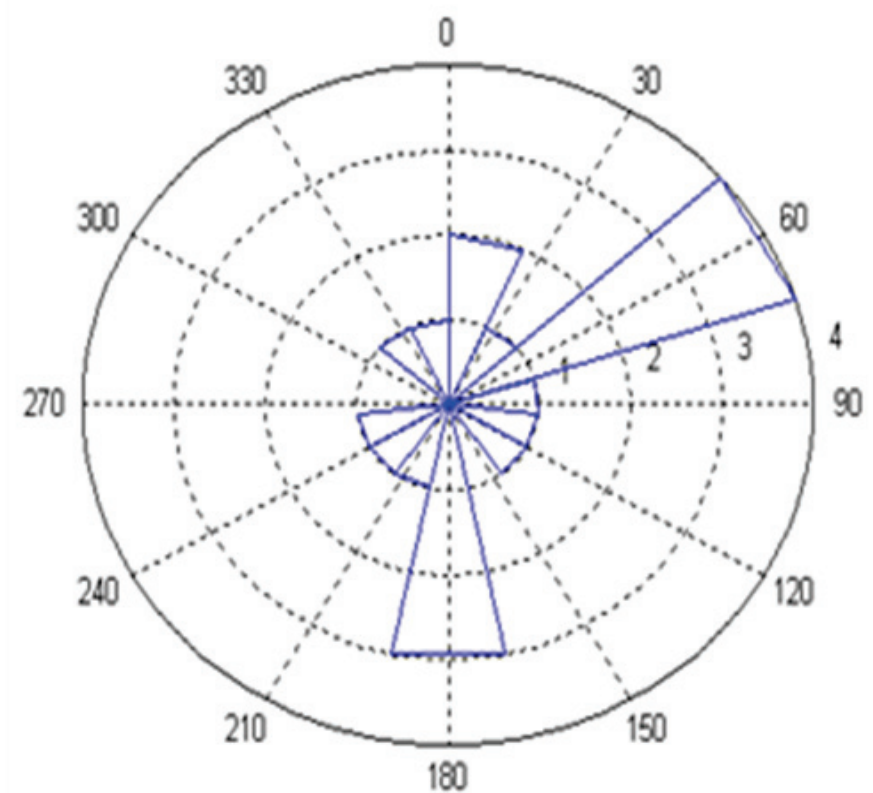

P-azimuth

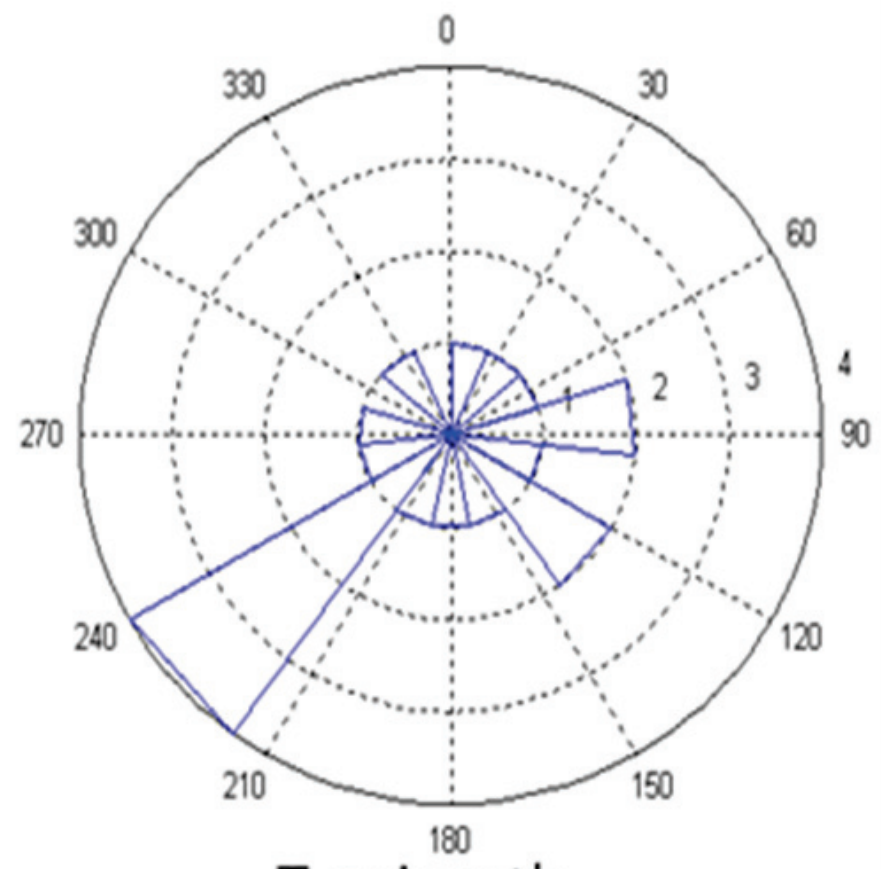

T-azimuth

Figure 4.5. Rose-Diagram of the azimuth of $\mathrm{P}$ and $\mathrm{T}$ axes NDSF. 


\section{Central Dead Sea Fault}

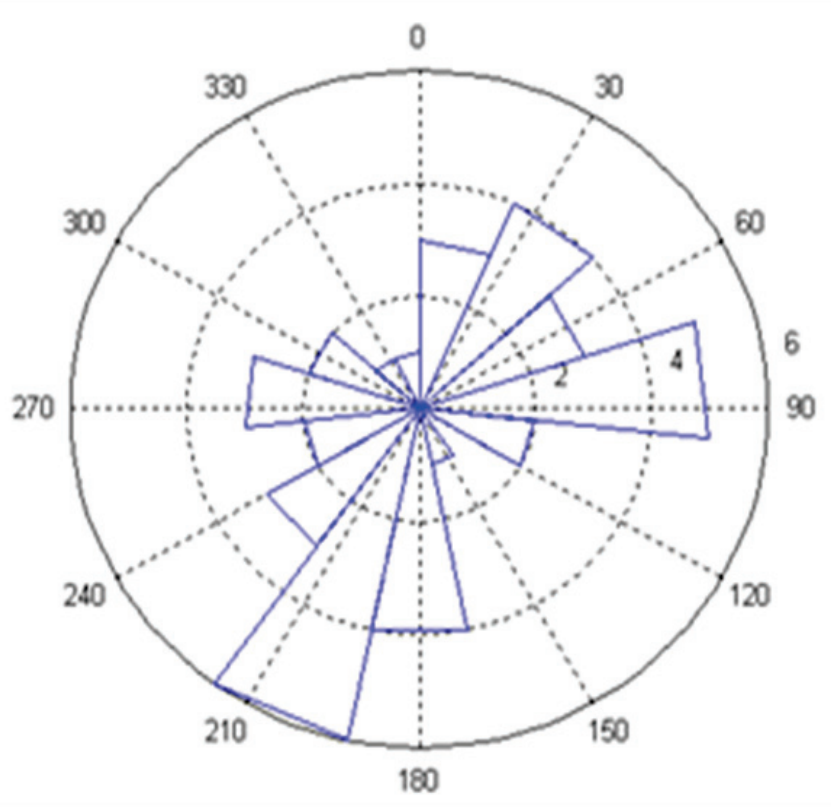

P-azimuth

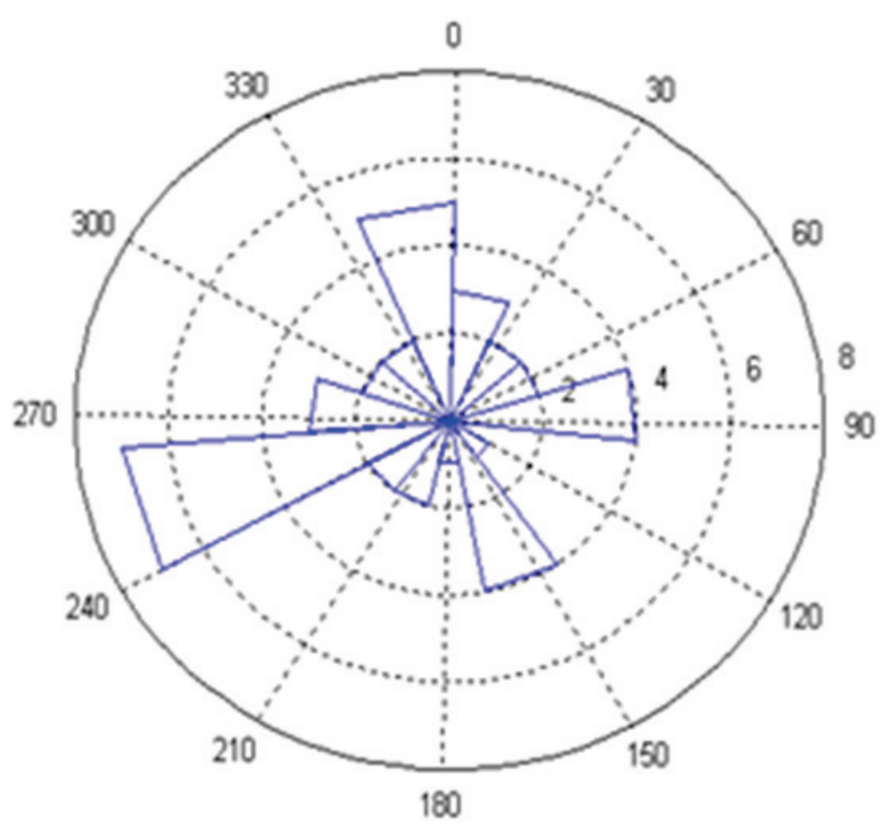

T-azimuth

Figure 4.6. Rose-Diagram of the azimuth of $\mathrm{P}$ and $\mathrm{T}$ axes for CDSF. 


\section{Palmyrides}

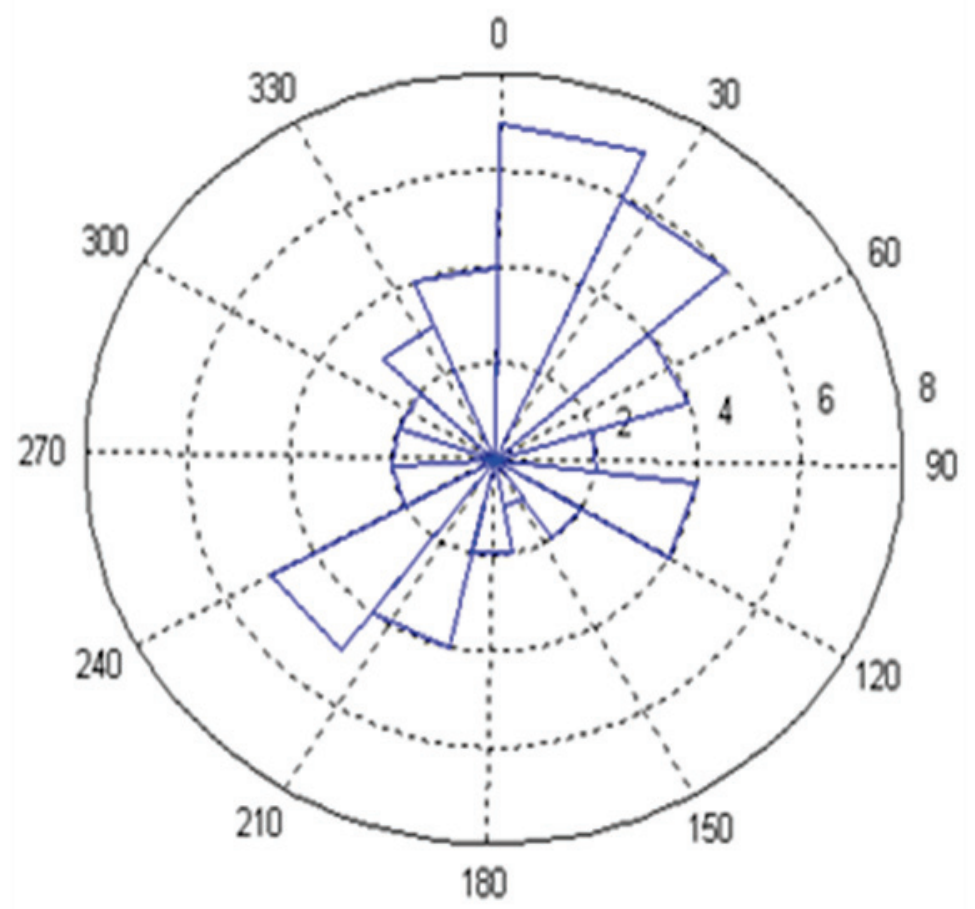

P-azimuth

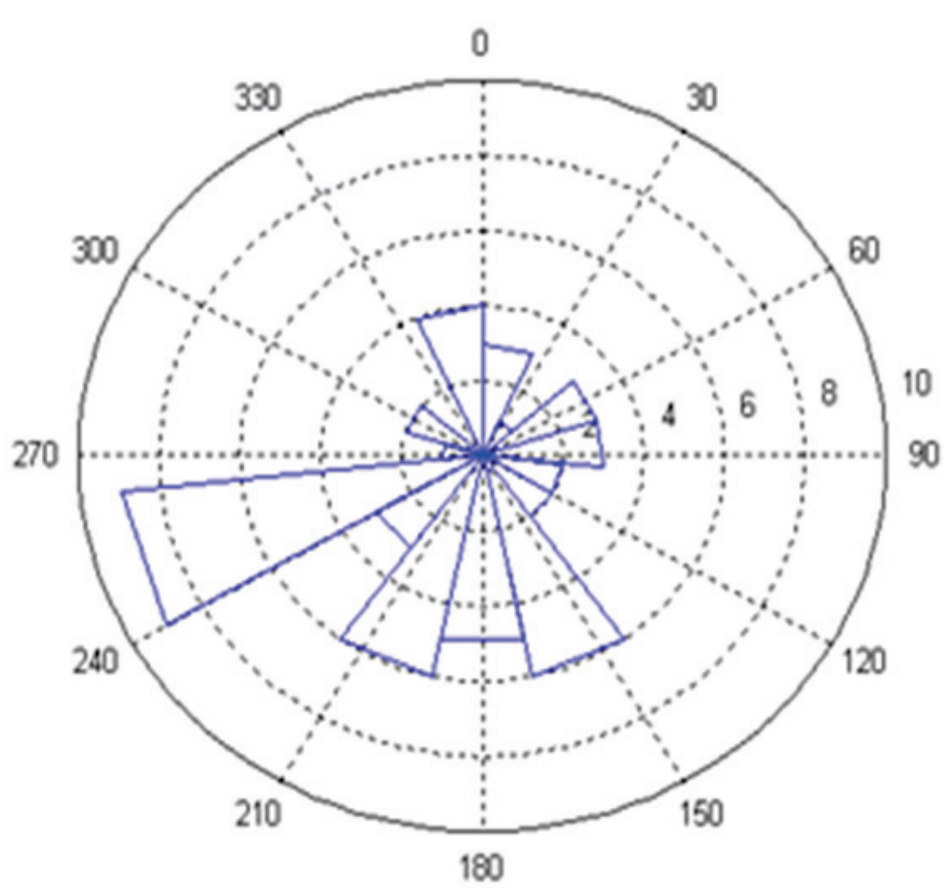

T-Azimuth

Figure 4.7. Rose-Diagram for the azimuth of the $\mathrm{P}$ and $\mathrm{T}$ axes for PFB 

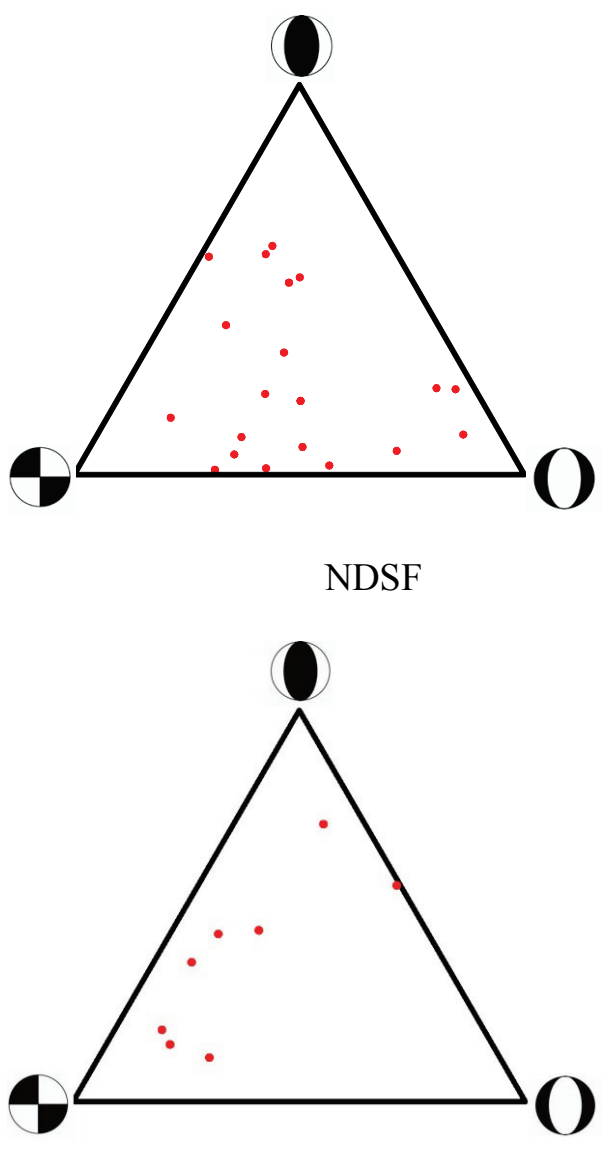

NPLM

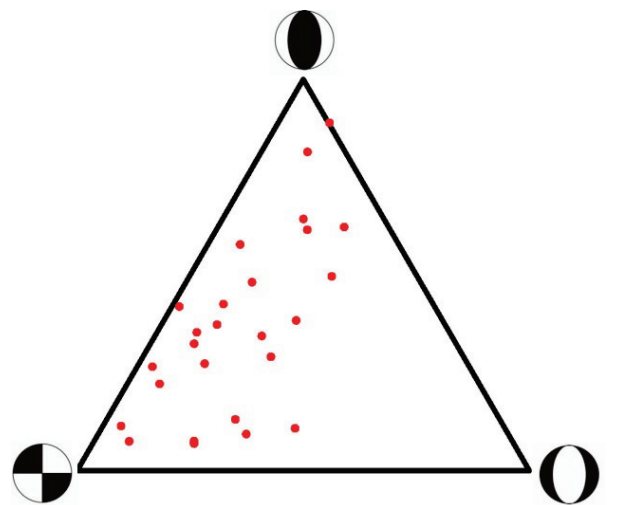

NCDSF

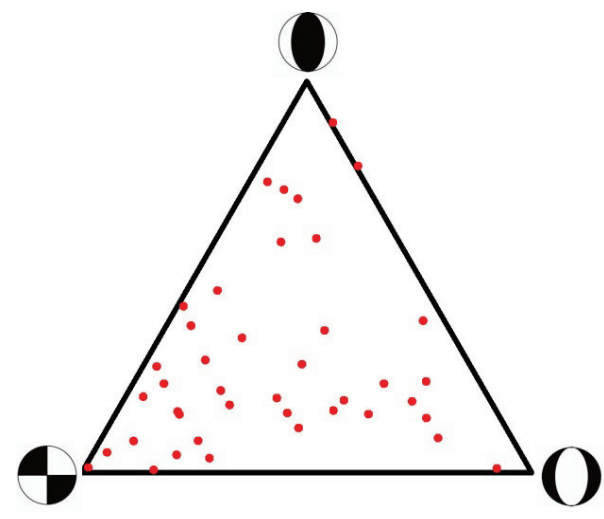

SPLM

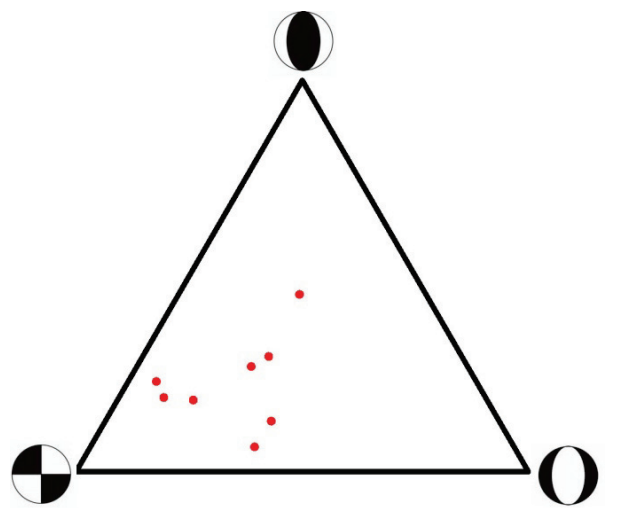

SCDSF

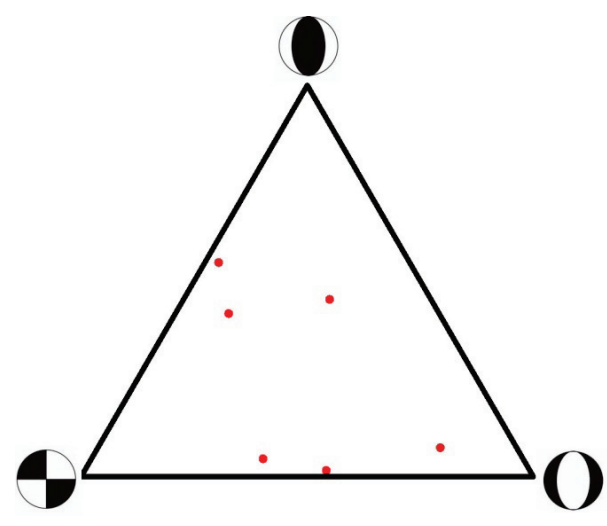

NE

Figure 4.8. Triangle diagram (Frohlich,C., 1992) of the focal mechanisms in the subregions: NDSF, NCDSF, SCDSF, NPLM, SPLM, SPLM, NE 


\section{Chapter 5 : Seismotectonic Analysis \& Discussion}

\subsection{Introduction:}

Earthquakes are expressions of active tectonic processes. The earthquake locations can help delineate plate boundaries and orhter active tectonic features. Additionally, focal mechanisms offer additional insight. As kinematic indicators, focal mechanism can be used to infer strain rates and relative velocity between the plates (e.g., Jackson \& McKenzie, 1988). Additionally, dynamic analyses of suites of focal mechanisms can provide constraints on the stress field (e.g., Gephart and Forsyth, 1984; Michael, 1984; Angelier, 1979; Rivera and Cisternas, 1990).

The principle axes of the moment tensor $(\mathrm{P}, \mathrm{B}, \mathrm{T})$ fully describe the focal mechanism. However, one should be aware that the moment tensor axes (kinematic axes) are not co-axial with the principal stress axes; the only restriction one can make is that the maximum principal stress $(\sigma 1)$ lies within the dilatational quadrant of the focal mechanism (McKenzie, 1969). However, since higher deviations between the P, B, and T axis and the principal stress axis $\sigma 1,2$, and 3 are unlikely they are used as proxies for the orientations of stress axes in many cases ((Bott, et. al., 1959).). The limits of stress derivation from focal mechanism are limited by the fault-plane ambiguity and the coefficient of friction (Bott, et. al., 1959).

\subsection{Stress inversion}

When a set of focal mechanism solution is available for a region with a homogeneous regional stress field, estimation of the tectonic stress orientation can be achieved; moreover, the mechanisms can be combined to determine the orientations of 
the principal stress axis by the inversion. The formal stress inversion of several focal mechanisms improves the quality of stress derivation, but it is linked to three main assumptions: (1) It is assumed that the chosen focal mechanisms lie in a region with a uniform stress field that is invariant in space and time. However, Townend and Zoback (2006) used a non-hierarchical clustering algorithm to group FMS in Japan for stress inversion to overcome the subjectivity. (2) It is assumed that the direction of earthquakes slip occurs in the direction of maximum shear stress (Wallace-Bott hypothesis, Bott, 1959). (3) All earthquakes used in the inversion are approximated at pure double-couple mechanisms.

A stress inversion determines the orientation of the principal stresses that minimize the average difference between the slip vector and the orientation of maximum shear stress on the inverted faults. This angle is commonly called "misfit angle" (Angelier, J., 2002).

Different algorithms of stress inversion have been developed by various authors (the most common routines are described by Gephart and Forsyth, 1984; Michael, 1984; Angelier, 1979; Rivera and Cisternas, 1990). The major difference between stress inversion techniques is the handling of the fault plane ambiguity. Some algorithms need the fault plane to be determined a priori. In most cases, this is not possible since further information is to determine the fault plane. Angelier (2002) provided a method automatically choosing the fault plane. Gephart and Forsyth (1984) perform the inversion as if all nodal planes were independent data, primary and remove the worse fitted auxiliary planes in a second step. The final inversion then includes the planes that are best fitted by a uniform stress field. The third approach, Michael (1987), applies a 
bootstrap routine that picks $x$ mechanisms at random from the original $x$ events. Each dataset than will have some mechanisms repeated two or more times (Michael, 1987). Random decisions of the true fault plane and a variety of bootstrapped datasets finally give a statistical determination of the stress orientation. A recent approach additionally includes a-priori information on the stress field into a probabilistic stress analysis of focal mechanism solution that accounts for the fault plane ambiguity by calculating probability density functions for the orientations of the principal stress axis (Arnold and Townend, 2007). All stress inversion techniques result in a deviatoric stress tensor, which gives four parameters: the orientation of the three principal stress axis, the relative magnitudes of the intermediate principal stress with respect to the maximum, and minimum principal stress. However, stress inversion is not capable of determining stress magnitudes. In this study, we apply Michael (1984). In Michael (1984) algorithm, the stress ratio is defined as

$$
\varphi=\left(\sigma_{2}-\sigma_{3}\right) /\left(\sigma_{1}-\sigma_{3}\right)
$$

To quantify the misfit between the data and the best stress tensor, the $\beta$ angle between the slip direction and tangential traction on the fault plane is used. $\beta$ will refer to the mean B for the data in single inversion. The availability of last information enables to calculate the shape and orientation of the stress ellipsoid.

\subsection{Data and analysis}

In this region, to complete analysis the stress field, the focal mechanisms resulted in this study were combined with those from previous studies, including the following: 
Abdul-wahed (2010) used largest events recorded by Syrian National

Seismological network (1995-2003), the database of fault plane solutions was obtained for 47 events with magnitude $>3$.

- 13 events from (T.Meirova, et. al., 2012) which has discussed the seismicity in southern Lebanon between 2008-2010 and concluded that several swarms, in total about 900 events in magnitude $0.05>\mathrm{Md}>5.2$.

- 133 events from EMMA Earthquake Mediterranean Catalogue, located within Anatolia plate and eastern Iran with magnitude $3<\mathrm{M}<8$.

- 5 events from (Saloman, et. al., 1996) seismicity of the eastern Mediterranean region.

Total events used in this study are 300; most of these events occurred between 2000 and 2013. This can be explained by that many local seismic networks have deployed in the study region and adjacent area (Figure 5.1). The combined focal mechanisms were divided into subsets based on the regional tectonic settings. For each region, Michael's (1984) algorithm was applied (Figure 5.2).

\subsection{Results}

The focal mechanism data base provides insight into regional, active tectonics. An initial view of faulting styles is provided by triangle (ternary) plots of focal mechanisms, as described by Frohlich (1992). Triangle plots are useful for plotting data in a 3-end-member system. For earthquake focal mechanisms the three end members are represented normal, thrust, strike- slip focal mechanisms - these correspond with the plunge values of the mutually orthogonal P, B, \& T axes. Clustering of data on these 
plots indicates a predominant style of faulting, although orientation information is lacking. Alternatively, scattered plots suggest heterogenous faulting. Triangle plots were constructed for each of the sub-regions, as shown in Figure 5.3 These are discussed for each study area below.

Deviatoric stress tensors for sub-regions (Figure 5.2) demonstrate spatial variabity of the horizontal stresses, including extension, contraction, and intermediate shear stress. Each region is discussed in more detail below:

1. Northern part of Dead Sea Faults(NDSF). Extending over a large portion of western Syria, consisting of the northern part of DSF. 37 focal mechanisms were located in this region, the focal mechanisms are strike-slip, normal oblige strike slip faulting, and reverse (Figure 5.2.A). The mechanism of these events show a high consistency over this delimited area. We have used these events in stress inversion logarithm, which characterized this region by the subhorizontal $\sigma 3$ axis oriented $\mathrm{N} 107^{\circ} \mathrm{E}$, and suggest NESW extension and $\varphi=0.66$ (Figure 5.3.C).

2. Northern part of Central Dead Sea Fault(NCDSF). We have selected 39 focal mechanisms located in NCDF region containing the Northern part of the central Dead Sea fault system. Particularly, a group of the events concentrates around the bending part of the fault in northern Lebanon. It seems many focal mechanisms have scattered off the main fault, but they are close by small branches. Focal mechanism data shows strike slip faulting and reverse oblige strike slip faulting (Figure 5.3.B), which usually lift lateral motion. The stress inversion result shows that the subhorizontal $\sigma 1$ axis trending N101E, the $\sigma 3$ axis is $\mathrm{N} 106 \mathrm{~W}$ with plunge $60, \varphi=0.74$ (Figure 5.4.D). 
3. Southern part of Central Dead Sea Fault (SCDSF). It is covering most of southern Lebanon, consisting of Southern part of the central Dead Sea Fault. 31 focal mechanisms were used; a large number is strike slip faulting (Figure 5.3.C). Moreover, result of stress inversion method shows the $\sigma 1$ axis is horizontal trending $\mathrm{N} 124^{\circ} \mathrm{E}$. The $\sigma 3$ axis also is horizontal with trend $\mathrm{N} 34^{\circ} \mathrm{E}, \varphi=0.8$. (Figure 5.4.E).

4. Southern Palmyrides Fold Belt (SPFB). It is extending southern Jhar fault, containing 48 focal mechanisms. Practically, most of the events are strike slip faulting (Figure 5.3.E). The result of the stress inversion shows that subhorizontal $\sigma 1$ axis trends $\mathrm{N} 140^{\circ} \mathrm{E}$ and. Subhorizontal $\sigma 3$ axis trends $\mathrm{N} 40^{\circ} \mathrm{E}$ and $\varphi=0.6$ (Figure 5.4.J).

5. Northern Palmyrides Fold Belt (NPFB). 12 focal mechanisms located in the region northern Jhar fault, dividing the Plamyrides into two parts. Despite the small number of focal mechanisms, we used them as primarily result(Figure 5.3.D) Most the focal mechanisms have reverse motion. Resulted stress inversion depicts that the $\sigma 1$ axis is subhorizontal and trending $\mathrm{N} 51^{\circ} \mathrm{E}$, and the $\sigma 3$ axis trending $\mathrm{N} 95^{\circ} \mathrm{W}$ with plunge $55^{\circ}$ (Figure 5.4.I).

6. Abd-Aziz. This region located in northern the Euphrates consists of the Singar -abd-aziz belt. Although we have Only 10 focal mechanisms used in this inversion, they show a primly stress filed pattern (Figure 5.3.F). The $\sigma 1$ axis is subhorizantal and trending $\mathrm{N} 15^{\circ} \mathrm{E}$, while the 63 axis plunge $63^{\circ}$ and trends $\mathrm{N} 118^{\circ} \mathrm{W}$ (Figure 5.4.C).

7. Euphrates fault system. This region extends between the Abd-Aziz and NPFB regions, consisting of Euphrates fault system. We have only 7 focal mechanisms to use in stress inversion (Figure 5.3.G). The primary result for stress field for this region 
shows that $\sigma 1$ axis $\mathrm{N} 108^{\circ} \mathrm{W}$ and plunge $60^{\circ}$, the horizontal $\sigma 3$ axis trending $\mathrm{N} 14^{\circ} \mathrm{W}$ (Figure 5.4.B).

In addition to the northern Arabia subregions, the Anatolian plate was divided into two sub-regions ( Figure 5.2):

8. Western Anatolian. The region extends west of the Karliova triple junction, including East Anatolian fault and North Anatolian fault. 52 focal mechanisms used in this inversion (Figure 5.3.H). The horizontal $\sigma 1$ axis trends $\mathrm{N} 12^{\circ} \mathrm{E}$, and $\sigma 3$ axis trends $\mathrm{N} 107^{\circ} \mathrm{W}$ and plunge $79^{\circ}$ (Figure 5.4.G).

9. Eastern Anatolian. The region east of the triple junction consists of the Turkish plateau. The dataset consists of 34 focal mechanisms (Figure 5.3.I). As the result, the horizontal $\mathrm{P}$ axis trending $\mathrm{N} 123^{\circ} \mathrm{W}$, the $\mathrm{T}$ axis trending $\mathrm{N} 2^{\circ} \mathrm{E}$ and plunge $78^{\circ}$ (Figure 5.4.H).

10. North Westernmost Zagros(NWZ): 9 focal mechanisms only used in this region. However, it is as primary result (Figure 5.3.J). The subhorizontal $\sigma 3$ axis trending $\mathrm{N} 17^{\circ} \mathrm{W}$, the $\sigma 1$ axis trending $\mathrm{N} 130^{\circ} \mathrm{E}$, the plunge $69^{\circ}$ (Figure 5.4.F).

The focal mechanisms are variable along the NDSF, but they become strike -slip and reverse in NCDSF, whereas in the SCSDF they convert to strike-slip and normal. The NPFB and SPFB have different mechanisms, they are variable in SPFB and strike slip and reverse in NPFB. While the primarily resulting mechanisms in the EFS are normal; towards the north in the Abd-Aziz, the mechanism becomes strike slip and reverse; moreover, west Anatolian has primarily strike slip and normal mechanisms and whereas the East has predominantly reverse and strike slip. 
In the study region, variation of maximum stress axis $\sigma 1$ was characterized using Zmap application. The Figure 5.5 shows that within the Anatolian plate, $\sigma 1$ changes from N-S in middle Anatolian plate to NE-SW towards the east, whereas in Arabia plate the $\sigma 1$ moves from NNW -SSE in the western boundary along DSF to N-S towards the east. Moreover, the number and distribution of the analyzed events play a big role in accuracy of the result. The most robust variation exists in the west along the DSF.

\subsection{Discussion}

Changing the stress field orientation between western and eastern Palmyrids, NW-SE to NNW-SSE, reflects the influence of the transform tectonism (DSF) against the Arabian-Eurasian collision. According to former studies, (Barazangi, et. al., 1993), the plate motion produced a huge stress at the plate boundary in northwestern Arabia, which transmitted across Aleppo plateau then generate ongoing deformation within Palmyrides. The difference in the stress field direction within the two parts of plamyrides was intercepted (Barazangi, et. al., 1993) by crustal variation between northern and southern plamyrides..

In northeastern Syria, the stress tensor is not well constrained likely because the limited data and data qualities. However, unreliable result can be interpret based on previous research (Brew, et. al., 2003). The formation of transtensional Euphrates graben depression resulted of the same compressional episodes formed the plamyrides, where minor late Neogene transpression reactivated some of the structures in response to the Zargro-Bitlis continental collision and some faults still normal mechanisms; probably that gives the region NW-SE extension stress field. 
Along the DSFS, the result of the stress inversion along the DSF allows addressing the stress field pattern of all sectors of the DSFS. The dominated extension in northern DSF turns into contraction in northern Central Dead Sea Fault, and then it becomes the strike-slip mechanism in the southernmost central DSF. This result agrees with kinematic changes suggested by GPS velocity measurements; the northern part of the DSF is characterized by NNW-SSE direction velocity field with motion decreasing towards the south of this sector. Consequently, the extension is probably compatible with the complex tectonism, the Arabian -Eurasian collision plate boundary in the north, the Sinai - Arabian transform plate boundary in the west, and the subduction process between Sinai and Eurasia.

In the North Westernmost Zagros (NWZ), the extension field is compatible with previous studies. COPLEY AND JACKSON, (2006) explained exiting normal faults by the following idea: The overall Arabia-Eurasia motion changes along the WNW-ESE strike of the Zagros belt. Therefore, the component of the motion, which is being expressed as right-lateral strike-slip faulting changes along the Zagros belt. If the northern boundary of the faults is effectively undeformed, then there is a difference in fault-parallel velocities south of the faults, which the normal faults can accommodate

Changing the stress field orientation in Anatolian plate, N-S in the west to NESW towards the east, can be explained as a response to the influence of continental collision zones in southern Turkey and the greater Caucasus.

\subsection{Conclusion}

In this study, focal mechanisms produced by both First Motion and Moment Tensor inversion methods were analyzed. Since the moment tensor inversion depends 
strongly on the crustal structure, we used the waveform modeling method to generate the 1-D velocity model for each region lacking the seismic stations, having noisy seismic data, or having lateral variation crustal structure.

\section{The main questions and the answers:}

What is the reliability and appropriateness of the regional moment tensor technique in a complex geological region? How we improve the effectiveness of RMT procedure?

The regional moment tensor solution is sanative to the station configuration, signal to noise ration and velocity model. Using 1-D velocity model in the regional moment tensor technique in a complex geological region contributes in unreliable solution due to the lithospheric heterogeneity. Regionalization, which is a process of dividing the study region into smaller sub-regions based on the geological settings, is recommended to improve regional moment tensor solutions.

What is effect of the competing relationship between the collision and the transform on the stress field direction?

The results indicate that the competing relationship between the transform and continental collision processes controls the stress field pattern and addresses the larger matter of seismotectonic. For example, extension stress fields were exist along the northern sector of Dead Sea Fault, Euphrates fault system. On contrary, contraction stress fields were located in the northern part of Central Dead Sea Fault, Northern Palmyrides, and Abd-Aziz regions. Shear stresses were founded in the southern Central Dead Sea Fault and southern Palmyrides. Most the horizontal compressional axis are perpendicular 
on the topographic trends. The compatible relationship between the stress field pattern and the GPS measurements insists the effect of the Sinai-Eurasia convergence, which interpret the stress field patterns

In order to extend the seismotectonic knowledge in the study region, I recommend deploying intensive seismic stations in all the study region. In addition, we suggest implying real time MT procedure, which provides the focal mechanism result for earthquakes with $\mathrm{Ml}>3$ automatically and immediately around the network area.. 


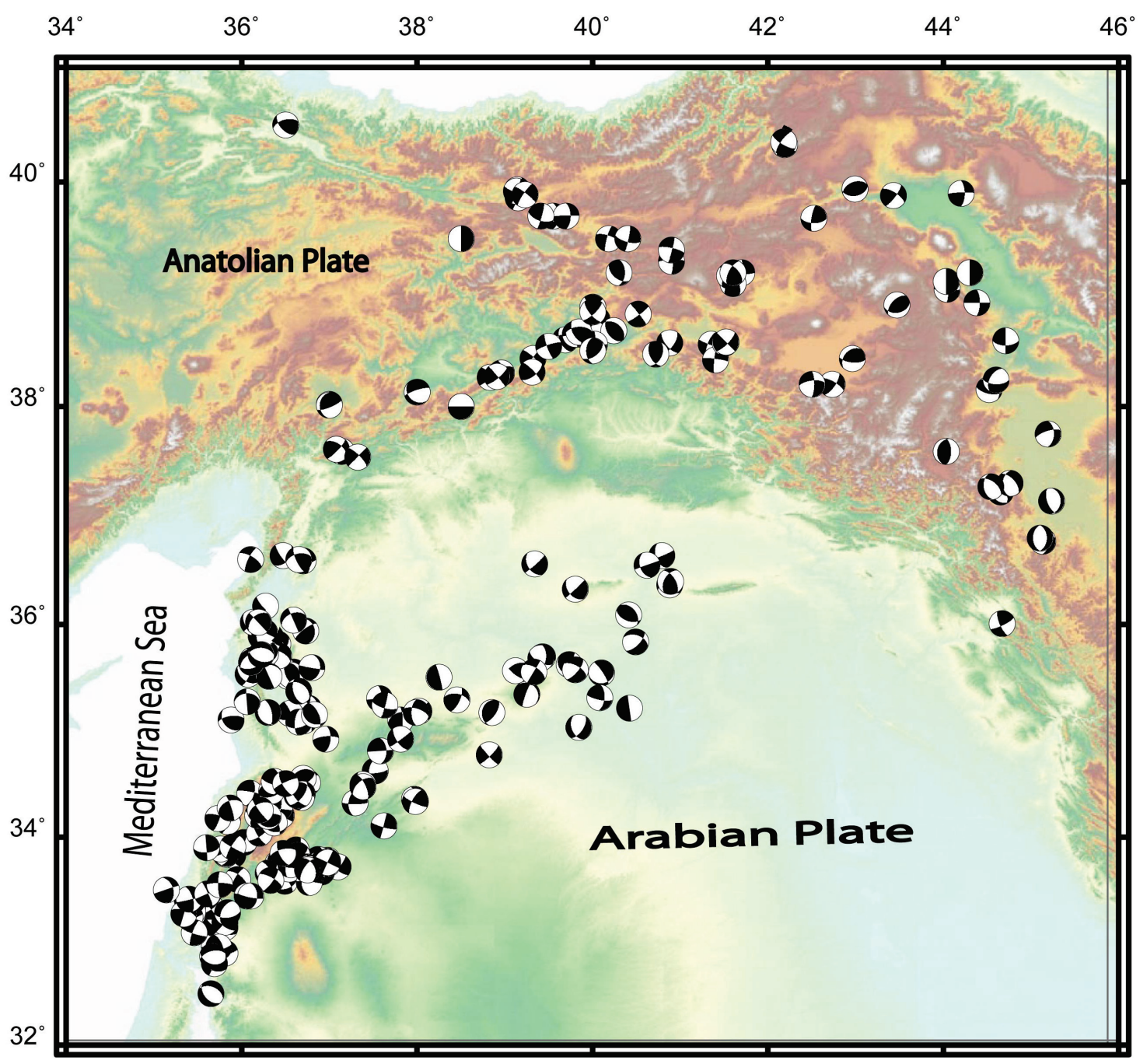

Figure 5.1. Focal Focal mechanisms in the study area, black::contractional quadrant; white: dilatation quadrant 


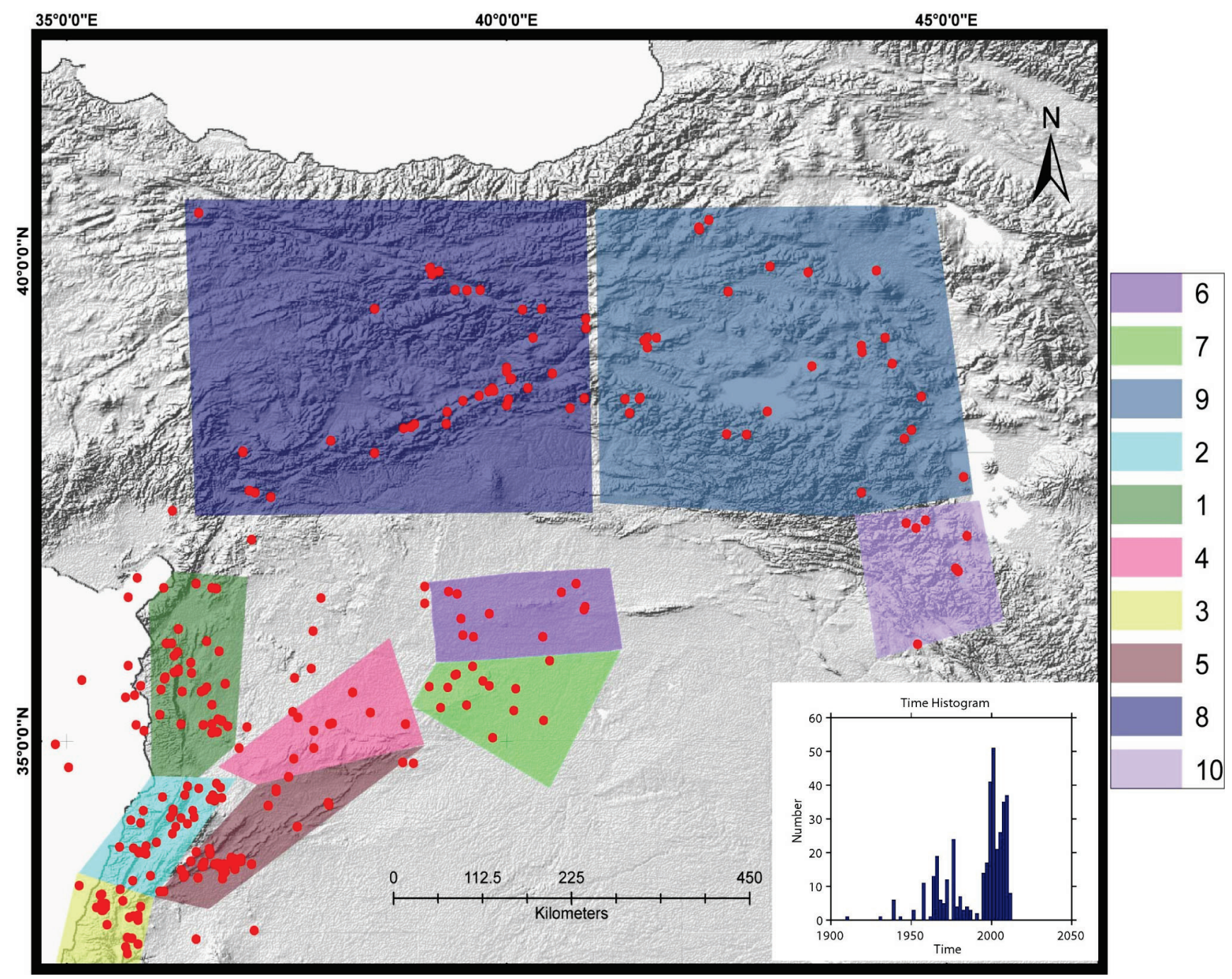

Figure 5.2. Map shows the divided subregions in the study area, the stars are the focal mechanisms used in the stess inversion. 1=Northern Dead Sea Fault, 2=Northern Central Dead Sea Fault, 3=Southern Central Dead Sea Fault, 4=Northern Palmyrides, 5=Southern Palyrides, 6= Abd-Aziz, $7=$ Euphrates system, 8=Eastern Anatolian, 9=western Anatolian. nd 10= North west Zagros. Histogram of the events used (both moment tensor inversion and first polarity methods). 


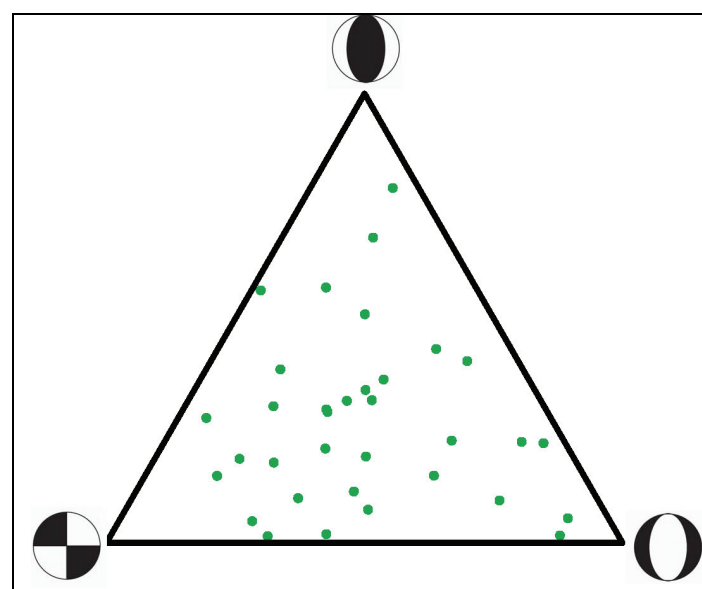

Northern Dead Sea Fault (NDSF)

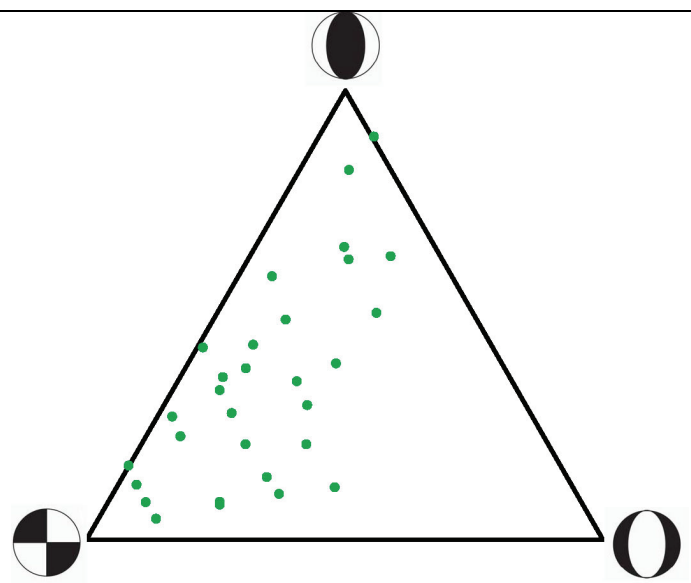

Northern Central Dead Sea fault (NCDSF)

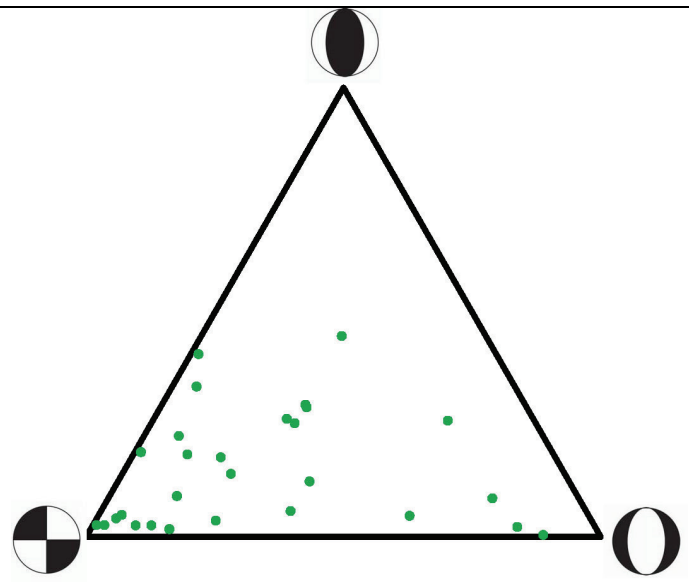

Southern Central Dead Sea fault (SCDSF)

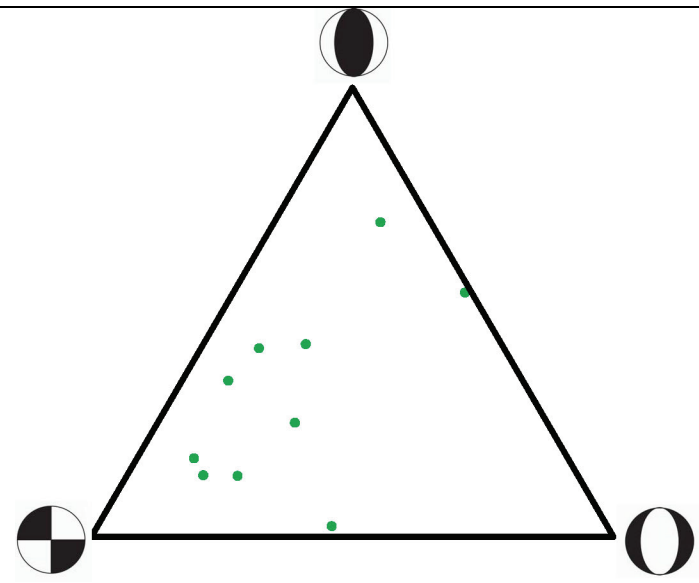

Northern Palmyrides (NPLM)

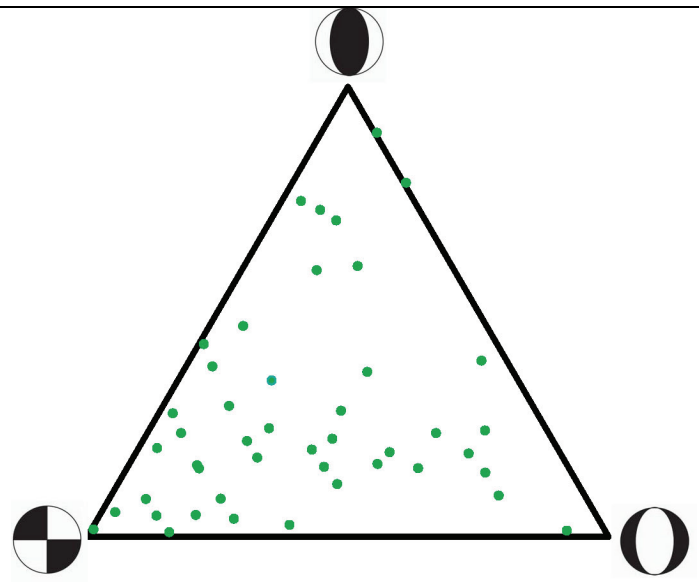

Southern Palmyrides (SPLM)

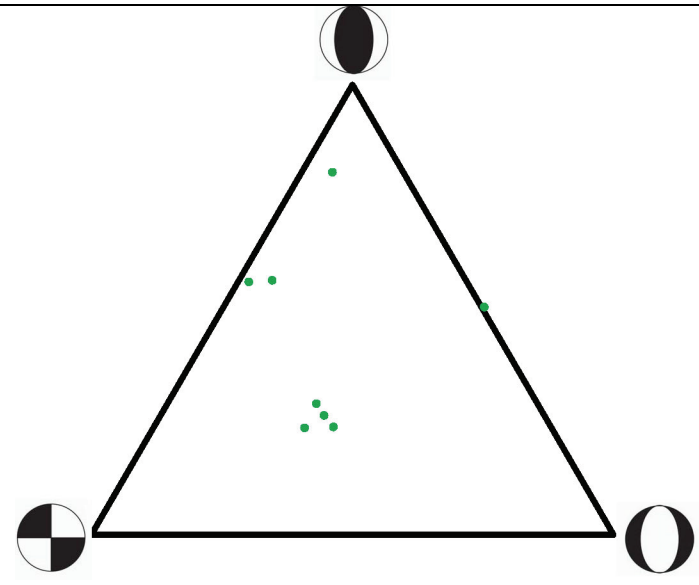

Abd-aziz

Figure 5.3. Triangle diagram (Frohlich, C., 1992) of the focal mechanisms in the subregions of study (see map in Figure 5.2). 


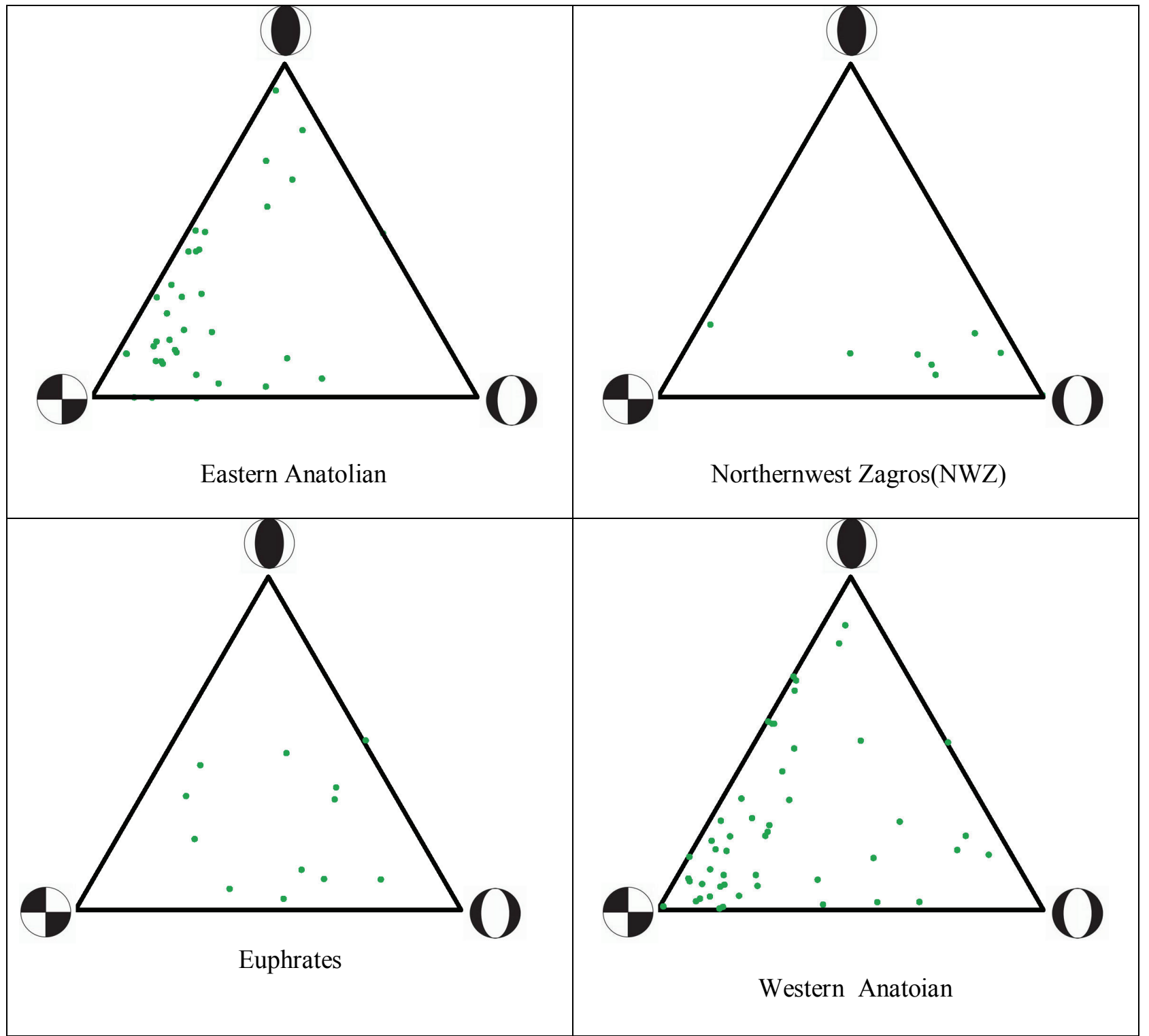

Figure5.3. Continued 


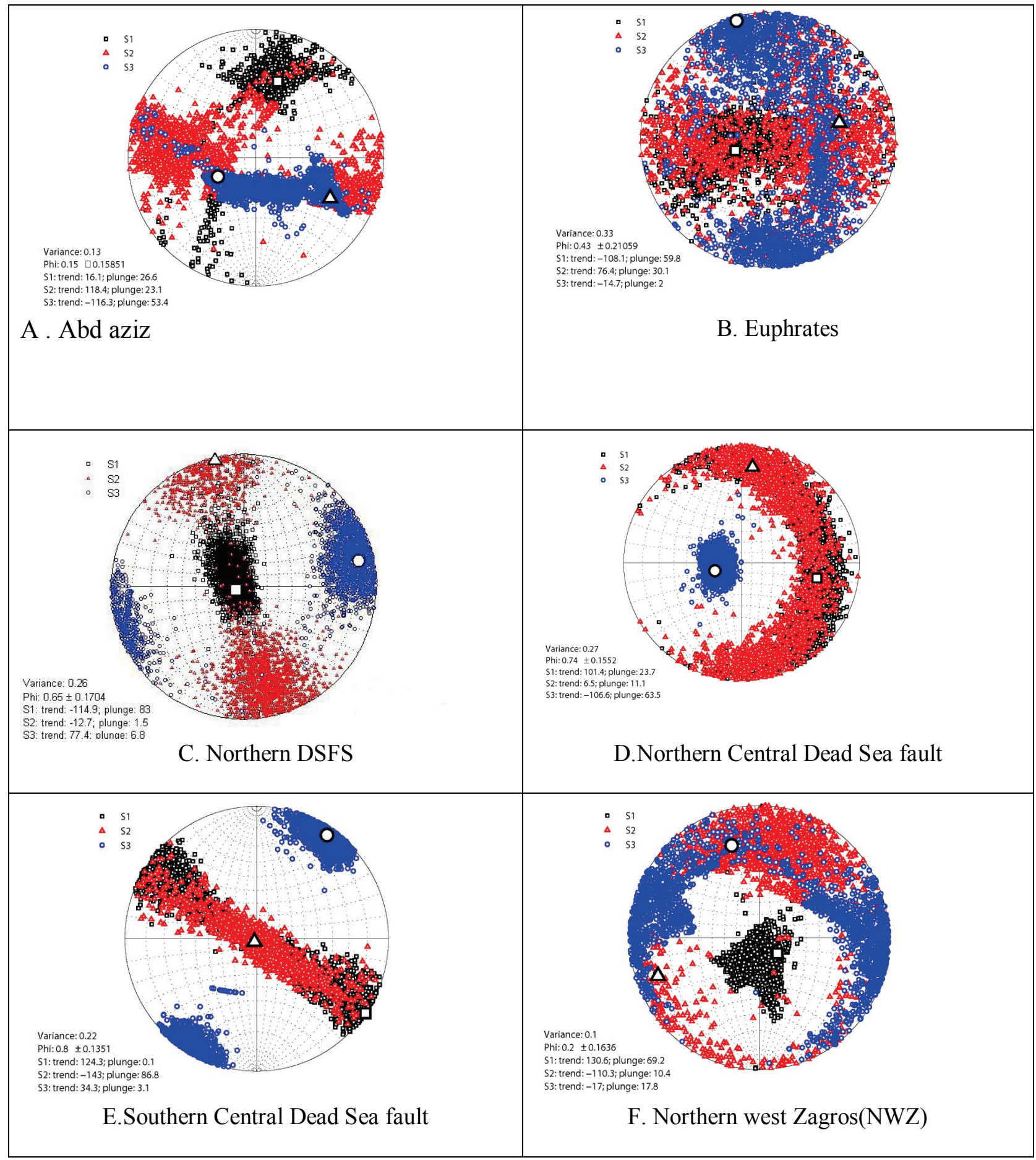

Figure 5.4. The result of the inversion. Maximum principal stress $\sigma 1$ (square), intermediate principal stress $-\sigma 2$ (triangle), and least principal axis $-\sigma 3$ (circle) . Determination inverting $P$ and $\mathrm{T}$ axes of selected focal mechanism. 


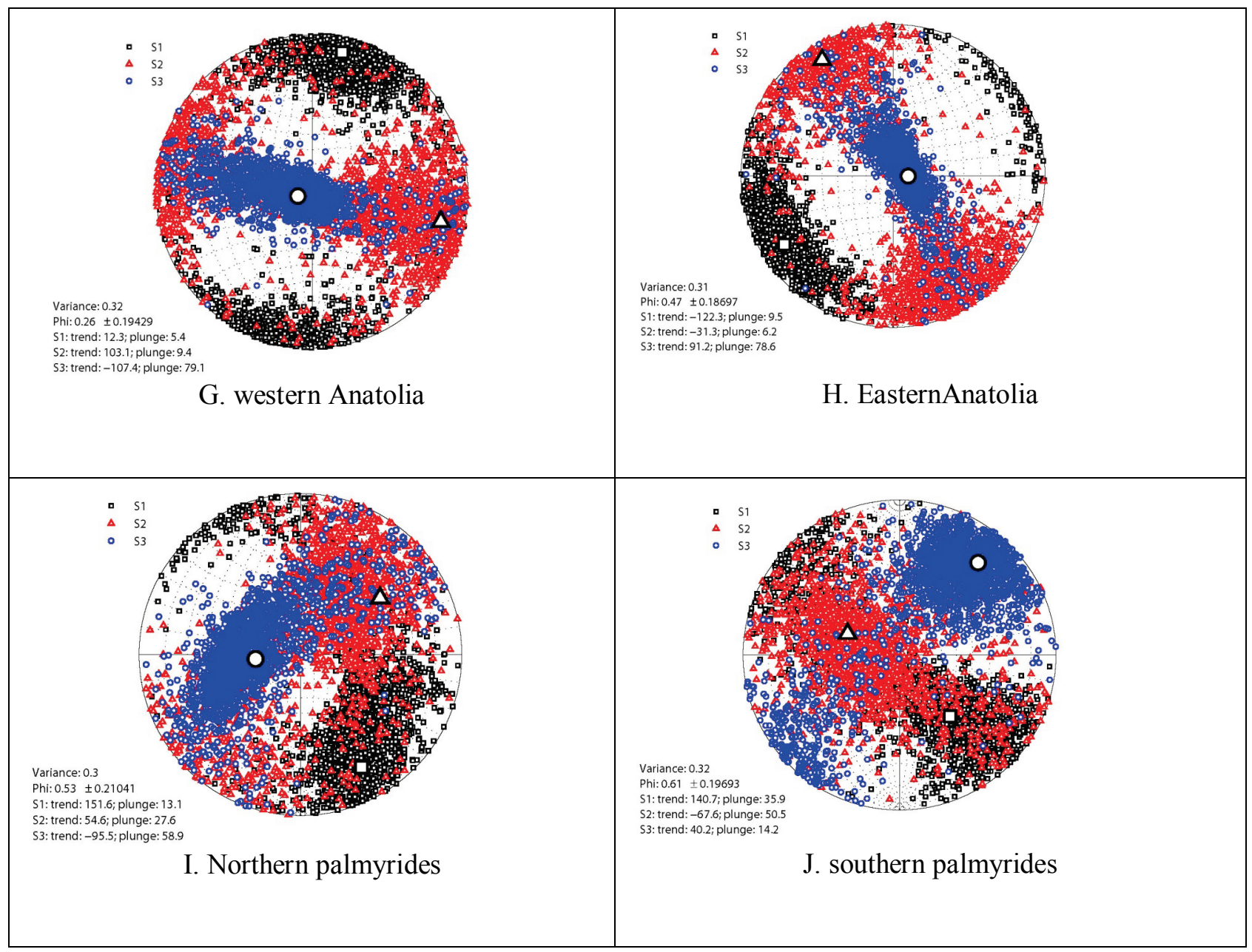

Figure5.4. Continued 


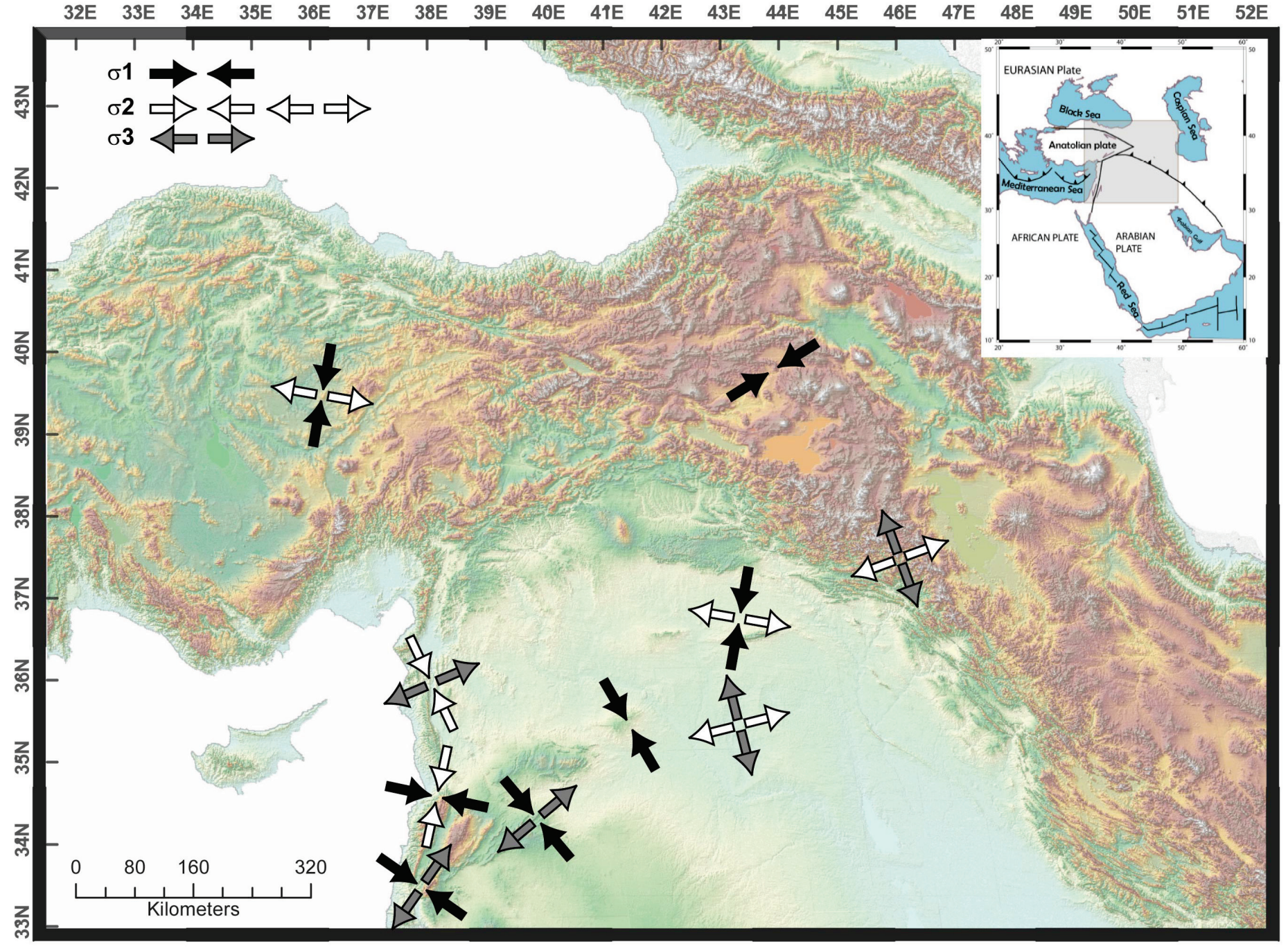

Figure 5.5. Variation of the stress principal $\sigma 1, \sigma 2$, and $\sigma 3$ in the study region . 


\section{References Cited}

Alchalbi, A., Daoud, M., Gomez, F., McClusky, S., Reilinger, R., Romeyeh, M. A., Alsouod, A., et al. (2010). Crustal deformation in northwestern Arabia from GPS measurements in Syria: Slow slip rate along the northern Dead Sea Fault. Geophysical Journal International, 180(1), 125-135. doi:10.1111/j.1365-246X.2009.04431.x

Al-damegh, K., Sandvol, E., \& Barazangi, M. (2005). Crustal structure of the Arabian plate?: New constraints from the analysis of teleseismic receiver functions, (607), 177-196p.

Al-Damegh, K., Sandvol, E., Al-Lazki, A., \& Barazangi, M. (2004). Regional seismic wave propagation ( $\mathrm{Lg}$ and $\mathrm{Sn}$ ) and $\mathrm{Pn}$ attenuation in the Arabian Plate and surrounding regions. Geophysical Journal International, 157(2), 775-795. doi:10.1111/j.1365246X.2004.02246.x

Al-Lazki, A. I. (2003). Tomographic Pn velocity and anisotropy structure beneath the Anatolian plateau (eastern Turkey) and the surrounding regions. Geophysical Research Letters, 30(24), 8043. doi:10.1029/2003GL017391

Al-Lazki, A. I., Sandvol, E., Seber, D., Barazangi, M., Turkelli, N., \& Mohamad, R. (2004). Pn tomographic imaging of mantle lid velocity and anisotropy at the junction of the Arabian, Eurasian and African plates. Geophysical Journal International, 158(3), 1024-1040. doi:10.1111/j.1365-246X.2004.02355.x

Bao, X., Sandvol, E., Ni, J., Hearn, T., Chen, Y. J., \& Shen, Y. (2011). High resolution regional seismic attenuation tomography in eastern Tibetan Plateau and adjacent regions. Geophysical Research Letters, 38(16), L16304. doi:10.1029/2011GL048012

Barazangi, M. (1982). continent convergence zone (the "Oman Line”) are carefully examined. A northeast trending zone of earthquakes terminates the Zagros belt of. October, 1(5), 389.412 .

D.V. Helmberger, G. R. E. (1980). Modeling the ling period body waves from shallow earthquakes ar regional ranges. October, 70(5), 1699-1714.

Dreger, D. S., \& Ford, S. (2011). PASI-MT-Tutorial ver. 06/05/2011 1. Tensor, 1-18.

Dziewonski, A. M., \& Woodhouse, and J. H. (1983). Earthquakes, L. (1983). then could be made that differences It the is inference Mij j dt, 88, 3247-3271., 88, 3247-3271.

Ekström, G., Dziewoński, a. M., Maternovskaya, N. N., \& Nettles, M. (2005). Global seismicity of 2003: centroid-moment-tensor solutions for 1087 earthquakes. Physics of the Earth and Planetary Interiors, 148(2-4), 327-351. doi:10.1016/j.pepi.2004.09.006 
Ford, S. R., Dreger, D. S., \& Walter, W. R. (2010). Network Sensitivity Solutions for Regional Moment-Tensor Inversions. Bulletin of the Seismological Society of America, 100(5A), 1962-1970. doi:10.1785/0120090140

Gök, R., Mahdi, H., Al-Shukri, H., \& Rodgers, A. J. (2008). Crustal structure of Iraq from receiver functions and surface wave dispersion: implications for understanding the deformation history of the Arabian-Eurasian collision. Geophysical Journal International, 172(3), 1179-1187. doi:10.1111/j.1365-246X.2007.03670.x

Gök, R., Pasyanos, M. E., \& Zor, E. (2007). Lithospheric structure of the continent-continent collision zone: eastern Turkey. Geophysical Journal International, 169(3), 1079-1088. doi:10.1111/j.1365-246X.2006.03288.x

.Gephart, J.W., Stress and the direction of slip on fault planes, Tectonics, 9, 845-858,1990b.

Gephart, J.W., and D.W. Forsyth, An Improved Method for Determining the Regional Stress Tensor Using Earthquake Focal Mechanism Data: Application to the San Fernando Earthquake Sequence, Journal of Geophysical Research, 89, 9305-9320, 1984.

Gillard, D., M. Wyss, and P. Okubo, Stress and strain tensor orientations in the south flank of Kilauea, Hawaii, estimated from fault plane solutions, Journal of Geophysical Research, 100, 16025-16042, 1995.

Hardebeck, J.L., and E. Hauksson, Stress orientations obtained from earthquake focal mechanisms: What are appropriate uncertainty estimates?, Bulletin of the Seismological Society of America, 91 (2), 250-262, 2001.

Hatzfeld, D., Tatar, M., Priestley, K., \& Ghafory-ashtiany, M. (2003). Seismological constraints on the crustal structure beneath the Zagros ARABIA. Most, 403-410.

Herrmann, R. B. (2006). COMPUTER PROGRAMS IN SEISMOLOGY AN OVERVIEW OF SYNTHETIC SEISMOGRAM COMPUTATION. Sciences-New York, (September).

Kuscu, I., Kuscu, G. G., Tosdal, R. M., Ulrich, T. D., \& Friedman, R. (2010). Magmatism in the southeastern Anatolian orogenic belt: transition from arc to post-collisional setting in an evolving orogen. Geological Society, London, Special Publications, 340(1), 437-460. doi:10.1144/SP340.19

Michael, A.J., Determination of Stress From Slip Data: Faults and Folds, Journal of Geophysical Research, 89, 11517-11526, 1984. 
Mahmoud, Y., Masson, F., Meghraoui, M., Cakir, Z., Alchalbi, A., Yavasoglu, H., Yönlü, O., et al. (2013). Kinematic study at the junction of the East Anatolian fault and the Dead Sea fault from GPS measurements. Journal of Geodynamics, 67, doi:10.1016/j.jog.2012.05.006.

Mohamad Khir Abdul-Wahad, Ibrahim Al-Tahan, Preliminary outline of the seismologically active zone in Syria,J. GEOPHYSICS, 53, 4, 2010; doi: 10.4401/ag-4683.

Reilinger, R., McClusky, S., Vernant, P., Lawrence, S., Ergintav, S., Cakmak, R., Ozener, H., et al. (2006). GPS constraints on continental deformation in the Africa-Arabia-Eurasia continental collision zone and implications for the dynamics of plate interactions.Journal of Geophysical Research, 111(B5), B05411. doi:10.1029/2005JB004051.

Ristau, J. (2008). Implementation of Routine Regional Moment Tensor Analysis in New Zealand. Seismological Research Letters, 79(3), 400-415. doi:10.1785/gssrl.79.3.400

Sengor, A. M. C., \& Yilmaz, Y. (1981). TETHYAN EVOLUTION APPROACH OF TURKEY: A PLATE TECTONIC APPROACH. Journal Tectonophysics, 75(1981) 181-241.

Sissakian, V.K., 2012. Geological evolution of the Iraqi Mesopotamia Foredeep, inner platform and near surroundings of the Arabian Plate. Journal of Asian Earth Sciences.

T. Meirova , R. Hofstter. Observation of seismic activity in southern Lebanon. J. Seismology (2013) 17:629 -644 DOI 10.1007/s10950-012-9343-2.

Yolsal-Çevikbilen, S., Biryol, C. B., Beck, S., Zandt, G., Taymaz, T., Adıyaman, H. E., \& Özacar, a. A. (2012). 3-D crustal structure along the North Anatolian Fault Zone in northcentral Anatolia revealed by local earthquake tomography. Geophysical Journal International, 188(3), 819-849. doi:10.1111/j.1365-246X.2011.05313.x. 